\title{
Structural Design of Lithium-Sulfur Batteries: From Fundamental Research to Practical Application
}

\author{
Xiaofei Yang ${ }^{1,2,3} \cdot$ Xia Li $^{1} \cdot$ Keegan Adair ${ }^{1} \cdot$ Huamin Zhang $^{2,4} \cdot$ Xueliang Sun $^{1}$
}

Received: 11 March 2018 / Revised: 30 April 2018 / Accepted: 7 May 2018 / Published online: 23 June 2018

(C) The Author(s) 2019, corrected publication April 2019

\begin{abstract}
Lithium-sulfur ( $\mathrm{Li}-\mathrm{S})$ batteries have been considered as one of the most promising energy storage devices that have the potential to deliver energy densities that supersede that of state-of-the-art lithium ion batteries. Due to their high theoretical energy density and cost-effectiveness, $\mathrm{Li}-\mathrm{S}$ batteries have received great attention and have made great progress in the last few years. However, the insurmountable gap between fundamental research and practical application is still a major stumbling block that has hindered the commercialization of $\mathrm{Li}-\mathrm{S}$ batteries. This review provides insight from an engineering point of view to discuss the reasonable structural design and parameters for the application of Li-S batteries. Firstly, a systematic analysis of various parameters (sulfur loading, electrolyte/sulfur $(E / S)$ ratio, discharge capacity, discharge voltage, Li excess percentage, sulfur content, etc.) that influence the gravimetric energy density, volumetric energy density and cost is investigated. Through comparing and analyzing the statistical information collected from recent $\mathrm{Li}-\mathrm{S}$ publications to find the shortcomings of $\mathrm{Li}-\mathrm{S}$ technology, we supply potential strategies aimed at addressing the major issues that are still needed to be overcome. Finally, potential future directions and prospects in the engineering of $\mathrm{Li}-\mathrm{S}$ batteries are discussed.
\end{abstract}

Keywords Lithium-sulfur batteries $\cdot$ High energy density $\cdot$ Practical application $\cdot$ All-solid-state electrolyte

PACS 84

\section{Introduction}

Lithium ion batteries (LIBs) with stable electrochemistry and long lifespan have been developed rapidly since the 1990s and are considered as ideal power supplies for

Xiaofei Yang and Xia Li have contributed equally to this work.

Huamin Zhang

zhanghm@dicp.ac.cn

$\bowtie$ Xueliang Sun

xsun9@uwo.ca

1 Department of Mechanical and Materials Engineering, University of Western Ontario, London, ON N6A 5B9, Canada

2 Division of Energy Storage, Dalian Institute of Chemical Physics, Chinese Academy of Sciences, Dalian 116023, China

3 University of Chinese Academy of Sciences, Beijing 100049, China

4 Collaborative innovation Center of Chemistry for Energy Materials (iChEM), Dalian 116023, China portable electronic devices such as mobile phones, computers, and electric vehicles [1, 2]. Unfortunately, state-of-theart LIBs based on insertion-type transition metals/metal oxides cannot deliver enough energy density to meet the increasing demands of long-range electric vehicles [2-4]. Hence, it is of significance to search for new electrode materials which possess low molecular/atomic weight and are capable of multi-ion/-electron transfers per molecule/ atom [3, 5-10]. As one of the most abundant elements in the earth's crust, sulfur possesses a relatively low atomic weight of $32 \mathrm{~g} \mathrm{~mol}^{-1}$ and is a cost-effective and environmental friendly alternative to tradition LIBs. Li-S batteries (coupled with Li metal anodes) hold tremendous potential as energy storage devices due to their high theoretical energy density of $2600 \mathrm{~W} \mathrm{~h} \mathrm{~kg}^{-1}$ based on the two electron transfer per S atom [2, 11-13]. Since 2009, Li-S batteries have received increasing attention and are considered as one of the most promising candidates for next-generation rechargeable batteries after Nazar et al. [14] reported the development of high-performance $\mathrm{Li}-\mathrm{S}$ batteries by introducing CMK-3 as a host. Intensive efforts have been focused on solving the 
core issues that hinder the application of $\mathrm{Li}-\mathrm{S}$ batteries and impressive breakthroughs have been achieved. Up to now, sulfur cathodes with high sulfur utilization $(>90 \%)$ [15], high sulfur content (>80 wt\%) [16-18], excellent cycling life (>1500 cycles), $[19,20]$ as well as C-rate performance (>40 C) [21] have been realized with the aid of advanced materials and structures. From the recent improvements in the $\mathrm{Li}-\mathrm{S}$ system, it seems that the practical application of $\mathrm{Li}-\mathrm{S}$ batteries is not far away. However, it should be noted that most research is conducted with the use of coin cells and is tested under ideal conditions (excessive electrolyte/ sulfur $(E / S)$ ratios up to $10 \mu \mathrm{L} \mathrm{mg}^{-1}$, excessive lithium metal, and low sulfur loadings less than $2 \mathrm{mg} \mathrm{cm}^{-2}$ ), which leads to extremely low practical energy densities. These laboratory-developed batteries are significantly different from practical Li-S batteries with high energy density. According to the estimation from Xiao et al., high areal capacities of 3-7 $\mathrm{mA} \mathrm{h} \mathrm{cm}^{-2}$ for $\mathrm{Li}-\mathrm{S}$ batteries are required to be comparable to state-of-the-art LIBs $\left(2-4 \mathrm{~mA} \mathrm{~h} \mathrm{~cm}^{-2}\right)$ when taking into consideration the lower average discharge voltage of $2.15 \mathrm{~V}$ for $\mathrm{Li}-\mathrm{S}$ batteries compared with traditional LIBs (3.5 V) [22]. Accordingly, the relatively high sulfur loadings of 3-7 mg cm $\mathrm{m}^{-2}$ are essential to meet the goals of practical Li-S batteries (assuming a practical discharge capacity output of $1000 \mathrm{~mA} \mathrm{~h} \mathrm{~g}^{-1}$ ). In addition to high areal capacity materials, the energy density calculations should take into account the whole device, which is necessary for practical $\mathrm{Li}-\mathrm{S}$ batteries. Pope and Aksay statistically analyzed the effects of the $E / S$ ratio and sulfur loading on energy density. The results showed that the sulfur loading presented a prominent contribution to the energy density when the sulfur loading was less than $2 \mathrm{mg} \mathrm{cm}^{-2}$, while the $E / S$ ratio exhibited a greater effect on energy density with an increase in sulfur loading. A high sulfur loading of more than $2 \mathrm{mg} \mathrm{cm}^{-2}$ and $E / S$ ratio less than $5 \mu \mathrm{L} \mathrm{mg}^{-1}$ were the boundary conditions to achieve a high energy density of over $400 \mathrm{~W} \mathrm{~h} \mathrm{~kg}^{-1}$ [23]. Other primary factors such as discharge capacity, discharge voltage, $\%$ Li excess, sulfur content in the cathode, as well as porosity of the cathode are rarely mentioned in reported literature but play important roles in determining the gravimetric energy density, volumetric energy density, as well as the cost of practical Li-S batteries. This review aims to provide guidance towards reasonable structural and parameter design for the practical application of $\mathrm{Li}-\mathrm{S}$ batteries. Principles, challenges, and material design in conventional liquid-based $\mathrm{Li}-\mathrm{S}$ batteries are firstly introduced. We then systematically investigate the relationships between the gravimetric energy density, volumetric energy density, cost, and the other aforementioned parameters. To find the shortcomings of $\mathrm{Li}-\mathrm{S}$ batteries, the statistical information from recent Li-S battery publications is collected and summarized, and potential strategies are proposed in aim of addressing these challenges. Following liquid $\mathrm{Li}-\mathrm{S}$ batteries, next-generation all-solid-state $\mathrm{Li}-\mathrm{S}$ batteries are presented with their fundamental principles, challenges, developed structure, and simulated energy densities. Finally, a summary and conclusion are presented with future perspectives on the direction of $\mathrm{Li}-\mathrm{S}$ technology.

\subsection{Principles of the Li-S Battery}

A typical Li-S cell is composed of a lithium metal anode, a separator, electrolyte, and a sulfur-based cathode. A schematic illustration of a typical $\mathrm{Li}-\mathrm{S}$ cell configuration and the two types of charge/discharge voltage profiles are shown in Fig. 1.

During the discharge process, lithium metal is oxidized to lithium ions, which travel to the sulfur cathode through the electrolyte where $\mathrm{Li}$ forms conversion-type $\mathrm{Li}-\mathrm{S}$ compounds. Figure $1 \mathrm{~b}$ (left) demonstrates the typical discharge-charge profiles of a solid-liquid dual-phase Li-S electrochemical reaction. At the first plateau around $2.3 \mathrm{~V}, \mathrm{~S}_{8}$ is reduced to $\mathrm{Li}_{2} \mathrm{~S}_{4}$, which delivers $1 / 4$ of the theoretical capacity $\left(418 \mathrm{~mA} \mathrm{~h} \mathrm{~g}^{-1}\right)$ due to $1 / 2$ electron transfer per sulfur atom. Then, $\mathrm{Li}_{2} \mathrm{~S}_{4}$ will further obtain $3 / 2$ electron per sulfur atom and reduce to $\mathrm{Li}_{2} \mathrm{~S}$ at the plateau around $2.1 \mathrm{~V}$, achieving a capacity of $1254 \mathrm{~mA} \mathrm{~h} \mathrm{~g}^{-1}[13,26,27]$. During the charge process, the

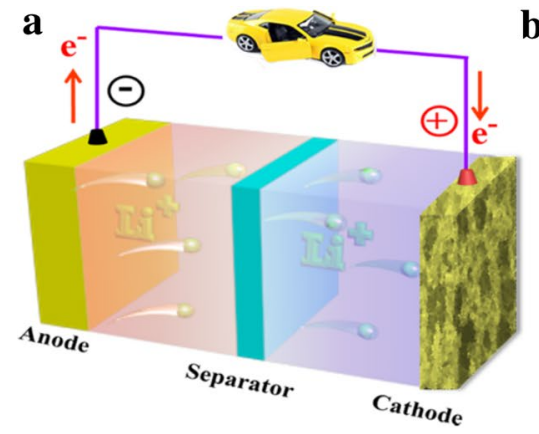

Fig. 1 a Schematic illustration of a $\mathrm{Li}-\mathrm{S}$ cell configuration and $\mathbf{b}$ the typical charge/discharge voltage profiles for solid-liquid dual-phase $\mathrm{Li}-\mathrm{S}$ reaction (left) and solid-phase $\mathrm{Li}-\mathrm{S}$ reaction (right). Reprinted with permission from Ref. [24], copyright 2016, Royal Society of Chemistry. Reprinted with permission from Ref. [25], copyright 2015, American Chemical Society 
reverse reactions occur and convert the $\mathrm{Li}_{2} \mathrm{~S}$ back to $\mathrm{S}_{8}$. The associated reaction equations can be seen as follows:

Discharge

Anode: $16 \mathrm{Li} \rightarrow 16 \mathrm{Li}^{+}+16 \mathrm{e}^{-}$

Cathode: $\mathrm{S}_{8}+4 \mathrm{Li}^{+}+4 \mathrm{e}^{-} \rightarrow 2 \mathrm{Li}_{2} \mathrm{~S}_{4}$

$$
2 \mathrm{Li}_{2} \mathrm{~S}_{4}+12 \mathrm{Li}^{+}+12 \mathrm{e}^{-} \rightarrow 8 \mathrm{Li}_{2} \mathrm{~S}
$$

\section{Charge}

Anode: $16 \mathrm{Li}^{+}+16 \mathrm{e}^{-} \rightarrow 16 \mathrm{Li}$

Cathode: $8 \mathrm{Li}_{2} \mathrm{~S} \rightarrow \mathrm{S}_{8}+16 \mathrm{Li}^{+}+16 \mathrm{e}^{-}$

The above mentioned electrochemical reaction of $\mathrm{Li}-\mathrm{S}$ batteries belongs to the "solid-liquid" dual-phase reaction $[2,28]$. These types of batteries employ ether-based electrolyte systems and are the predominant systems which have attracted the most attention for research and application. However, the solid-liquid dual-phase reaction is not the only route that completes the $\mathrm{Li}-\mathrm{S}$ electrochemical reaction. As shown in Fig. 1b, there is another $\mathrm{Li}-\mathrm{S}$ electrochemical reaction route which exhibits a single voltage plateau at around $2.0 \mathrm{~V}$ during the discharge process $[29,30]$. Due to the single potential plateau presented in the electrochemical reaction, this type of $\mathrm{Li}-\mathrm{S}$ reaction is considered as a "solid-phase" reaction. In liquid-based $\mathrm{Li}-\mathrm{S}$ batteries, the most reported solid-phase $\mathrm{Li}-\mathrm{S}$ reactions occur in carbonate electrolytes with some delicately designed sulfur cathodes. The two different electrochemical reaction processes of $\mathrm{Li}-\mathrm{S}$ batteries lead to different challenges and materials design in sulfur cathodes. In the following sections, the fundamental challenges and basic strategies of material design for the sulfur cathodes are proposed and summarized.

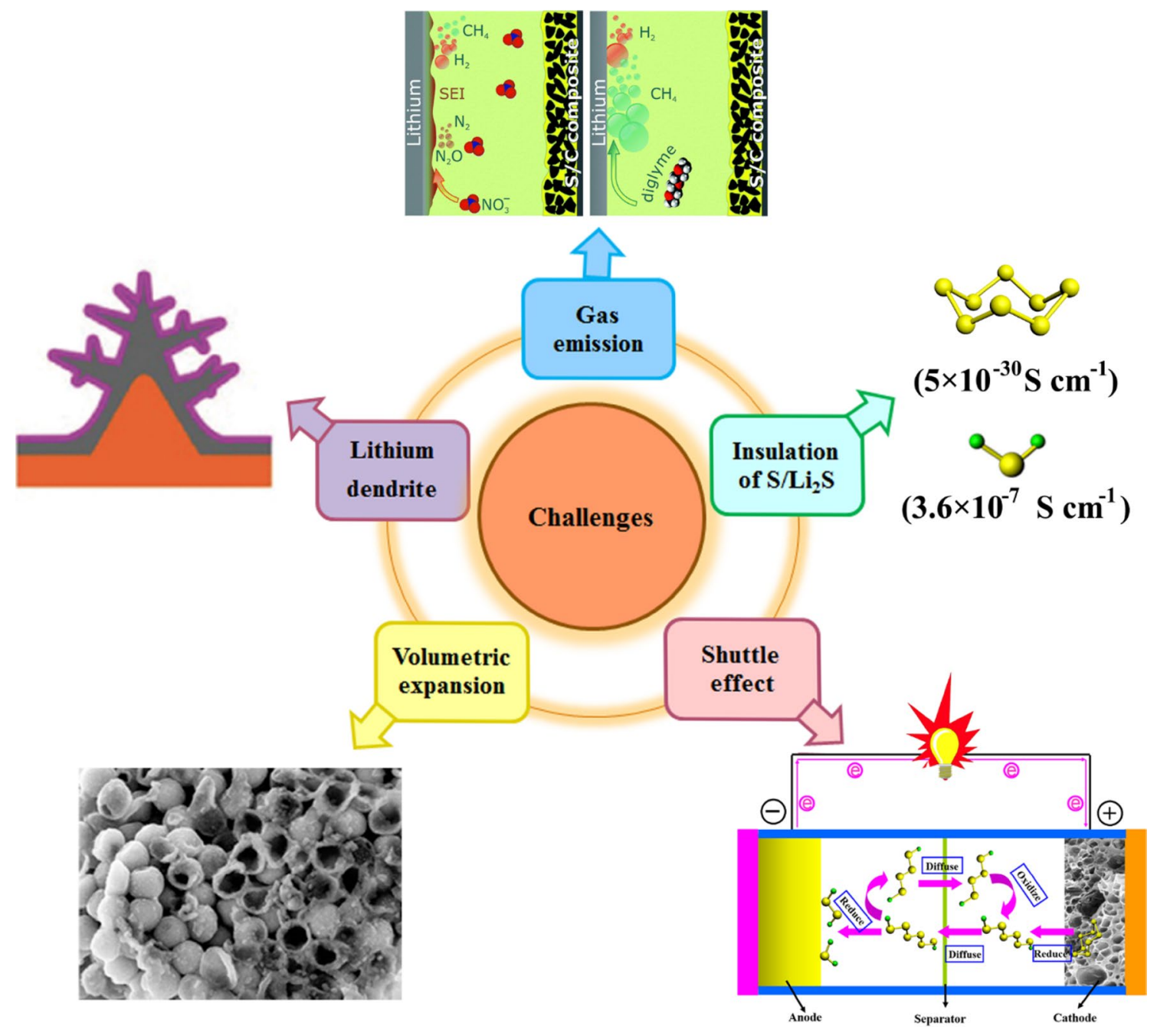

Fig. 2 The remaining challenges of modern ether-based Li-S batteries. Reprinted with permission from Ref. [11], copyright 2013, American Chemical Society. Reprinted with permission from Ref. [37], copyright 2016, Royal Society of Chemistry. Reprinted with permission from Ref. [38], copyright 2016, Wiley-VCH 


\subsection{The Fundamental Challenges of Li-S Batteries}

Despite the high-energy advantage and great progresses in the development of Li-S systems, several key challenges shown in Fig. 2 still need to be addressed to improve the electrochemical performance and enable future commercialization.

1. The "Shuttle effect" results from the dissolution of soluble polysulfides into the electrolyte (solid-liquid dualphase reaction system). During the charge process, the solid $\mathrm{Li}_{2} \mathrm{~S} / \mathrm{Li}_{2} \mathrm{~S}_{2}$ particles are oxidized into long-chain polysulfides. At the early charge state, the concentration of long-chain polysulfides at the cathode side is low, leading to poor diffusion gradients compared with electric field force. When the charge state deepens, the concentration of long-chain polysulfides increases significantly. At the end of charge process, the diffusion force is stronger than the electric field force, which results in long-chain polysulfides diffusing to the anode side. Considering the strong reducing property of the Li metal anode, the long-chain polysulfides can react with $\mathrm{Li}$ via a disproportionation reaction. A portion of the products become short-chain polysulfide intermediates that then return back to cathode side under the electric field force, whereas the rest of the polysulfides are directly reduced to insoluble $\mathrm{Li}_{2} \mathrm{~S}_{2} \mathrm{Li}_{2} \mathrm{~S}_{2}$ particles that coat the surface of Li metal, leading to the loss of active material, Li metal anode corrosion, and low Coulombic efficiency.

2. Large volumetric expansion during lithiation. Because of the significant difference in density between $\mathrm{Li}_{2} \mathrm{~S}$ and $\mathrm{S}$ (1.66 vs. $2.07 \mathrm{~g} \mathrm{~cm}^{-3}$ ), a large volumetric expansion is accompanied with complete lithiation of sulfur, leading to the pulverization of cathode materials and cathode structural disintegration $[11,14,31,32]$.

3. Low conductivity of $\mathrm{S}$ and $\mathrm{Li}_{2} \mathrm{~S}$. The natural electrical conductivities of $\mathrm{S}$ and $\mathrm{Li}_{2} \mathrm{~S}$ at room temperature are only $5 \times 10^{-30}$ and $3.6 \times 10^{-7} \mathrm{~S} \mathrm{~cm}^{-1}$, respectively [33-35]. Moreover, the $\mathrm{Li}^{+}$transport in $\mathrm{S}$ and $\mathrm{Li}_{2} \mathrm{~S}$ is also extremely slow. This makes the reversible transformation of $\mathrm{S}$ and $\mathrm{Li}_{2} \mathrm{~S}$ difficult and further leads to low utilization of active materials [33]. In addition, the precipitation of $\mathrm{Li}_{2} \mathrm{~S}$ as a passive coating on both the anode and cathode surfaces during cycling leads to an increase in overpotential and limited discharge capacity output.

4. Growth of lithium dendrites. Lithium dendrites can penetrate the solid-electrolyte interphase (SEI) film, resulting in continuous consumption of electrolyte to reform the SEI film during continued cycling and decreased Coulombic efficiency along with increased interfacial resistance [36]. Shortened battery life can be expected after the electrolyte is eventually exhausted. In addi- tion, lithium dendrites have the potential to penetrate the separator and generate internal short circuits, leading to thermal runaway and fire hazards [24].

5. Side reactions between lithium and electrolyte. Due to the high activity of Li with the electrolyte, complex side reactions occur on the interface of the electrolyte and $\mathrm{Li}$ metal anode, which can generate significant amounts of gaseous byproducts [37]. Li-S batteries are sealed systems and the internal volume is fixed. On the one hand, the gases can increase the distance of the electrodes, which will increase the resistance or even lead to broken circuits. On the other hand, the increased internal pressure of the batteries can break the sealed package, resulting in fire hazards from the exposed Li metal reacting with air.

The above mentioned key issues significantly limit the cycling life and energy density and have thus hindered the practical application of advanced $\mathrm{Li}-\mathrm{S}$ batteries. It is well known that the performance of $\mathrm{Li}-\mathrm{S}$ batteries is conditiondependent. Under different testing conditions such as different sulfur loadings and $E / S$ ratios, the electrochemical performance is quite different. Hence, before solving the electrochemical problems, we need to clarify the requirements for the engineering of high-energy $\mathrm{Li}-\mathrm{S}$ batteries. Proposing effective strategies to solve the problems associated with the engineering of $\mathrm{Li}-\mathrm{S}$ batteries under quantified conditions is more reasonable. $\mathrm{Li}-\mathrm{S}$ batteries, as promising energy storage systems, are aimed to supply power for electric vehicles and portable electronic devices. Additionally, the cost of a device is another crucial factor when judging whether it can achieve commercialization. Hence, in the following sections, we will first evaluate the components of $\mathrm{Li}-\mathrm{S}$ batteries and their effects on gravimetric energy density, volumetric energy density and cost. Afterwards, the engineering requirements of high-energy $\mathrm{Li}-\mathrm{S}$ batteries will be summarized according to the investigated results.

\subsection{Evaluation and Target of High-Energy Li-S Batteries}

\subsubsection{Parameterization of Li-S Battery Components Based on Gravimetric Energy Density}

Gravimetric energy density is one of the most important parameters to evaluate the performance of $\mathrm{Li}-\mathrm{S}$ batteries. Table 1 is the simulated components based on a $\mathrm{Li}-\mathrm{S}$ soft package (Fig. 3a) used to estimate the practical gravimetric energy density. Here we choose the most prevalent etherbased electrolyte $\mathrm{Li}-\mathrm{S}$ system as the model to calculate the energy density. In these systems, the weight of the separator and current collector is fixed. The rest of the components such as binder, $\mathrm{Li}$ anode, carbon additive and electrolyte are 
Table 1 Components of a Li-S soft package

\begin{tabular}{ll}
\hline Components & Mass $\left(\mathrm{mg} \mathrm{cm}^{-2}\right)$ \\
\hline Cathode current collector (aluminum foil, & 4.32 \\
$\quad 16 \mu \mathrm{m})$ & \\
Separator (Celgard 2325) & $\mathrm{a}$ \\
Sulfur $^{\mathrm{b}}$ & 1.80 \\
Carbon $^{\mathrm{c}}$ & $2 x$ \\
Binder (PVDF) $^{\mathrm{d}}$ & $0.5 x$ \\
Anode (lithium metal) $^{\mathrm{e}}$ & $0.28 x$ \\
Electrolyte $^{\mathrm{f}}$ & $1.31 x$ \\
Others (cathode tap, Anode tap, Al laminate $^{\mathrm{g}}$ & $2 \mathrm{n} x$ \\
film, etc. $^{\mathrm{g}}$ & $0.32+0.22 x+0.1 \mathrm{nx}$ \\
Total & $6.40+4.31 x+2.10 n x$ \\
\hline
\end{tabular}

${ }^{a}$ Double layers of membranes per piece of cathode, the areal density of each layer of Celgard 2325 is $0.9 \mathrm{mg} \mathrm{cm}^{-2}$

${ }^{\mathrm{b}}$ Slurry coated on both sides of cathode current collector with a sulfur loading of $x \mathrm{mg} \mathrm{cm}^{-2}$

${ }^{\mathrm{c}}$ Mass ratio of carbon to sulfur in the S/C composite is $1: 4$

${ }^{\mathrm{d}}$ There is $10 \mathrm{wt} \%$ binder in the cathode

e $50 \mathrm{wt} \%$ lithium excess accords to the stoichiometric ratio of sulfur

${ }^{\mathrm{f}}$ Mass ratio of electrolyte to sulfur is $\mathrm{n}$

${ }^{\mathrm{g}}$ The mass ratio of such other components as cathode tap, anode tap, Al laminate film is $5 \mathrm{wt} \%$ of the whole Li-S package

scaled with the sulfur loading. The S/C composites we have chosen herein contain $80 \mathrm{wt} \%$ sulfur, which is mixed with binder with a mass ratio of 9:1 as the cathode materials, and coated on both sides of the current collector. That is to say, the sulfur content is calculated based on the whole cathode (not including the current collector) and is determined to be $72 \mathrm{wt} \% .50 \mathrm{wt} \%$ lithium excess is taken based on the theoretical consumption of lithium due to the formation of $\mathrm{Li}_{2} \mathrm{~S}$ on the anode surface. On the basis of the above conditions, the practical energy density can be calculated by Eq. (1) and the relative results are presented in Fig. 3b-d.

$M_{\text {Energy density }}=\frac{E \times Q \times \mathrm{Ar}_{(\mathrm{S})} \times m_{\mathrm{S}}}{\operatorname{Ar}_{\left(\mathrm{Li}_{2} \mathrm{~S}\right)} \times m_{\text {Total }}}$

As shown in this formula, $\operatorname{Ar}_{(\mathrm{S})}$ and $\mathrm{Ar}_{(\mathrm{Li2S})}$ are the relative atomic mass of sulfur (32) and lithium sulfide (64), respectively. $\mathrm{E}$ is the average discharge voltage, $\mathrm{Q}$ is specific discharge capacity based on sulfur, $m_{\mathrm{S}}$ is the sulfur loading, and $m_{\text {Total }}$ is the total weight of the Li-S soft package listed in Table 1.

At a fixed $E / S$ ratio, the relationship between energy density and sulfur loading is consistent with a parabolic curve. With an increase in sulfur loading, the energy density increases significantly at relatively low sulfur content and then levels off, which coincides well with previous reports [23, 39]. For instance, at a $E / S$ ratio of $3 \mu \mathrm{L} \mathrm{mg}^{-1}$, an optimized parameter for current soft packages, the energy density can be increased to 623 from $446 \mathrm{~W} \mathrm{~h} \mathrm{~kg}^{-1}$ when the sulfur loading increases from 1 to $6 \mathrm{mg} \mathrm{cm}^{-2}$. If we further increase the sulfur loading to $10 \mathrm{mg} \mathrm{cm}^{-2}$, we can only observe a $21 \mathrm{~W} \mathrm{~h} \mathrm{~kg}^{-1}$ increase in energy density compared with the batteries with $6 \mathrm{mg} \mathrm{cm}^{-2}$ sulfur loading. In this regard, the sulfur loading has a great impact on the practical energy density of $\mathrm{Li}-\mathrm{S}$ batteries. In other words, although it is not necessarily the case that higher sulfur loading is better, a relatively high sulfur loading is indeed required for engineering practical $\mathrm{Li}-\mathrm{S}$ batteries. In this case, the energy density is calculated based on a theoretical discharge capacity of $1675 \mathrm{~mA} \mathrm{~h} \mathrm{~g}^{-1}$ and an average theoretical voltage of $2.15 \mathrm{~V}$, which is overestimated compared with batteries in practical operation. Especially for high loading sulfur cathodes, the increase in sulfur active material is always at the cost of decreased capacities and lower voltage plateaus. If we assume that each $1 \mathrm{mg} \mathrm{cm}^{-2}$ sulfur loading increase will lead to $30 \mathrm{~mA} \mathrm{~h} \mathrm{~g}^{-1}$ discharge capacity and a $20 \mathrm{mV}$ discharge voltage drop, the corresponding energy density-areal sulfur loading- $E / S$ ratio relationship can be revealed as seen in Fig. 3c. With an increase in sulfur loading, the practical energy density of the battery is firstly increased and then declines gradually, which give us an indication of the ideal range of sulfur loading for real application. The optimized sulfur loading range is between 4 and $6 \mathrm{mg} \mathrm{cm}^{-2}$. The $E / S$ ratio is another crucial parameter that has a significant impact on the practical energy density of $\mathrm{Li}-\mathrm{S}$ batteries [40, 41]. As shown in Fig. 3b, c, the energy density decreases dramatically when the $E / S$ ratio is increased due to the decreased ratio of sulfur (Fig. 3d), especially for the batteries with high sulfur loadings. For instance, for a $\mathrm{Li}-\mathrm{S}$ battery with a $1 \mathrm{mg} \mathrm{cm}^{-2}$ sulfur loading cathode, the energy density with a $E / S$ ratio of $1 \mu \mathrm{L} \mathrm{mg}^{-1}$ is $559 \mathrm{~W} \mathrm{~h} \mathrm{~kg}^{-1}$, which is $333 \mathrm{~W} \mathrm{~h} \mathrm{~kg}^{-1}$ higher than the counterpart with a $E / S$ ratio of $10 \mu \mathrm{L} \mathrm{mg}^{-1}\left(226 \mathrm{~W} \mathrm{~h} \mathrm{~kg}^{-1}\right)$. This gap is further increased to $743 \mathrm{~W} \mathrm{~h} \mathrm{~kg}^{-1}$ when the sulfur loading increased to $10 \mathrm{mg} \mathrm{cm}^{-2}$. In this regard, high loading cathodes should be coupled with a relatively low $E / S$ ratio that can ensure high energy density output for Li-S batteries. Nevertheless, due to the crucial role that the electrolyte plays in transporting $\mathrm{Li}^{+}$and wetting electrodes, many publications can only enable long-term cycling life when the $E / S$ ratios are higher than $10 \mu \mathrm{L} \mathrm{mg}^{-1}$ [42-44]. Based on these high $E / S$ ratios and our calculations, the energy density of $\mathrm{Li}-\mathrm{S}$ batteries cannot reach $250 \mathrm{~W} \mathrm{~h} \mathrm{~kg}^{-1}$ no matter how high the sulfur loading, and cannot meet the demand of long-range electric vehicles. If we want to achieve a high energy density of more than $500 \mathrm{~W} \mathrm{~h} \mathrm{~kg}^{-1}$, the $E / S$ ratio should be lower than $3 \mu \mathrm{L} \mathrm{mg}^{-1}$. Hence, developing Li-S batteries with relative high sulfur loadings (4-6 $\left.\mathrm{mg} \mathrm{cm}^{-2}\right)$ and low $E / S$ ratios $\left(<3 \mu \mathrm{L} \mathrm{mg}^{-1}\right)$ has been of the utmost importance over the last decade.

Other than the sulfur loading and $E / S$ ratio, electrochemical performance parameters such as discharge capacity 

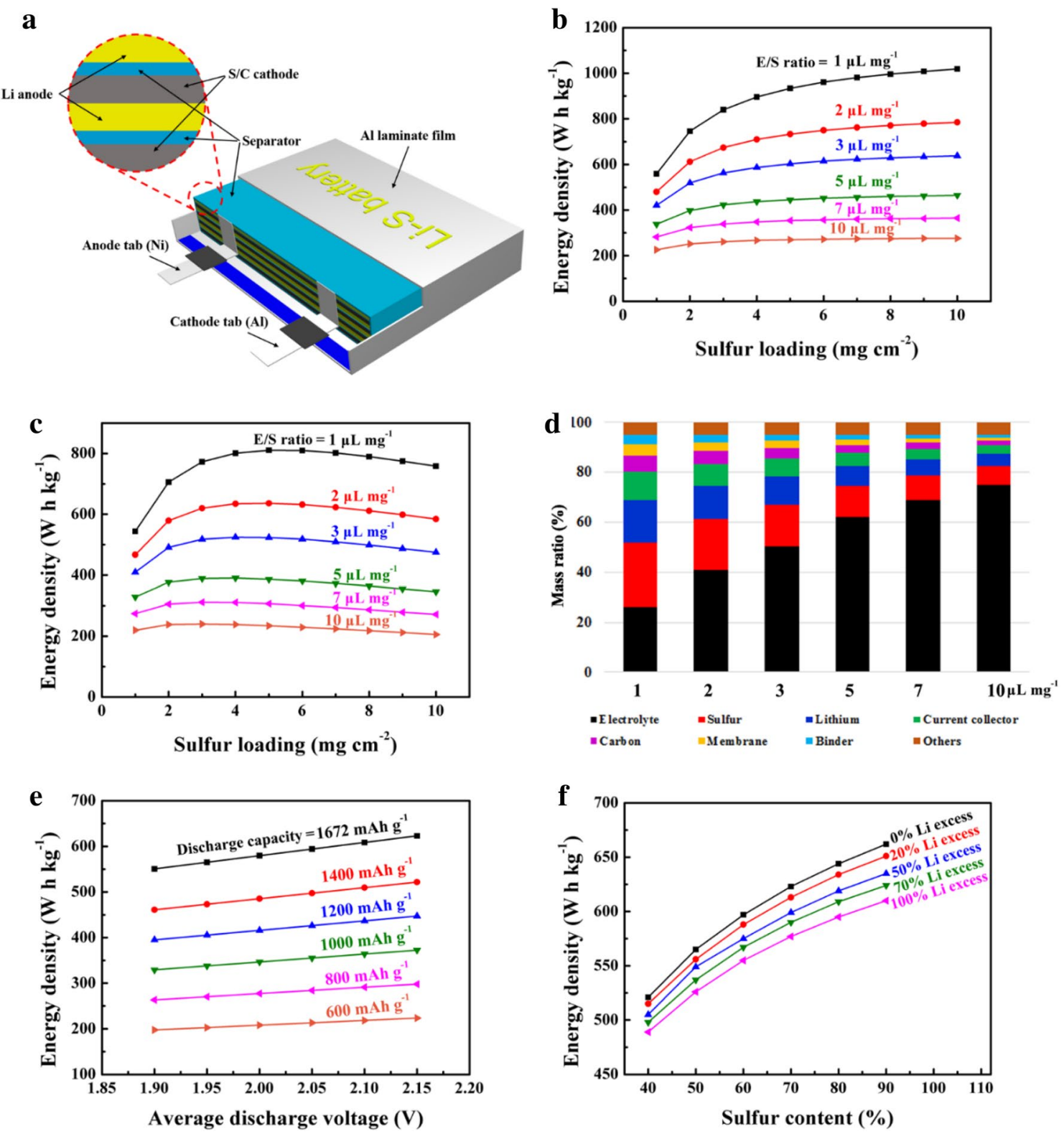

Fig. 3 Estimation of the practical energy density of Li-S batteries. a Schematic illustration of a Li-S soft package. b Energy density calculated based on a theoretical discharge capacity of $1675 \mathrm{~mA} \mathrm{~h} \mathrm{~g}^{-1}$ and an average discharge voltage of $2.15 \mathrm{~V}$ as a function of sulfur loading for various $E / S$ ratios. c Energy density calculated based on various theoretical discharge capacities and average discharge voltages (discharge capacity $=(1675-30 x) \mathrm{mA} \mathrm{h} \mathrm{g}$, average discharge volt-

output, discharge voltage, $\% \mathrm{Li}$ excess and sulfur content are also closely related to the practical energy density. As shown in Fig. 3e (all of results are calculated based on a sulfur loading of $5 \mathrm{mg} \mathrm{cm}^{-2}$ and a $E / S$ ratio of $3 \mu \mathrm{L} \mathrm{mg}^{-1}$ ), the energy density-discharge capacity-discharge voltage shows a perfect linear relationship. As seen by the relationship, it seems that a high discharge capacity of $1400 \mathrm{~mA} \mathrm{~h} \mathrm{~g}^{-1}$ and a theoretical average voltage of $2.10 \mathrm{~V}$ are essential to achieve a high

age $=(2.15-0.02 x) \mathrm{V}, x$ is the sulfur loadings $)$ as a function of sulfur loading for various $E / S$ ratios. d Mass ratios of different components as a function of sulfur loading for various $E / S$ ratios. Energy density calculated based on an optimized sulfur loading of $5 \mathrm{mg} \mathrm{cm}^{-2}$ and an $E / S$ ratio of $3 \mu \mathrm{L} \mathrm{mg}^{-1}$ as a function of e average discharge voltage for various discharge capacities and $\mathbf{f}$ sulfur contents for various $\mathrm{Li}$ excess percentages

energy density of $500 \mathrm{~W} \mathrm{~h} \mathrm{~kg}^{-1}$. These performance values are not hard to obtain for batteries assembled with large $E / S$ ratios and relative low sulfur loadings with the help of uniformly dispersed or well-confined nanosulfur [15]. However, the situation is quite different for the batteries with high sulfur loading cathodes and low $E / S$ ratios due to the worsening $\mathrm{Li}^{+} / \mathrm{e}^{-}$transport. It is also noteworthy that rechargeable $\mathrm{Li}-\mathrm{S}$ batteries are aimed to supply power for several thousands of 
cycles and maintaining the performance at such high level for a long time is another significant challenge. The sulfur content in the cathode and the coupled $\mathrm{Li}$ excess ratio also exert a direct effect on the energy density output of Li-S batteries. It should be emphasized that the sulfur content mentioned here is based on the whole cathode (including interlayer) rather than in the S/C composites due to the introduction of conductive additives, binders and interlayers further reducing the sulfur content to a low level. As shown in Fig. $3 \mathrm{f}$ (all of results are calculated based on a sulfur loading of $5 \mathrm{mg} \mathrm{cm}^{-2}$ and a $E / S$ ratio of $3 \mu \mathrm{L} \mathrm{mg}^{-1}$ ), with sulfur content increasing and $\% \mathrm{Li}$ excess decreasing, the $\mathrm{Li}-\mathrm{S}$ batteries show the trend to deliver higher energy density. For the typical $\mathrm{Li}$ anode with $50 \%$ excess $\mathrm{Li}, \mathrm{Li}-\mathrm{S}$ batteries assembled with cathodes containing $40 \mathrm{wt} \%$ sulfur have the potential to deliver an energy density of around $500 \mathrm{~W} \mathrm{~h} \mathrm{~kg}-1$. When the sulfur content is increased to $70 \mathrm{wt} \%$, the energy density will be further increased to $600 \mathrm{~W} \mathrm{~h} \mathrm{~kg}^{-1}$. On the basis of $70 \mathrm{wt} \%$ sulfur content, the Li excess percentage shows a less significant effect on the energy density output due to the light specific weight of lithium and its low weight ratio in the whole devices. Nevertheless, it doesn't mean that $\mathrm{Li}$ excess percentage is meaningless. In addition to the important role it plays in ensuring good electronic conductivity in the absence of a metal current collector on anode side, the amount of Li metal in batteries also dramatically influences the volumetric energy density and the cost of the $\mathrm{Li}-\mathrm{S}$ batteries that we will discuss below.

\subsubsection{Parameterization of Li-S Battery Components Based on Volumetric Energy Density}

In addition to the practical gravimetric energy density, the volumetric energy density and cost are two important parameters that are rarely mentioned in publications and should also be taken into consideration for the real application of $\mathrm{Li}-\mathrm{S}$ batteries [45-47]. The volumetric energy density is mainly determined by the tap density of the cathodes due to the fixed thickness of other components such as separator, current collector, and lithium metal (for the fixed sulfur loading and excess percentage). The tap density of cathodes $\left(\rho_{\text {cathode }}\right)$ and volumetric energy density $\left(V_{\text {Energy density }}\right)$ are closely related to the porosity and sulfur content of the cathodes, which can be calculated by Eqs. (2)-(9). The relationships between volumetric energy density, sulfur content, and porosity of cathode are shown in Fig. 4a (with fixed sulfur loading of $5 \mathrm{mg} \mathrm{cm}^{-2}$ and $50 \mathrm{wt} \% \mathrm{Li}$ excess percentage). It can be clearly seen that the volumetric energy density gradually decreases with increasing porosity and decreasing sulfur content. According to the curves, in order to achieve high volumetric energy densities of up to $500 \mathrm{~W} \mathrm{~h} \mathrm{~L}^{-1}$, a high sulfur content (in S/C composite) of more than $70 \mathrm{wt} \%$ and porosity lower than $40 \%$ are necessary. It should be mentioned that all of the data points are calculated on the basis of a theoretical discharge capacity of $1675 \mathrm{~mA} \mathrm{~h} \mathrm{~g}^{-1}$ and average voltage of $2.15 \mathrm{~V}$. Therefore, more stringent requirements are put forward on the sulfur content and porosity of practical $\mathrm{Li}-\mathrm{S}$ batteries in order to achieve high volumetric energy density.

$\omega_{\text {Composite }}=\frac{\frac{V \times \rho_{\mathrm{S}}}{1.8}}{\frac{V \times \rho_{\mathrm{S}}}{1.8}+1}$

$\omega_{\text {Cathode }}=\omega_{\text {Composite }} \times 0.9$

$P_{\mathrm{C}}=\frac{V}{V+\frac{1}{\rho_{\text {Graphite }}}}$

$\rho_{\mathrm{C}}=\rho_{\text {Graphite }} \times\left(1-P_{\mathrm{C}}\right)$

$\rho_{\text {Composite }}=\rho_{\mathrm{C}} \times\left(1-\omega_{\text {Composite }}\right)+\rho_{\mathrm{S}} \times \omega_{\text {Composite }}$

$\rho_{\text {Electrode }}=\left(\rho_{\text {Composite }} \times 0.9+\rho_{\text {Binder }} \times 0.1\right) \times\left(1-P_{\text {Cathode }}\right)$

$$
\begin{aligned}
T_{\text {Battery }}= & \frac{m_{\mathrm{S}}}{\omega_{\text {Cathode }} \times \rho_{\text {cathode }}}+T_{\text {Seperator }} \\
& +T_{\text {Current collector }}+\frac{m_{\mathrm{S}} \times 1.5 \times 14}{32 \times \rho_{\mathrm{Li}}}
\end{aligned}
$$

Fig. 4 a Volumetric energy density of Li-S soft packages based on a theoretical discharge capacity of $1675 \mathrm{~mA} \mathrm{~h} \mathrm{~g}^{-1}$ and an average discharge voltage of $2.15 \mathrm{~V}$ as a function of porosity for differing sulfur contents. b Cost calculated based on a theoretical discharge capacity of $1675 \mathrm{~mA} \mathrm{~h} \mathrm{~g}^{-1}$ and an average discharge voltage of $2.15 \mathrm{~V}$ as a function of energy density for $E / S$ ratios and Li excess percentages

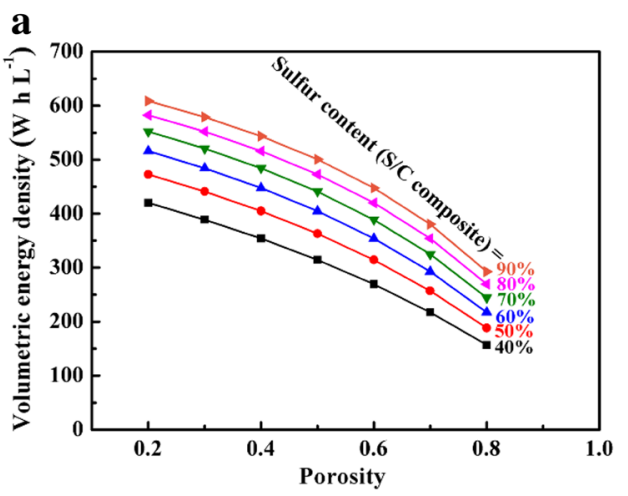

b

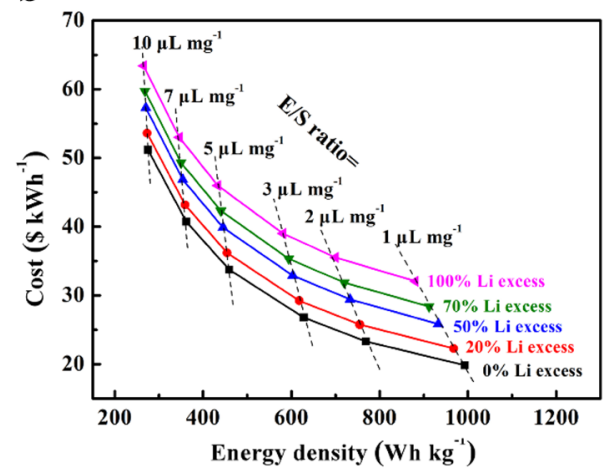


$V_{\text {Energy density }}=\frac{E \times Q}{T_{\text {Battery }} \times S}$

where $\omega_{\text {Composite }}$ and $\omega_{\text {Cathode }}$ are the sulfur content in the $S / C$ composite and cathode, respectively. $V$ is the pore volume of the carbon. $P_{\mathrm{C}}$ and $P_{\text {Cathode }}$ are the porosity of carbon and cathode, respectively. $\rho_{\text {Graphite }}, \rho_{\mathrm{C}}, \rho_{\mathrm{S}}, \rho_{\mathrm{Li}}, \rho_{\text {Binder }}, \rho_{\text {Composite }}$, and $\rho_{\text {Cathode }}$ are the density of graphite $\left(2.25 \mathrm{~g} \mathrm{~cm}^{-3}\right)$, carbon, sulfur $\left(2.07 \mathrm{~g} \mathrm{~cm}^{-3}\right)$, Li metal $\left(0.534 \mathrm{~g} \mathrm{~cm}^{-3}\right)$, binder (PVDF, $0.8 \mathrm{~g} \mathrm{~cm}^{-3}$ ), and $\mathrm{S} / \mathrm{C}$ composite and cathode, respectively. $T_{\text {battery }}, T_{\text {separator }}$ and $T_{\text {current collector }}$ are the thickness of battery, separator $(25 \mu \mathrm{m})$, and current collector ( $\mathrm{Al}$ foil, $16 \mu \mathrm{m}$ ), respectively. $\mathrm{E}$ is the average discharge voltage (here is $2.15 \mathrm{~V}$ ), $\mathrm{Q}$ is specific discharge capacity (here is the theoretical specific discharge capacity of $\left.1675 \mathrm{~mA} \mathrm{~h} \mathrm{~g}^{-1}\right), m_{\mathrm{S}}$ is the sulfur loading (here is the optimized sulfur loading of $5 \mathrm{mg} \mathrm{cm}^{-2}$ ), and $\mathrm{S}$ is the surface area of the cathode (here is $1 \mathrm{~cm}^{-2}$ ).

\subsubsection{Parameterization of Li-S Battery Components Based on Cost}

Cost plays a crucial role in determining whether a technology is suitable for practical and commercial application. Investigating the cost of the components in $\mathrm{Li}-\mathrm{S}$ batteries is necessary to propose effective strategies that can further decrease the cost and accelerate their development. Table 2 shows the baseline cost of the main material components in $\mathrm{Li}-\mathrm{S}$ soft packages (values of some components are collected from a previous report [48]) with the corresponding weight and cost ratios (Fig. 3d). All of the data are obtained on the basis of an optimized sulfur loading of $5 \mathrm{mg} \mathrm{cm}^{-2}, 50 \mathrm{wt} \% \mathrm{Li}$ excess and a $E / S$ ratio of $3 \mu \mathrm{L} \mathrm{mg}^{-1}$. Obviously, the $\mathrm{Li}$ anode and electrolyte are the most costly components making up $55.4 \%$ and $30.5 \%$ of the total cost,

Table 2 Weight and cost ratios of raw materials in Li-S batteries [48]

\begin{tabular}{|c|c|c|c|}
\hline Component & $\begin{array}{l}\text { Baseline } \\
\text { cost } \\
\left(\$ \mathrm{~kg}^{1}\right)\end{array}$ & Weight ratio (\%) & Cost ratio $(\%)$ \\
\hline Electrolyte & 12 & 50.4 & 30.5 \\
\hline Sulfur & 0.22 & 16.8 & 0.2 \\
\hline Lithium metal & 100 & 11.0 & 55.4 \\
\hline $\begin{array}{l}\text { Current collector (Al } \\
\text { foil) }\end{array}$ & 18.5 & 7.3 & 6.8 \\
\hline Carbon & 15 & 4.2 & 3.2 \\
\hline Membrane & 2 & 3 & 0.3 \\
\hline Binder & 10 & 2.3 & 1.2 \\
\hline $\begin{array}{l}\text { Others (cathode tap, } \\
\text { Anode tap, Al lami- } \\
\text { nate film, etc.) }\end{array}$ & 10 & 5 & 2.5 \\
\hline
\end{tabular}

respectively. Taking this into account, reducing the weight ratio of the $\mathrm{Li}$ anode and electrolyte can effectively reduce the overall cost of $\mathrm{Li}-\mathrm{S}$ soft packages. Figure $4 \mathrm{~b}$ shows the change in cost with adjusted Li excess percentage and $E / S$ ratios. It can be clearly seen that the material cost of the Li-S soft package can drastically change from $19.8 \$$ to $63.4 \$ \mathrm{~kW} \mathrm{~h}^{-1}$ with the Li excess percentage ranging from 0 to $100 \%$. For the optimized Li-S batteries with a sulfur loading of $5 \mathrm{mg} \mathrm{cm}^{-2}$, a low $E / S$ ratio of $3 \mu \mathrm{L} \mathrm{mg}^{-1}$ and $50 \mathrm{wt} \% \mathrm{Li}$ excess, the cost is $32.9 \$ \mathrm{~kW} \mathrm{~h}^{-1}$, which is equal to the reported $\mathrm{Li}$ metal batteries with $\mathrm{Li}$-rich materials or NMC as cathodes $[49,50]$. Considering the materials cost is only $60 \%-70 \%$ of the whole $\mathrm{Li}-\mathrm{S}$ soft package [50] and the discharge capacity output is always $70 \%-80 \%$ of the theoretical discharge capacity, the real cost of Li-S soft packages is $58.8-78.3 \$ \mathrm{~kW} \mathrm{~h}^{-1}$, which is still much lower than commercial $\mathrm{Li}$-ion batteries. It should be note that the cost of the batteries not only reflects the price of materials, but also the total cycling lifetime. In reality, the cycling life of the reported Li-S soft packages with energy densities greater than $300 \mathrm{~W} \mathrm{~h} \mathrm{~kg}^{-1}$ and capacity retentions of up to $80 \%$ is less than 100 cycles. That is to say, there is currently no obvious price advantage in terms of costeffectiveness per cycle in Li-S soft packages compared with commercialized Li-ion batteries, which can last for several thousand cycles. In other words, apart from the low $E / S$ ratio and low Li excess, prolonging the cycling life of $\mathrm{Li}-\mathrm{S}$ soft packages can, from a certain point of view, also reduce the cost of this device.

\subsubsection{Target of High-Energy Li-S batteries}

As discussed above, in order to achieve low-cost practical $\mathrm{Li}-\mathrm{S}$ batteries with an energy density greater than $500 \mathrm{~W} \mathrm{~h} \mathrm{~kg}^{-1}$ and volumetric energy density of over $500 \mathrm{~W} \mathrm{~h} \mathrm{~L}^{-1}$ the following requirements should be met (Table 3).

Table 3 Target of low-cost practical Li-S batteries with high energy density

\begin{tabular}{ll}
\hline Parameters & Target \\
\hline Sulfur content (based on the whole cathode) & $\geq 70 \mathrm{wt} \%$ \\
Specific capacity & $\geq 1400 \mathrm{~mA} \mathrm{~h} \mathrm{~g}^{-1}$ \\
Sulfur loading & $4-6 \mathrm{mg} \mathrm{cm}^{-2}$ \\
$E / S$ ratio & $\leq 3 \mu \mathrm{mg}^{-1}$ \\
Average voltage & Around $2.1 \mathrm{~V}$ \\
Cathode porosity & $\leq 40 \%$ \\
$\%$ Li excess & $\leq 50 \mathrm{wt} \%$ \\
Preparation and fabrication method (for both & Feasible and low cost \\
materials and systems) &
\end{tabular}


Based on the target of high-energy Li-S batteries, researchers have made great efforts on the development of cathodes, electrolytes, and anodes, ranging from material selection, structure design, and mechanism investigations. In the next section, we present details on material synthesis, electrochemical performance, and reaction mechanisms related to high-energy $\mathrm{Li}-\mathrm{S}$ batteries. The future application, prospects, and comparison with different types of $\mathrm{Li}-\mathrm{S}$ batteries will also be summarized.

\section{Research Progress of High-Energy Li-S Batteries}

\subsection{Sulfur Cathodes}

The development of sulfur cathodes began nearly 2 decades ago [11, 13, 14, 26, 27, 32, 51-105]. Until now, various nanomaterials and nanostructures have been employed in sulfur cathodes in pursuit of high performance in $\mathrm{Li}-\mathrm{S}$ batteries. In this section, we will briefly introduce the fundamentals of the sulfur cathode in terms of different $\mathrm{Li}-\mathrm{S}$ redox reactions. The strategies for achieving high loading sulfur cathodes will then be summarized in detail with the synthetic method, structure design, and electrochemical characterizations.

\subsubsection{Fundamental Studies and Material Selection for Sulfur Cathodes}

\subsubsection{Sulfur Cathodes in "Solid-Liquid Dual-Phase" Reac-} tion System As mentioned before, the insulating nature of sulfur, dissolution of polysulfides, and volume expansion of sulfur are the three main issues of sulfur cathodes. The design of multi-architectural and multi-functional cathode materials has the potential to overcome these challenges and has been one of the most researched strategies in recent years. Currently, physical routes including capillary force absorption [14, 51-57], shell coating [58-75], and chemical routes containing heteroatom-doped carbons [76-90] and metal-based additives [91-105] are proposed to obtain high discharge capacities and excellent cycling stability. These strategies can improve performance by providing intimate electrical contact for insulating active materials, limiting the free shuttle of soluble polysulfides and buffering volumetric expansion during sulfur lithiation (Fig. 3). There have been several reviews that expand on these topics and can be found in the references [106-118] (Fig. 5).

\subsubsection{Sulfur Cathodes in the "Solid-Phase" Reaction Sys-} tem Carbonate electrolytes are one of the most prevailing electrolyte systems in Li-ion batteries [119, 120]. Compared

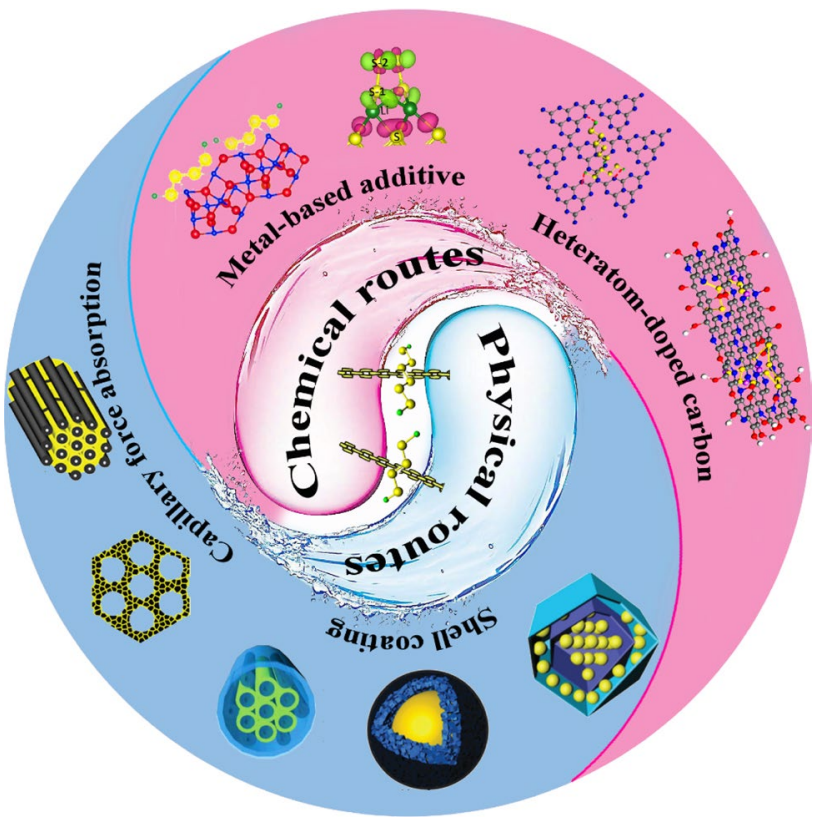

Fig. 5 Scheme for designing cathode materials for $\mathrm{Li}-\mathrm{S}$ batteries. Reprinted with permission from Ref. [14], copyright 2009, Nature Publishing Group. Reprinted with permission from Ref. [51], copyright 2009, American Chemical Society. Reprinted with permission from Ref. [75], copyright 2011, American Chemical Society. Reprinted with permission from Ref. [71], copyright 2016, Nature Publishing Group. Reprinted with permission from Ref. [72], copyright 2016, Wiley-VCH. Reprinted with permission from Ref. [90], copyright 2015, American Chemical Society. Reprinted with permission from Ref. [105], copyright 2015, American Chemical Society. Reprinted with permission from Ref. [99], copyright 2014, Nature Publishing Group

with ether-based electrolytes, which is the most popular system in $\mathrm{Li}-\mathrm{S}$ batteries, carbonate-based electrolytes have enhanced electrochemical stability, wide temperature windows, as well as lower cost [121, 122]. The reported Li-S batteries with carbonate electrolyte have also demonstrated improved safety and stabilized electrochemical performance. However, it is well known that most sulfur cathodes cannot undergo reversible $\mathrm{Li}-\mathrm{S}$ redox reaction in carbonate electrolyte $[123,124]$. The irreversibility is due to the side reactions between intermediate polysulfides and carbonate solvents, which results in the decomposition of electrolyte and sharply reduced ionic conductivity [125]. Therefore, conventional sulfur cathodes cannot complete the "solidliquid" dual-phase $\mathrm{Li}-\mathrm{S}$ redox reaction in carbonate electrolytes. As an alternative option, sulfur cathodes employing a solid-phase $\mathrm{Li}-\mathrm{S}$ reaction have been adopted in carbonate electrolyte. To the best of our knowledge, all of the reported $\mathrm{Li}-\mathrm{S}$ batteries in carbonate electrolyte undergo a single pair of discharge-charge plateaus during the discharge/ charge process. Based on aforementioned issues, undergoing a solid-phase $\mathrm{Li}-\mathrm{S}$ reaction is essential in carbonate electrolyte. Many reported literatures have developed dif- 


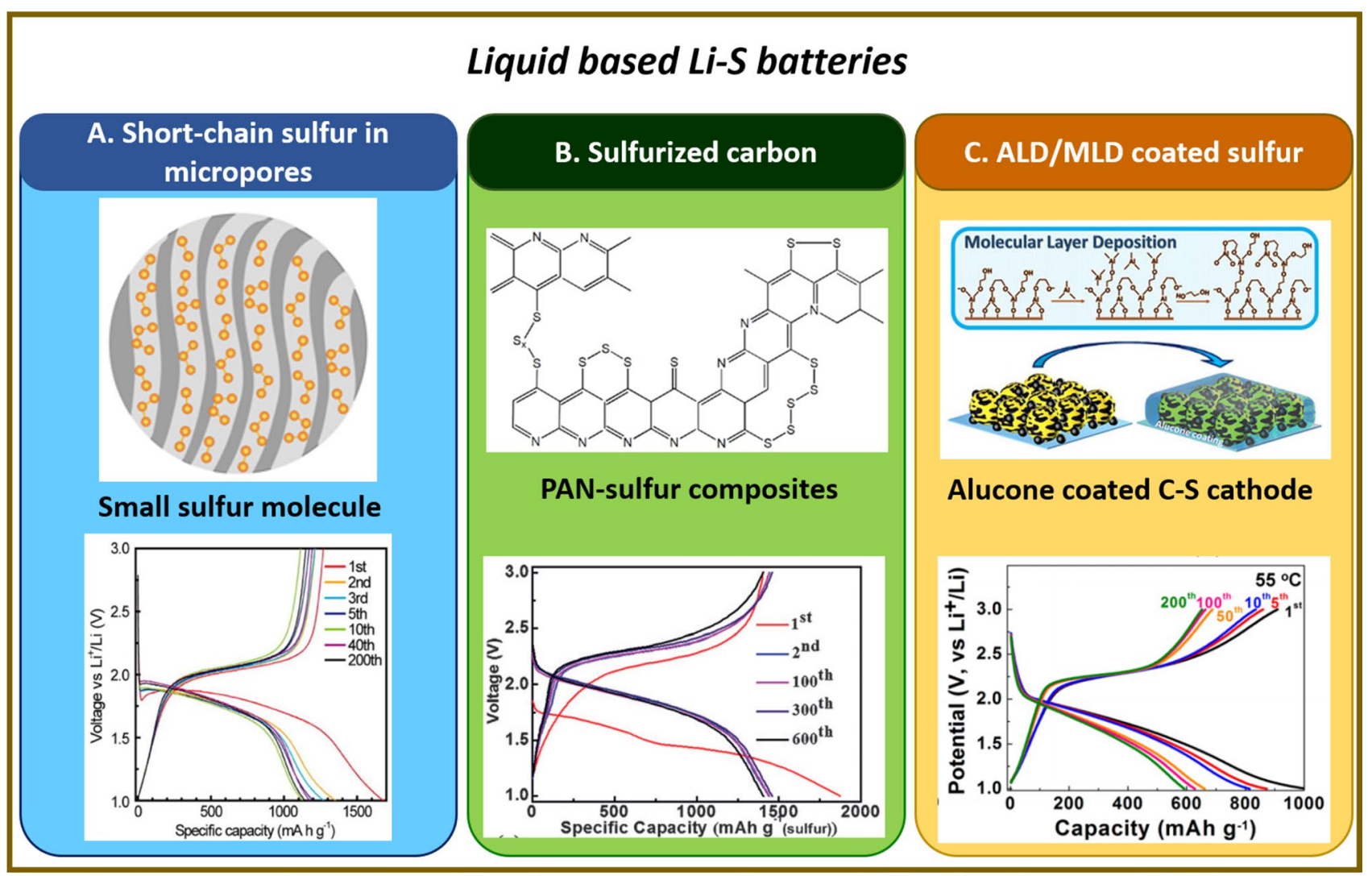

Fig. 6 Different sulfur cathodes delivering solid-phase Li-S electrochemical reaction: a Short-chain sulfur confined in microporous structure. Reprinted with permission from Ref. [126], copyright 2012, American Chemical Society. b PAN-sulfur composites. Reprinted with permission from Ref. [127], copyright 2011, Ameri- can Chemical Society. Reprinted with permission from Ref. [128], copyright 2017, Wiley-VCH. c Atomic layer deposition (ALD)/MLD coated sulfur-based electrodes. Reprinted with permission from Ref. [129], copyright 2016, American Chemical Society

some side reaction happened during the electrochemical process. Following this study, Gao's group developed different kinds of microporous carbon materials originating from polyacrylonitrile (PAN) and sucrose [131, 132]. The developed carbon materials delivered high surface areas and confined pore size. Interestingly, the study demonstrated that the sulfur content in $\mathrm{C}-\mathrm{S}$ composites is directly related to the reversibility of $\mathrm{Li}-\mathrm{S}$ reaction. The $\mathrm{S}-\mathrm{C}$ composites with $57 \mathrm{wt} \%$ sulfur content are reversible, while the S-C composites with $75 \mathrm{wt} \%$ sulfur content are not. The paper proposed that the molecular structure of the sulfur formed in the micropores may be different from the species on the outer surface and the low molecular weight sulfur chains may be the key to achieving reversible $\mathrm{Li}-\mathrm{S}$ redox reactions in carbonate electrolyte. However, the paper did not provide a consolidated working mechanism for the sulfur cathodes in carbonate electrolyte. In 2012, Guo's research team proposed the concept of "small sulfur molecules" in $\mathrm{Li}-\mathrm{S}$ batteries [126]. For the first time, they introduced different allotropes of sulfur molecules (small sulfur molecules and cyclo- $\mathrm{S}_{8}$ ) into microporous and mesoporous structures. The 
logic behind the use of small sulfur molecules is to diminish the formation of long-chain polysulfides $\left(\mathrm{Li}_{2} \mathrm{~S}_{n}, n=5-8\right)$ and therefore avoid the side reactions in carbonate electrolyte. During electrochemical cycling, the small sulfur moleculebased cathodes present only one pair of discharge-charge plateaus, which is different from the conventional $\mathrm{Li}-\mathrm{S}$ redox behavior in ether-based electrolyte. The as-prepared small sulfur cathodes demonstrate excellent electrochemical performances in both ether and carbonate electrolytes, while the capacity maintaining greater than $1000 \mathrm{~mA} \mathrm{~h} \mathrm{~g}^{-1}$ for over 200 cycles. This paper highlights the different electrochemical routes of cyclo- $\mathrm{S}_{8}$ and small sulfur molecule in carbonate electrolyte and demonstrated the compatibility of the carbonate electrolyte with the as-prepared small sulfur molecule cathodes. Following these results, Guo's team further demonstrated the small sulfur allotrope concept $[126,133]$. They developed a one-dimensional sulfur chain encapsulated in CNTs as a model system for Li-S batteries. The short sulfur chains show improved kinetics and output potentials compared with their long chains counterparts and conventional cyclo- $S_{8}$. Soon after, different types of small sulfur molecule-based cathodes were developed and this concept has been demonstrated in many papers [124, 134-139]. Microporous structure plays an important role in the formation of small sulfur molecules. To confine the sulfur, a variety of microporous carbon hosts have been developed, such as nitrogen-doped microporous carbon, subnanometer 2D graphene, microporous structure carbon nanotubes, and pyrolyzed polymer derived carbon [140-142]. Lou et al. [134] employed novel metal-organic-framework (MOF), ZIF-8, to develop a microporous carbon host for sulfur cathodes. The highly ordered structure of MOFs with confined pores is favorable for the synthesis of microporous carbon materials. The study illustrated the different electrochemical process of as-prepared $\mathrm{C}-\mathrm{S}$ electrodes in carbonate and ether-based electrolytes and concluded that the sulfur content of carbon-sulfur composites was related to the sulfur molecular allotropes which were critical for the Li-S battery performance in carbonate electrolyte. Another paper also employed highly ordered microporous carbon (FDU) as carbon hosts for sulfur cathodes where the authors investigated the electrochemical routes of $\mathrm{S}_{2-4}$ cathodes in different electrolytes [143]. The electrochemical results indicate that the microstructure of carbon matrixes plays an important role in the electrochemical performance and the lithiation/ delithiation for $\mathrm{S}_{2-4}$ and occurs as a solid-solid process if the micropores of carbon are small enough.

In additional to the development of pristine sulfur-carbon composites, another promising approach to synthesize small sulfur molecules is to introduce non-metal or metal particles into the sulfur cathodes. Qian's group developed sulfur-rich $\mathrm{S}_{1-x} \mathrm{Se}_{x} / \mathrm{C}$ composites [144]. The introduction of Se in the sulfur cathode has two important functions: (1) reducing the formation of long-chain polysulfides; and (2) improving electronic conductivity. The as-prepared sulfur cathodes demonstrate excellent electrochemical performance capable of delivering a capacity of $910 \mathrm{~mA} \mathrm{~h} \mathrm{~g}^{-1}$ at $1 \mathrm{~A} \mathrm{~g}^{-1}$ over 500 cycles, $1105 \mathrm{~mA} \mathrm{~h} \mathrm{~g}^{-1}$ at $0.2 \mathrm{~A} \mathrm{~g}^{-1}$ after 100 cycles and a goodrate capability of $617 \mathrm{~mA} \mathrm{~h} \mathrm{~g}^{-1}$ at $20 \mathrm{~A} \mathrm{~g}^{-1}$. Another paper published by Wang et al. [145] employed copper nanoparticle-decorated microporous carbon as a host for sulfur cathodes. The study illustrated the use of $\mathrm{Cu}$ could chemically stabilize sulfur by the formation of solid $\mathrm{Cu}$-polysulfide clusters through strong interaction between $\mathrm{Cu}$ and $\mathrm{S}$. The $\mathrm{Cu}$-polysulfide clusters reduced the amount of $\mathrm{S}_{8}$ and high-order polysulfides, allowing the use of carbonate-based electrolytes.

Based on recent literature, the developed small sulfur molecule-based cathodes have some common characteristics: (1) sulfur should be confined in microporous structures; (2) low sulfur content C-S composites (mostly less than $50 \mathrm{wt} \%$ ); (3) solid-phase Li-S reactions; and (4) highly stable and reversible electrochemical performance [124, $135,143,146,147]$. It should be noted that sulfur cathode with the low content and areal loading is hard to meet the requirement for high-energy $\mathrm{Li}-\mathrm{S}$ batteries. Further, there are many challenges and unrevealed electrochemical mechanisms related to the use of small sulfur molecule. One review paper published by Aurbach et al. [142] raised questions on the mechanism of small sulfur molecules and stated that they are not the only way to make functionalized sulfur cathodes in carbonate electrolyte. The author proposed that the SEI layer formation on the cathode during the initial charging process played a key role in quasi-solid-state $\mathrm{Li}-\mathrm{S}$ reactions.

\section{B. Sulfurized Polymers}

Sulfurized polymers are another facile approach to anchoring short-chain sulfur on polymer matrices, as firstly reported by Wang et al. in [148]. The synthetic process employed a one-pot reaction of the mixture of polyacrylonitrile (PAN) and sulfur with a heating treatment of around $300{ }^{\circ} \mathrm{C}$. The as-prepared PAN-S demonstrated a highly reversible electrochemical performance with a specific capacity above $600 \mathrm{~mA} \mathrm{~h} \mathrm{~g}^{-1}$ after 50 cycles. This study provided some insight on the molecular structure of PAN-S composites with the use of nuclear magnetic resonance (NMR), which indicates that sulfur is in the elemental statement in the composites. Following this study, Buchmeiser et al. [127] investigated the structure of PAN-S composites and related it to the electrochemical mechanisms of $\mathrm{Li}-\mathrm{S}$ batteries. The comparison of S-PAN composites and S-carbonized PAN (S-cPAN) composites via NMR found $\mathrm{S}-\mathrm{C}-\mathrm{N}$ bonds between $\mathrm{S}$ and PAN skeleton while the S-cPAN composites do not have such $\mathrm{S}-\mathrm{C}-\mathrm{N}$ bonding. This evidence confirmed the chemical interaction formed between chain-based sulfur molecules 
$\left(0<S_{x}<6\right)$ and the polymer matrix during synthetic process. Based on the observed results, the study proposed a molecular structure of PAN-S, in which cyclo- $\mathrm{S}_{8}$ molecules are transformed to chain-based sulfur molecules and form covalently bound sulfur with the polymer backbone. According to the different structure of PAN-S composites and cyclo- $\mathrm{S}_{8}$ composites, the electrochemical behavior of PAN-S composites is different from the conventional sulfur-based cathodes, which exhibits a single pair of discharge-charge plateaus during cycling $[149,150]$.

After the pioneering of PAN-S composites, many researcher focused on the optimization of sulfurized PAN and investigated their electrochemical mechanisms. Wang et al. [150] investigated the sulfur content effect on PAN-S composites. The C-S composites with $42 \mathrm{wt} \%$ sulfur demonstrate the best cycling performance and maintain excellent cycling reversibility even with high active material loading $\left(6 \mathrm{mg} \mathrm{cm}^{-2}\right)$. It should be noted that the different sulfur content of PAN-S composites determined the interaction of sulfur and carbon. To summarize the reported literature, it becomes difficult to achieve greater than $45 \mathrm{wt} \%$ sulfur content in S-PAN composites due to saturation of the polymer matrix. Based on the challenges of low sulfur content, Chen et al. [151] developed a vulcanization accelerator (VA) supported PAN-S to enhance the sulfur loading in the cathode material. The sulfur content with the support of VA increased from 48 to $56 \mathrm{wt} \%$ and the as-prepared PAN-SVA demonstrated excellent electrochemical performance. In addition to the investigation of electrochemical performance, different nanostructures incorporating PAN-S composites were also developed. Ai's group developed 2D nanofiber PAN-S composites with the use of a single-nozzle electrospinning technique [152]. Later, Buchmeiser et al. [153] also developed fiber-based PAN-S composites derived from commercially available poly(methyl methacrylate)/poly(acrylonitrile) (PMMA/PAN) fibers. The two developed 2D fiber-based PAN-S composites were used to investigate the chemical bonds and schematic structural motifs of PAN-S composites and demonstrate excellent electrochemical performance of the cathodes in $\mathrm{Li}-\mathrm{S}$ batteries with carbonate electrolyte.

The developed PAN-S composites demonstrate very stable electrochemical performances in carbonate electrolyte and therefore it is important to investigate the novel electrochemical behavior to further improve the safety and performance of Li-S batteries. Yanna et al. [154] developed a nonflammable carbonate electrolyte by introducing flameretardant additives (FRs) to liquid electrolytes. The results demonstrated that dimethyl methylphosphonate (DMMP) as FRs can significantly suppress the flammability and improve the thermal stability of the commercialized electrolyte $1 \mathrm{M} \mathrm{LiPF}_{6} / \mathrm{EC}+\mathrm{EMC}$. Meanwhile, with an optimized DMMP loading (7-11 wt $\%$ ), the Li-S batteries with PAN-S composites demonstrated outstanding electrochemical performances. Feng et al. [155] employed $\mathrm{Li}_{2} \mathrm{SiO}_{3}$ as an interlayer between the PAN-S cathode and separator. The study demonstrated that carbonate solvents can be protected from reacting with $\mathrm{Li}_{2} \mathrm{~S}_{\mathrm{n}} / \mathrm{PF}_{5} / \mathrm{HF}$ during cycling since $\mathrm{Li}_{2} \mathrm{SiO}_{3}$ could consume $\mathrm{PF}_{5} / \mathrm{HF}$. The formation of a thick passivation layer on the cathode surface is avoided and the deactivation of sulfur is alleviated. Another interesting study in carbonate Li-S batteries is from Miao's team. To address the issue of Li metal dendrite formation in carbonate electrolyte, they developed a novel carbonate electrolyte LiODFB/ECDMC-FEC [128]. Under the synergistic effect of LiODFB and FEC, a unique SEI layer is formed on the lithium anode to prevent further side reactions with electrolyte, leading to a high Coulombic efficiency and cycling stability. Furthermore, with the PAN-S composites as the cathode, the use of this electrolyte system for Li-S battery results in extraordinary electrochemical performances, including a capacity retention of $89 \%$ for 1100 cycles, a superior rate performance up to $10 \mathrm{C}$, high cycling stability at $60^{\circ} \mathrm{C}$ and negligible self-discharge. These studies demonstrated enhanced safety, an improved SEI layer, and prevention of Li dendrite formation in Li-S batteries. Despite the employed PAN-S cathodes having low sulfur content, these studies show significant progress for future carbonate-based $\mathrm{Li}-\mathrm{S}$ batteries.

\section{Alucone-Coated Porous Carbon-Sulfur Electrodes}

The two aforementioned sulfur-based cathodes demonstrate excellent cycling performance in $\mathrm{Li}-\mathrm{S}$ batteries and both of them present a single pair of discharge-charge plateaus during the discharge-charge process. It was found that both of the confined short-chain sulfur molecules and sulfurized polymers are not conventional cyclo- $\mathrm{S}_{8}$ molecules. Therefore, it is critical to limit the sulfur content to maintain their unique chemical structure. The low sulfur content (mostly $<50 \mathrm{wt} \%$ ) of the cathodes, even with excellent cycling performance, is not sufficient enough to achieve high-energy Li-S batteries. Furthermore, the delicate synthesis of confined sulfur cathodes decreases the feasibility of carbonate Li-S batteries in practical application.

Considering the significant challenges associated with high sulfur content cathodes, Sun's group developed an alucone-coated C-S electrode via molecular layer deposition and applied it in carbonate electrolyte [129]. Notably, the carbon host used in this research is a commercially available mesoporous carbon host and the sulfur content is over $65 \mathrm{wt} \%$, which is a breakthrough compared with previous studies. The alucone-coated $\mathrm{C}-\mathrm{S}$ electrode demonstrates a single pair of discharge-charge plateaus, which indicates that conventional commercial carbon-sulfur cathodes can be operated in carbonate electrolyte. Furthermore, this study demonstrates safe and high-temperature $\mathrm{Li}-\mathrm{S}$ batteries 
with the use of carbonate electrolyte for the first time. On the other hand, these are many challenges and underlying mechanisms that should be further explored in this study. Firstly, the cycling performance and Coulombic efficiency of alucone-coated $\mathrm{C}-\mathrm{S}$ electrodes at room temperature is relatively low, which should be further improved. Secondly, the underlying mechanism of alucone-coated $\mathrm{C}-\mathrm{S}$ electrode is still unclear. The study did not reveal why the use of alucone coating could enable cyclo- $\mathrm{S}_{8}$ molecule cathodes to operate in carbonate electrolyte and the reason behind this unique electrochemical behavior. Thirdly, despite the high content of the sulfur cathodes employed in this study, the areal loading of the developed sulfur cathodes is still not sufficient. The high content and areal loading sulfur cathodes applied in carbonate electrolytes will be an important direction for practical application.

In a brief summary, this section introduced $\mathrm{Li}-\mathrm{S}$ batteries utilizing a unique solid-phase $\mathrm{Li}-\mathrm{S}$ redox reaction. One important characteristic of this reaction is the single pair of discharge-charge plateaus, which is different from the previously reported $\mathrm{Li}-\mathrm{S}$ batteries with solid-liquid dualphase reactions. For most of the reported solid-phase Li-S reactions, the batteries are operated in carbonate electrolyte and the sulfur cathodes need delicate design and synthesis. Three different types of sulfur cathodes were introduced in this section with different chemical structures, and each of them has specific advantages and challenges in $\mathrm{Li}-\mathrm{S}$ batteries. Compared with conventional ether-based electrolytes, the $\mathrm{Li}-\mathrm{S}$ batteries in carbonate electrolytes demonstrate safe, stable, and prolonged cycle life during cycling. However, one undeniable challenge of these sulfur cathodes is the low sulfur content and areal loading, which will be an important direction in the future development of $\mathrm{Li}-\mathrm{S}$ batteries. Another challenge is the understanding of the fundamental mechanisms behind these developed sulfur cathodes, such as the chemical structure of PAN-S composites, the electrochemical behavior of alucone-coated $\mathrm{C}-\mathrm{S}$ electrodes (Table 4).

\subsubsection{High Loading Sulfur Cathodes}

As mentioned in the last section, the development of various sulfur cathodes has led to great improvements in $\mathrm{Li}-\mathrm{S}$ batteries with excellent electrochemical performance. It seems that the industrialization and commercialization of $\mathrm{Li}-\mathrm{S}$ batteries is close at hand. However, it should be noted that almost all of the electrochemical performances were obtained with a low sulfur loading of less than $2 \mathrm{mg} \mathrm{cm}^{-2}$, which deviates greatly from the target set out in Sect. 1.3.4 (4-6 mg cm${ }^{-2}$ ) and is believed to significantly decrease the energy density. Therefore, developing high sulfur loading electrodes is required for high-energy Li-S batteries. In this section, we will firstly introduce the structure design of high loading electrodes from reported literatures and then summarize the state of sulfur cathodes with statistical analysis.

\subsubsection{Structural Design of High Loading Sulfur Cathodes}

A. 2D current collector design for high-loading cathodes

The traditional slurry casting method on Al foil is still widely used in the synthesis of sulfur-based electrodes for both fundamental research and engineering scale-up. Al foil provides high conductivity to enable electron transport from the current collector to active material/conductive additives without significant resistance. Nanocarbon materials with high specific areas and large pore volumes have received significant attention due to their economic value, large-scale reliability, ability to shorten ion/electron transport pathways and availability of active sites [53, 159-162]. However, a problem associated with many nanocarbon materials is that they are difficult to be anchored on the current collector, leading to delamination and loss of active materials [161, 163]. What's worse, if the detached electrode materials can make contact with the opposing electrode, short-circuiting will occur and may lead to severe safety hazards. Recently, researchers have proposed many methods to solve this problem in order to obtain sulfur electrodes with high loadings and excellent mechanical properties.

One of the most popular strategies to utilize nanocarbon is the integration of primary nanoparticles into microsized secondary structures [22, 164-167]. As shown in Fig. 7a, $\mathrm{Xiao}$ et al. proposed to cross-link commercial KB into integrated KB (IKB) by carbonizing a mixture of KB and polymer binder. Through this method, S/IKB with $80 \%$ sulfur content can be homogenously coated on the current collector in the absence of cracking and delamination. The result shows an optimized battery performance at a sulfur loading of $3.5 \mathrm{mg} \mathrm{cm}^{-2}$, which possesses a reversible discharge capacity of around $800 \mathrm{~mA} \mathrm{~h} \mathrm{~g}^{-1}$ delivered after 100 cycles at $0.1 \mathrm{C}$. However, the $\mathrm{Li}^{+}$transportation can be limited, at least to some extent, by the extended $\mathrm{Li}^{+}$transfer pathway and increased resistance from binder-derived carbon. As a result, when the sulfur loading is further increased to $5 \mathrm{mg} \mathrm{cm}^{-2}$, the discharge capacity remarkably decreased to around $400 \mathrm{~mA} \mathrm{~h} \mathrm{~g}^{-1}$ at $0.2 \mathrm{C}$. A similar strategy was adopted to develop cauliflower-like $\mathrm{C} / \mathrm{S}$ cathodes with a high sulfur loading of $14 \mathrm{mg} \mathrm{cm}^{-2}$, where a high practical energy density $504 \mathrm{~W} \mathrm{~h} \mathrm{~kg}^{-1}$ was delivered. However, the electrode could only operate at $0.01 \mathrm{C}$ and the electrode is designed for primary batteries [164]. In order to solve the challenge of limited $\mathrm{Li}^{+}$transport, Wang et al. [167] introduced F127 and silica species as templates for secondary particles. After the removal of the templates, the interconnected pore network can act as channels for fast $\mathrm{Li}^{+}$transport, resulting in the Li-S batteries assembled with $5 \mathrm{mg} \mathrm{cm}^{-2}$ sulfur-loaded 
Table 4 Summary of the solid-phase reaction Li-S batteries

\begin{tabular}{|c|c|c|c|c|c|c|c|}
\hline Cathode & $\begin{array}{l}\text { Sulfur } \\
\text { content in } \\
\text { C-S-active } \\
\text { materials }\end{array}$ & $\begin{array}{l}\text { Sulfur loading } \\
\text { in electrode }\end{array}$ & Electrolyte & $\begin{array}{l}\text { Voltage } \\
\text { range }(\mathrm{V})\end{array}$ & $\begin{array}{l}\text { Voltage } \\
\text { plateau }(\mathrm{V})\end{array}$ & $\begin{array}{l}\text { Performance } \\
\text { (calculation only } \\
\text { based on sulfur) }\end{array}$ & References \\
\hline \multicolumn{8}{|c|}{ Confined sulfur in microporous structure } \\
\hline $\begin{array}{l}\text { MWNTs-sulfur } \\
\text { nanocomposite }\end{array}$ & $\begin{array}{l}\text { Not men- } \\
\text { tioned }\end{array}$ & Not mentioned & $\mathrm{LiPF}_{6}(\mathrm{EC}: \mathrm{DMC}: \mathrm{EMC})$ & $1.8-3.2$ & 2.1 & $\begin{array}{l}500 \mathrm{~mA} \mathrm{~h} \mathrm{~g}^{-1} \\
\text { sulfur over } 60 \\
\text { cycles }\end{array}$ & [130] \\
\hline $\begin{array}{l}\text { Sulfur/high porous } \\
\text { carbon }\end{array}$ & $57 \mathrm{wt} \%$ & Not mentioned & $\mathrm{LiPF}_{6}(\mathrm{PC}: \mathrm{EC}: \mathrm{DEC})$ & $1.0-3.0$ & $2.2-1.9$ & $\begin{array}{l}745 \mathrm{~mA} \mathrm{~h} \mathrm{~g}^{-1} \\
\text { sulfur over } 84 \\
\text { cycles }\end{array}$ & [131] \\
\hline $\begin{array}{l}\text { Microporous } \\
\text { carbon-sulfur } \\
\text { composites }\end{array}$ & $42 \mathrm{wt} \%$ & $\begin{array}{l}1.47 \mathrm{mg} \mathrm{cm}^{-2} \\
\quad \text { (Sulfur) }\end{array}$ & $\mathrm{LiPF}_{6}(\mathrm{PC}: \mathrm{EC}: \mathrm{DEC})$ & $1.0-3.0$ & 1.8 & $\begin{array}{l}730 \mathrm{~mA} \mathrm{~h} \mathrm{~g}{ }^{-1} \\
\text { over } 100 \text { cycles }\end{array}$ & [132] \\
\hline $\mathrm{S}_{2}-\mathrm{S}_{4}$ molecules & $40 \mathrm{wt} \%$ & $\begin{array}{l}1 \mathrm{mg} \mathrm{cm}^{-2} \\
\text { (active mate- } \\
\text { rial) }\end{array}$ & $\mathrm{LiPF}_{6}(\mathrm{EC}: \mathrm{DEC})$ & $1.0-3.0$ & $2.0-1.9$ & $\begin{array}{l}1190 \mathrm{~mA} \mathrm{~h} \mathrm{~g}^{-1} \\
\text { over } 200 \text { cycles }\end{array}$ & [126] \\
\hline $\begin{array}{l}\text { Microporous- } \\
\text { mesoporous } \\
\text { carbon-sulfur }\end{array}$ & $43 \mathrm{wt} \%$ & Not mentioned & $\mathrm{LiPF}_{6}(\mathrm{EC}: \mathrm{DMC}: \mathrm{EMC})$ & $1.5-2.8$ & $2.0-1.5$ & $\begin{array}{l}\sim 1000 \mathrm{~mA} \mathrm{~h} \mathrm{~g}^{-1} \\
\quad \text { over } 50 \text { cycles }\end{array}$ & [146] \\
\hline $\begin{array}{l}\text { MOF-derived } \\
\text { microporous } \\
\text { carbon-sulfur } \\
\text { composites }\end{array}$ & $<43 \mathrm{wt} \%$ & Not mentioned & $\mathrm{LiPF}_{6}(\mathrm{EC}: \mathrm{DEC})$ & $1.25-3.0$ & 1.75 & $\begin{array}{l}500 \mathrm{~mA} \mathrm{~h} \mathrm{~g} \\
\text { over } 100 \text { cycles }\end{array}$ & [134] \\
\hline $\begin{array}{l}\text { Microporous } \\
\text { carbon-sulfur } \\
\text { composite }\end{array}$ & $40 \mathrm{wt} \%$ & Not mentioned & $\mathrm{LiPF}_{6}$ (PC:EC:DEC) & $1.0-3.0$ & 1.75 & $\begin{array}{l}720 \mathrm{~mA} \mathrm{~h} \mathrm{~g}^{-1} \\
\text { over } 100 \text { cycles }\end{array}$ & [135] \\
\hline $\begin{array}{l}\text { Ordered micropo- } \\
\text { rous carbon } \\
\text { confined sulfur }\end{array}$ & $<40 \mathrm{wt} \%$ & $\begin{array}{l}1 \mathrm{mg} \mathrm{cm}^{-2} \\
\text { (active mate- } \\
\text { rial) }\end{array}$ & $\mathrm{LiPF}_{6}(\mathrm{EC}: \mathrm{DMC})$ & $1.0-3.0$ & 1.75 & $\begin{array}{l}600 \mathrm{~mA} \mathrm{~h} \mathrm{~g}{ }^{-1} \\
\text { over } 500 \text { cycles }\end{array}$ & [124] \\
\hline $\begin{array}{l}\text { Microporous } \\
\text { carbon-sulfur } \\
\text { composites }\end{array}$ & $30-50 \mathrm{wt} \%$ & $\begin{array}{l}1 \mathrm{mg} \mathrm{cm}^{-2} \\
\text { (active mate- } \\
\text { rial) }\end{array}$ & $\mathrm{LiPF}_{6}(\mathrm{EC}: \mathrm{DEC})$ & $1.0-3.0$ & 1.6 & $\begin{array}{l}850 \mathrm{~mA} \mathrm{~h} \mathrm{~g}^{-1} \\
\text { over } 500 \text { cycles }\end{array}$ & [156] \\
\hline $\begin{array}{l}\text { Copper-stabilized } \\
\text { sulfur-micropo- } \\
\text { rous carbon }\end{array}$ & $<50 \mathrm{wt} \%$ & $\begin{array}{l}1 \mathrm{mg} \mathrm{cm}^{-2} \\
\text { (active mate- } \\
\text { rial) }\end{array}$ & $\mathrm{LiPF}_{6}(\mathrm{EC}: \mathrm{DEC})$ & $1.0-3.0$ & 1.5 & $\begin{array}{l}630 \mathrm{~mA} \mathrm{~h} \mathrm{~g}^{-1} \\
\text { over } 500 \text { cycles }\end{array}$ & [145] \\
\hline $\begin{array}{l}\text { Sulfur/microporous } \\
\text { carbon composites }\end{array}$ & $<50 \mathrm{wt} \%$ & Not mentioned & $\mathrm{LiPF}_{6}(\mathrm{PC}: \mathrm{EC}: \mathrm{DEC})$ & $1.0-3.0$ & 1.8 & $\begin{array}{l}520 \mathrm{~mA} \mathrm{~h} \mathrm{~g}^{-1} \\
\text { over } 180 \text { cycles }\end{array}$ & [147] \\
\hline $\begin{array}{l}\text { Amorphous S-rich } \\
\mathrm{S}_{1-x} \mathrm{Se}_{x} / \mathrm{C}(x<0.1) \\
\text { composites }\end{array}$ & $<50 \mathrm{wt} \%$ & $\begin{array}{l}0.8- \\
1.5 \mathrm{mg} \mathrm{cm}^{-2} \\
\text { (active mate- } \\
\text { rial) }\end{array}$ & $\mathrm{LiPF}_{6}(\mathrm{EC}: \mathrm{DMC})$ & $0.8-3.0$ & 2.0 & $\begin{array}{l}1090 \mathrm{~mA} \mathrm{~h} \mathrm{~g}^{-1} \\
\text { over } 200 \text { cycles }\end{array}$ & [144] \\
\hline $\begin{array}{l}\text { Confined sulfur } \\
\text { in microporous } \\
\text { carbon }\end{array}$ & $15-31 \mathrm{wt} \%$ & $0.17 \mathrm{mg} \mathrm{cm}^{-2}$ & $\mathrm{LiPF}_{6}(\mathrm{EC}: \mathrm{DEC})$ & $1.0-3.0$ & 1.7 & $\begin{array}{l}500 \mathrm{~mA} \mathrm{~h} \mathrm{~g}^{-1} \\
\text { over } 4000 \\
\text { cycles }\end{array}$ & [157] \\
\hline $\begin{array}{l}\text { Sulfur confined in } \\
\text { sub-nanometer- } \\
\text { sized 2D graphene } \\
\text { interlayers }\end{array}$ & $\sim 35 \mathrm{wt} \%$ & $\begin{array}{c}1 \mathrm{mg} \mathrm{cm}^{-2} \\
\text { (Sulfur) }\end{array}$ & $\mathrm{LiPF}_{6}(\mathrm{EC}: \mathrm{DMC}: \mathrm{DEC})$ & $1.0-3.0$ & 2.0 & $\begin{array}{l}<600 \mathrm{~mA} \mathrm{~h} \mathrm{~g}^{-1} \\
\text { over } 120 \text { cycles }\end{array}$ & [140] \\
\hline $\begin{array}{l}\text { Sulfur confined in } \\
\text { sub-nanoporous } \\
\text { carbon }\end{array}$ & $30 \mathrm{wt} \%$ & Not mentioned & $\mathrm{LiPF}_{6}(\mathrm{EC}: \mathrm{DEC})$ & $1.0-3.0$ & 1.7 & $\begin{array}{l}\sim 800 \mathrm{~mA} \mathrm{~h} \mathrm{~g}^{-1} \\
\quad \text { over } 100 \text { cycles }\end{array}$ & [141] \\
\hline $\begin{array}{l}\text { Sulfur confined in } \\
\text { nitrogen-doped } \\
\text { microporous } \\
\text { carbon }\end{array}$ & $\sim 50 \mathrm{wt} \%$ & $\begin{array}{l}1.2- \\
1.4 \mathrm{mg} \mathrm{cm}^{-2} \\
\text { (Sulfur) }\end{array}$ & $\mathrm{LiPF}_{6}(\mathrm{EC}: \mathrm{DMC})$ & $1.0-3.0$ & 1.7 & $\begin{array}{l}1002 \mathrm{~mA} \mathrm{~h} \mathrm{~g}^{-1} \\
\text { over } 200 \text { cycles }\end{array}$ & [136] \\
\hline $\begin{array}{l}\text { Microporous } \\
\text { carbon-sulfur } \\
\text { composites }\end{array}$ & $40 \mathrm{wt} \%$ & $\begin{array}{l}1 \mathrm{mg} \mathrm{cm}^{-2} \\
\text { (Sulfur) }\end{array}$ & $\mathrm{LiPF}_{6}(\mathrm{EC}: \mathrm{DMC})$ & $1.0-3.0$ & 2.0 & $\begin{array}{l}616 \mathrm{~mA} \mathrm{~h} \mathrm{~g}^{-1} \\
\text { over } 600 \text { cycles } \\
(1 \mathrm{C})\end{array}$ & [137] \\
\hline
\end{tabular}


Table 4 (continued)

\begin{tabular}{|c|c|c|c|c|c|c|c|}
\hline Cathode & $\begin{array}{l}\text { Sulfur } \\
\text { content in } \\
\text { C-S-active } \\
\text { materials }\end{array}$ & $\begin{array}{l}\text { Sulfur loading } \\
\text { in electrode }\end{array}$ & Electrolyte & $\begin{array}{l}\text { Voltage } \\
\text { range }(\mathrm{V})\end{array}$ & $\begin{array}{l}\text { Voltage } \\
\text { plateau (V) }\end{array}$ & $\begin{array}{l}\text { Performance } \\
\text { (calculation only } \\
\text { based on sulfur) }\end{array}$ & References \\
\hline $\begin{array}{l}\text { Ultra-microporous } \\
\text { carbon-sulfur } \\
\text { composites }\end{array}$ & $39.72 \mathrm{wt} \%$ & $\begin{array}{l}0.8 \mathrm{mg} \mathrm{cm}^{-2} \\
\quad \text { (Sulfur) }\end{array}$ & $\mathrm{LiPF}_{6}(\mathrm{EC}: \mathrm{DMC}: \mathrm{DEC})$ & $1.0-3.0$ & 1.75 & $\begin{array}{l}507 \mathrm{~mA} \mathrm{~h} \mathrm{~g}^{-1} \\
\text { over } 500 \text { cycles } \\
(3 \mathrm{C})\end{array}$ & [138] \\
\hline $\begin{array}{l}\text { Ultra-microporous } \\
\text { carbons-small } \\
\text { sulfur composites }\end{array}$ & $37.7 \mathrm{wt} \%$ & $\begin{array}{l}1 \mathrm{mg} \mathrm{cm}^{-2} \\
\text { (Sulfur) }\end{array}$ & $\mathrm{LiPF}_{6}(\mathrm{EC}: \mathrm{DEC})$ & $1.0-3.0$ & 1.6 & $\begin{array}{l}852 \mathrm{~mA} \mathrm{~h} \mathrm{~g}^{-1} \\
\text { over } 150 \text { cycles }\end{array}$ & [139] \\
\hline \multicolumn{8}{|l|}{ PAN-S composites } \\
\hline $\begin{array}{l}\text { Conductive-sulfur } \\
\text { composites }\end{array}$ & $\begin{array}{l}\text { Not men- } \\
\text { tioned }\end{array}$ & Not mentioned & $\mathrm{LiPF}_{6}(\mathrm{EC}: \mathrm{DMC})$ & $1.0-3.0$ & 2.0 & $\begin{array}{l}600 \mathrm{~mA} \mathrm{~h} \mathrm{~g}^{-1} \\
\text { over } 50 \text { cycles }\end{array}$ & {$[148]$} \\
\hline $\begin{array}{l}\text { Sulfurized polyacry- } \\
\text { lonitrile composite }\end{array}$ & $42 \mathrm{wt} \%$ & $\begin{array}{l}2.1 \mathrm{mg} \mathrm{cm}^{-2} \\
\text { (Sulfur) }\end{array}$ & $\mathrm{LiPF}_{6}(\mathrm{EC}: \mathrm{DEC})$ & $1.0-3.0$ & 2.0 & $\begin{array}{l}680 \mathrm{~mA} \mathrm{~h} \mathrm{~g}^{-1} \\
\text { over } 80 \text { cycles }\end{array}$ & [149] \\
\hline $\begin{array}{l}\text { Sulfurized polyacry- } \\
\text { lonitrile composite }\end{array}$ & $50 \mathrm{wt} \%$ & $\begin{array}{l}<1.4 \mathrm{mg} \mathrm{cm}^{-2} \\
\quad(\text { SPAN) }\end{array}$ & $\mathrm{LiPF}_{6}(\mathrm{EC}: \mathrm{EMC}: \mathrm{DMMP})$ & $1.0-3.0$ & 2.0 & $\begin{array}{l}\sim 700 \mathrm{~mA} \mathrm{~h} \mathrm{~g}^{-1} \\
\text { over } 50 \text { cycles }\end{array}$ & {$[154]$} \\
\hline $\begin{array}{l}\text { Carbonized } \\
\text { polyacrylonitrile- } \\
\mathrm{SeS}_{x} \text { cathodes }\end{array}$ & $\begin{array}{l}33 \mathrm{wt} \% \\
\left(\mathrm{SeS}_{x}\right)\end{array}$ & $\begin{array}{l}1.2 \mathrm{mg} \mathrm{cm}^{-2} \\
\quad \text { (total elec- } \\
\text { trode) }\end{array}$ & $\mathrm{LiPF}_{6}(\mathrm{EC}: \mathrm{DEC})$ & $0.8-3.0$ & 1.7 & $\begin{array}{l}780 \mathrm{~mA} \mathrm{~h} \mathrm{~g}^{-1} \\
\text { over } 1200 \\
\text { cycles }\end{array}$ & [150] \\
\hline $\begin{array}{l}\text { PAN-sulfur com- } \\
\text { posites }\end{array}$ & $45.6 \mathrm{wt} \%$ & $\begin{array}{l}0.85 \mathrm{mg} \mathrm{cm}^{-2} \\
\quad(\mathrm{SPAN})\end{array}$ & $\mathrm{LiPF}_{6}(\mathrm{EC}: \mathrm{DEC})$ & $1.0-3.0$ & 1.5 & $\begin{array}{l}1000 \mathrm{~mA} \mathrm{~h} \mathrm{~g}^{-1} \\
\text { over } 1000 \\
\text { cycles }\end{array}$ & [158] \\
\hline $\begin{array}{l}\text { Sulfurized polyacry- } \\
\text { lonitrile }\end{array}$ & $41.8 \mathrm{wt} \%$ & $\begin{array}{l}1.5 \mathrm{mg} \mathrm{cm}^{-2} \\
\quad \text { (Sulfur) }\end{array}$ & $\begin{array}{l}\mathrm{LiPF}_{6} \\
\quad(\mathrm{PC}: \mathrm{EC}: \mathrm{DEC})+\mathrm{LiSiO}_{3}\end{array}$ & $1.0-3.0$ & 1.7 & $\begin{array}{l}450 \mathrm{~mA} \mathrm{~h} \mathrm{~g}^{-1} \\
\text { over } 100 \text { cycles }\end{array}$ & [155] \\
\hline $\begin{array}{l}\text { S@pPAN compos- } \\
\text { ites }\end{array}$ & $<44.1 \mathrm{wt} \%$ & $\begin{array}{l}1.5-2 \mathrm{mg} \mathrm{cm}^{-2} \\
\text { (Electrode } \\
\text { load) }\end{array}$ & LiODFB (EC:DMC:FEC) & $1.0-3.0$ & 2.0 & $\begin{array}{l}1410 \mathrm{~mA} \mathrm{~h} \mathrm{~g}^{-1} \\
\text { over } 600 \text { cycles }\end{array}$ & [128] \\
\hline $\begin{array}{l}\text { Fiber-based } \\
\text { sulfurized } \\
\text { poly(acrylonitrile) }\end{array}$ & $46 \mathrm{wt} \%$ & $0.672 \mathrm{mg} \mathrm{cm}^{-2}$ & LiTFSI (FEC:DOL) & $1.0-3.0$ & $1.5(1 \mathrm{C})$ & $\begin{array}{l}\sim 850 \mathrm{~mA} \mathrm{~h} \mathrm{~g}^{-1} \\
\quad \text { over } 1000 \\
\quad \text { cycles }\end{array}$ & [153] \\
\hline \multicolumn{8}{|c|}{ Alucone-coated $C-S$ electrode } \\
\hline $\begin{array}{l}\text { Alucone-coated C-S } \\
\text { electrodes }\end{array}$ & $65 \mathrm{wt} \%$ & $\begin{array}{l}1.0 \mathrm{mg} \mathrm{cm}^{-2} \\
\text { (Sulfur) }\end{array}$ & $\mathrm{LiPF}_{6}(\mathrm{EC}: \mathrm{DEC}: \mathrm{FEC})$ & $1.0-3.0$ & $2.0-1.5$ & $\begin{array}{l}500 \mathrm{~mA} \mathrm{~h} \mathrm{~g}^{-1} \\
\text { over } 300 \text { cycles }\end{array}$ & [129] \\
\hline
\end{tabular}

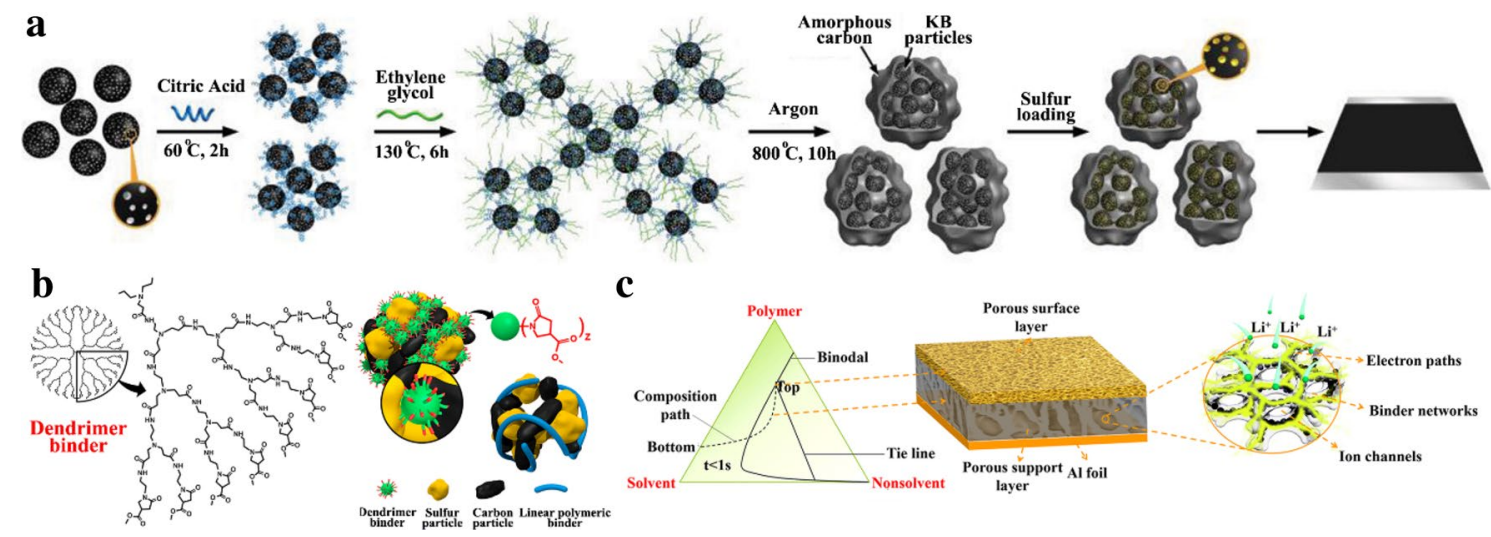

Fig. 7 Strategies for high loading 2D current collector cathodes. a Schematic illustration of the synthesis process of integrated Ketjen black (IKB) electrodes. Reprinted with permission from Ref. [22], copyright 2015, Wiley-VCH. b Schematic illustration of a dendrimer binder and interactions among dendrimer binder carbon and sulfur. Reprinted with permission from Ref. [168], copyright 2016, Elsevier. c The formation mechanism of phase inversion electrodes and internal ion/electron transport, including ternary phase diagram of phase inversion, schematic illustration of electrode structure, and internal ion/electron transport. Reprinted with permission from Ref. [161], copyright 2016, Wiley-VCH 
cathode continuously running for 200 cycles with a stable capacity of around $1200 \mathrm{~mA} \mathrm{~h} \mathrm{~g}^{-1}$ at $1.68 \mathrm{~mA} \mathrm{~cm}$. Recently, Chen et al. [165] designed an oval-like microstructures (OLCMs) via assembling the KB nanoparticles into microstructure on the basis of a double "Fischer esterification" mechanism. Benefiting from the "omnidirectional" and isotropic electron transportation and internal pinholes, which facilitate the electron transfer and $\mathrm{Li}^{+}$diffusion, the batteries assembled with a high sulfur loading of $8.9 \mathrm{mg} \mathrm{cm}^{-2}$ sulfur-loaded OLCMs could deliver a high areal capacity of $8.417 \mathrm{~mA} \mathrm{~h} \mathrm{~cm}^{-2}$ at $0.1 \mathrm{C}$. Furthermore, the large-scale production of advanced lithium-sulfur battery pouch cells with an energy density of $460.08 \mathrm{~W} \mathrm{~h} \mathrm{~kg}^{-1} @ 18.6 \mathrm{Ah}$ were also observed to operate for seven cycles. Even the strategy of "transferring nanoparticles into secondary ones" has been widely proven to be an effective method, however, the relatively complicated material preparation processes still need to be simplified. The search for novel and facile methods to prepare high loading Li-S battery cathodes based on $2 \mathrm{D}$ current collectors and nanomaterials with high specific surface areas is still of great importance.

The binder plays a key role in bonding interactions between active materials and the current collector (or conductive agent), as well as the maintenance of intimate contact among active materials themselves [169]. Poly(vinylidene fluoride) (PVDF), one of the most widely used binders in electrode preparation, shows relatively poor bonding performance because of its linear structure and lack of strong interactions with electrode materials. It is not suitable for high loading sulfur electrodes, especially for the nanosized electrode materials with high specific surface area. Recently, polyamidoamine (PAMAM) dendrimers with hydroxyl (G4OH), 4-carboxymethylpyrrolidone (G4CMP) or carboxylate (G4COONa) surface functional groups were proposed as functional binders in $\mathrm{Li}-\mathrm{S}$ batteries (Fig. 7b) [168]. Owing to the high degree of surface functionalities, interior porosity, and polarity, these dendrimers showed stronger interfacial interactions with $\mathrm{C} / \mathrm{S}$ composite materials and could enable the fabrication of an electrode with a sulfur loading of $4 \mathrm{mg} \mathrm{cm}^{-2}$ and $70 \%$ sulfur content. Excellent cycling stability with up to $90 \%$ capacity retention was demonstrated by the electrodes, which is mainly attributed to the effectively reduced lithium polysulfide agglomeration due to the abundant pores of the dendrimers. Nevertheless, it should be noted that the reversible discharge capacity is around $600 \mathrm{~mA} \mathrm{~h} \mathrm{~g}^{-1}$ at $0.2 \mathrm{C}$. In other words, only an areal discharge capacity of around $2.4 \mathrm{~mA} \mathrm{~h} \mathrm{~cm}{ }^{-2}$ can be delivered, which is even less than the state-of-theart Li-ion batteries (typically $4 \mathrm{~mA} \mathrm{~h} \mathrm{~cm}^{-2}$ ) $[163,170]$. A $7.2 \mathrm{mg} \mathrm{cm}^{-2}$ sulfur-loaded electrode with similar components was also obtained by using a modified polybenzimidazole (mPBI). Due to the chemical interactions between
mPBI and polysulfides, the electrode coupled with mPI binder showed a strong ability to inhibit sulfur loss. Furthermore, the electrode enabled an excellent performance of $750 \mathrm{~mA} \mathrm{~h} \mathrm{~g}^{-1}\left(5.2 \mathrm{~mA} \mathrm{~h} \mathrm{~cm}^{-2}\right)$ after 500 cycles at $0.2 \mathrm{C}$ with an ultra-low capacity fade rate of $0.08 \%$ per cycle [171]. Recently, N-GG-XG binder, a robust biopolymer network, was prepared via an intermolecular binding effect of extensive functional groups in guar gum and xanthan gum [172]. This binder possesses a unique 3D network structure with an abundance of oxygen-containing functional groups. For the $11.9 \mathrm{mg} \mathrm{cm}^{-2}$ sulfur-loaded S@N-GG-XG electrode, a discharge capacity of $733 \mathrm{~mA} \mathrm{~h} \mathrm{~g}^{-1}$ was obtained after 60 cycles at $1.6 \mathrm{~mA} \mathrm{~cm}^{-2}$, corresponding to a high areal discharge capacity of $8.7 \mathrm{~mA} \mathrm{~h} \mathrm{~cm}{ }^{-2}$. When the sulfur loading was further increased to $19.8 \mathrm{mg} \mathrm{cm}^{-2}$, an initial areal discharge capacity of $26.4 \mathrm{~mA} \mathrm{~h} \mathrm{~cm}^{-2}$ was delivered, which is the highest reported areal discharge capacity among 2D current collector sulfur cathodes. However, the sulfur content in the electrode is only $48 \mathrm{wt} \%$, which will decrease the gravimetric and volumetric energy densities in practical application. Phase inversion is a well-known method in manufacturing membranes with interconnected polymer skeletons and hierarchical pores from micron- to nanoscale $[173,174]$, potentially acting as binder network and ion transport channels in electrodes. Inspired by this, Zhang' group employed PVDF-HFP binder to develop high loading sulfur cathodes. During the synthetic process, the current collector coated with slurry was immersed into the water coagulation bath and obtained a unique tri-continuous structured electrode. The tri-continuous structured electrode, labeled as PIE (Fig. 7c), possessed a continuous binder network, unblocked electron paths, and interconnected ion channels, which can simultaneously improve the adhesive strength and $\mathrm{Li}^{+} / \mathrm{e}^{-}$transport. Compared with the electrode prepared by the traditional drying method, the sulfur loading can be increased more than threefold. The Li-S soft package (geometric area: $77 \times 50 \mathrm{~mm}^{2}$, sulfur content in electrode is $42 \mathrm{wt} \%$ ) assembled with $4.0 \mathrm{mg} \mathrm{cm}^{-2}$ sulfurloaded PIE showed a reversible discharge capacity of around $900 \mathrm{~mA} \mathrm{~h} \mathrm{~g}^{-1}$ and a high capacity retention of $90 \%$ after 100 cycles at $0.1 \mathrm{C}$. When the sulfur content and loading was further increased to $60 \mathrm{wt} \%$ and $7 \mathrm{mg} \mathrm{cm}^{-2}$, respectively, a high capacity retention of $89 \%$ was maintained at $0.05 \mathrm{C}$ after 50 cycles. It is also noteworthy to mention that in order to anchor the carbon-based nanoparticles on the current collector, the binder content in the electrode was as high as $20 \mathrm{wt} \%$, which decreases the practical energy density to some extent. Phase inversion is a brand-new technique in 2D current collector fabrication for high loading sulfur electrodes. It will receive increasing attention for the nextgeneration battery engineering due to its simple, low cost, and scalable process. 


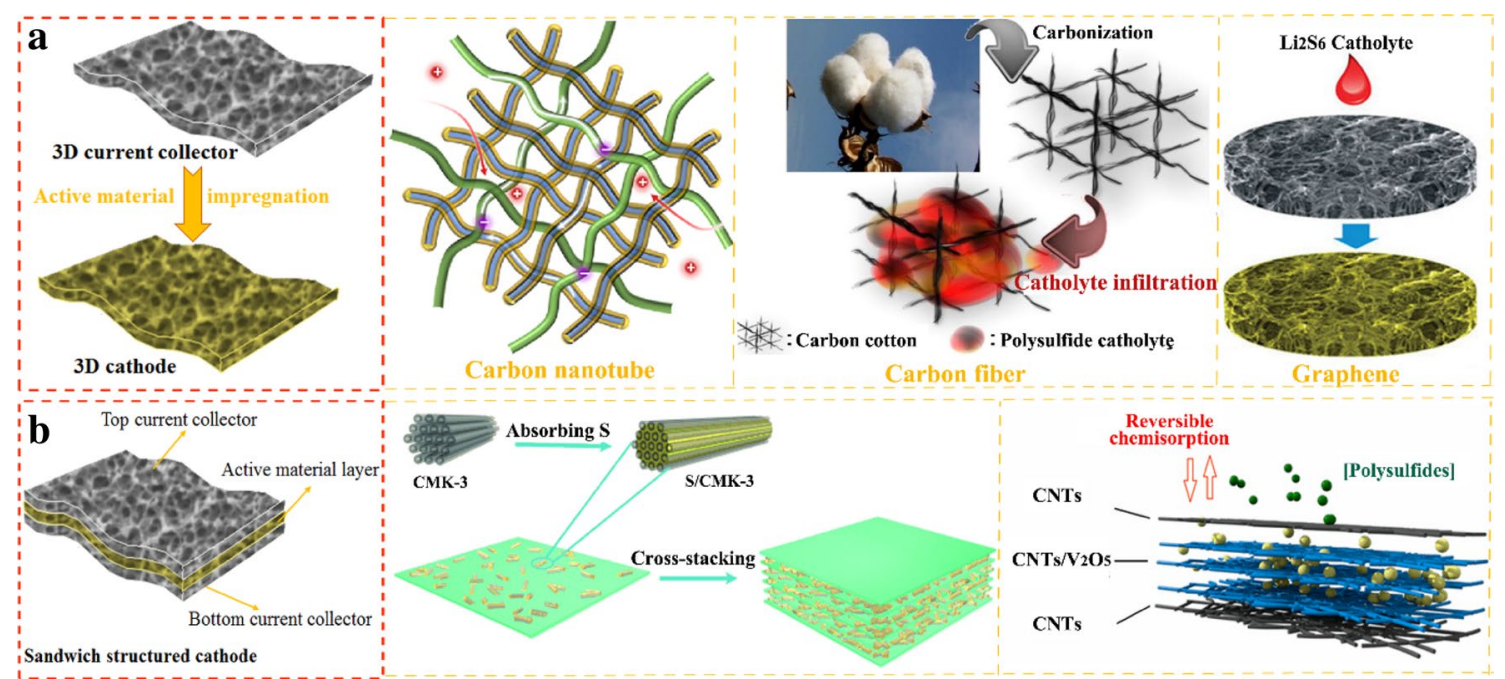

Fig. 8 Two main structures for high loading 3D current collector cathodes. a Simple 3D structure by directly impregnating sulfur into the 3D current collectors, including carbon nanotubes. Reprinted with permission from Ref. [180], copyright 2014, Wiley-VCH, carbon fiber. Reprinted with permission from Ref. [179], copyright 2016, American Chemical Society, and graphene. Reprinted with permission from Ref. [88], copyright 2015, Nature Publishing Group. b

\section{B. 3D Current Collector Design for High-Loading Cath- odes}

Constructing 3D carbonaceous architectures and utilization of impregnation techniques is a facile strategy to achieving high sulfur loading electrodes (Fig. 8a) [68, 163, 175-180]. Compared with the 2D current collector cathodes, the abundant pore networks in the 3D architectures can accommodate more electrode materials and electrolyte and have been demonstrated to be effective in increasing the sulfur loading and improving electrochemical performance [163]. Typically, 1D (carbon nanotube, fiber) and 2D (graphene) nanomaterials are chosen to fabricate 3D structures due to their ability to intertwine with each other and provide excellent mechanical strength. Anactivated carbon fiber cloth (CFC) with $6.5 \mathrm{mg} \mathrm{cm}^{-2}$ sulfur loading was first proposed by D. Aurbach's group. Benefiting from the pores within the CFC that could provide enough space for sulfur impregnation and confine polysulfide dissolution, the assembled $\mathrm{Li}-\mathrm{S}$ batteries delivered a stable discharge capacity of around $600 \mathrm{~mA} \mathrm{~h} \mathrm{~g}^{-1}$ for 80 cycles [175]. Since then, more 3D-based current collector cathodes with high sulfur loadings have been designed for high-energy Li-S batteries. Miao et al. reported a feasible synthesis of S/hollow CFC electrodes with high sulfur loadings ranging from 3.8 to $8.0 \mathrm{mg} \mathrm{cm}^{-2}$. Attributed to the excellent conductive network built by the interconnected carbon fibers and homogeneous sulfur distribution, the $6.7 \mathrm{mg} \mathrm{cm}^{-2}$ sulfur-loaded S/hollow CFC electrode delivered a reversible areal capacity
Sandwiched structure with active materials layer between top/bottom current collectors or repeating such structure layer by layer; Middle: fabrication process of the sandwiched CNT/CMK-3@sulfur cathode. Reprinted with permission from Ref. [182], copyright 2015, Wiley$\mathrm{VCH}$; Right: $\mathrm{V}_{2} \mathrm{O}_{5} / \mathrm{CNT}$ sandwiched structure and its blocking effects for polysulfides. Reprinted with permission from Ref. [183], copyright 2017, American Chemical Society

of $7 \mathrm{~mA} \mathrm{~h} \mathrm{~cm}{ }^{-2}$ with a high capacity retention for over 50 cycles [176]. However, a caveat is that the $E / S$ ratio was calculated to be $19.4 \mu \mathrm{L} \mathrm{mg}^{-1}$, which is believed to deliver a low energy density of less than $200 \mathrm{~W} \mathrm{~h} \mathrm{~kg}^{-1}$ and cannot meet the requirements of high-energy Li-S batteries. With further innovative design in both cathode materials and structures, the CF-based cathodes have led to sulfur loadings as high as 21.2 and $61.4 \mathrm{mg} \mathrm{cm}^{-2}[151,166]$. In addition to the 1D materials mentioned above, graphene-based 2D materials have also received great attention and been extensively studied due to their high electronic conductivity, excellent flexibility, and ease of functionalization [24, 177, 178]. Graphene sponges (GS) were reported as a 3D framework to accommodate sulfur, enabling high areal sulfur loadings of $12 \mathrm{mg} \mathrm{cm}^{-2}$. The highly conductive network constructed by the interconnected graphene enables electrodes with fast electron transport. Moreover, the abundant pores among the graphene structure is beneficial for suppressing the polysulfides diffusion, ensuring fast $\mathrm{Li}^{+}$transport, as well as accommodating volume changes during the charge/discharge process. In this concept, the S-GS electrode delivered a high areal specific capacity of $6.0 \mathrm{~mA} \mathrm{~h} \mathrm{~cm} \mathrm{~cm}^{-2}$ on the 11th cycle, and maintained $4.2 \mathrm{~mA} \mathrm{~h} \mathrm{~cm}^{-2}$ after 300 cycles at $0.1 \mathrm{C}$ [181]. Despite the ultra-high sulfur loading, the highest discharge capacity is only $500 \mathrm{~mA} \mathrm{~h} \mathrm{~g}^{-1}$, which is far from the target of high-energy Li-S batteries. In order to solve this problem, 3D N/S-co-doped graphene was chosen as the cathode materials for GS preparation and $\mathrm{Li}_{2} \mathrm{~S}_{6}$ was supplied as the active material to further improve 
the electrochemical performance. Benefiting from the synergetic effects between physical confinement and chemical adsorption (strong interactions between polysulfides and $\mathrm{N}$, $\mathrm{S}$ functional group in GS), and increased electrochemical kinetics of $\mathrm{Li}_{2} \mathrm{~S}_{6}$ compared with sulfur, the $8.5 \mathrm{mg} \mathrm{cm}^{-2}$ sulfur-loaded electrode presented a reversible discharge capacity of $550 \mathrm{~mA} \mathrm{~h} \mathrm{~g}^{-1}$ with a $\sim 0.078 \%$ capacity decay per cycle over 500 cycles [88]. Even though it is a great achievement at this stage of research, the discharge capacity and high $E / S$ ratio $\left(16.9 \mu \mathrm{L} \mathrm{mg}^{-1}\right)$ is still need to be further optimized to meet the demand of practical high-energy Li-S batteries.

Apart from the cathode architectures mentioned above, fabricating free-standing sandwich-structured cathodes is another option for the design of high-performance electrodes [43, 182-187]. The top and bottom layers act as current collectors as well as physical barriers to prevent polysulfide dissolution, and the middle section contains sulfur-based active materials. Nanotubes-, nanofibers-, and graphenebased materials can be chosen as the scaffolds. Wang et al. inserted a layer of sulfur active materials into two layers of porous carbon films and manufactured a sandwich-structured cathode. Due to the effectively suppressed polysulfide shuttling and significantly decreased charge transfer resistance, $4 \mathrm{mg} \mathrm{cm}^{-2}$ sulfur-loaded electrodes could deliver areal discharge capacities of $4 \mathrm{~mA} \mathrm{~h} \mathrm{~cm}{ }^{-2}$ without obvious decay over 150 cycles [185]. Fabrication of layer-by-layer 3D electrodes can offer more facile and practical approaches by direct application of sulfur powders between two porous carbon nanofiber (PCNF) layers [186]. The sulfur loading can be easily controlled by adjusting the number of layers. For the six-layer electrodes, corresponding to a sulfur loading of $11.4 \mathrm{mg} \mathrm{cm}^{-2}$, an output areal discharge capacity of more than $7 \mathrm{~mA} \mathrm{~h} \mathrm{~cm}^{-2}$ can be achieved for 100 cycles [186]. In order to further improve the electrochemical performance of 1D carbon materials, porous carbon materials were added to fabricate hybrid electrodes. Peng et al. fabricated a laminated hybrid cathode by cross-stacking aligned CNT sheets and CMK-3/S composite particles layer by layer. Benefiting from excellent electron transport along the aligned CNT sheets and polysulfide confinement by CMK3 , the electrodes with a sulfur loading of up to $20 \mathrm{mg} \mathrm{cm}^{-2}$ showed a stable discharge capacity of $900 \mathrm{~mA} \mathrm{~h} \mathrm{~g}^{-1}$ for 50 cycles [182]. Chemical interactions via introducing polar groups or materials are another promising strategy. Wang et al. proposed a sandwich-structured cathode which sulfurnitrogen-doped graphene (NG) as the primary active material and carbon nanotube/nanofibrillated cellulose (CNT/ NFC) as both top and bottom layers. Under the synergistic effects of physical encapsulation by carbonaceous materials and chemical interaction between polysulfides and functional groups $(\mathrm{N}, \mathrm{O})$, the cathode exhibited an excellent cycling performance. An areal discharge capacity of around $8 \mathrm{~mA} \mathrm{~h} \mathrm{~cm}{ }^{-2}$ and an ultra-low capacity fading of $0.067 \%$ per cycle over 1000 cycles at $0.5 \mathrm{C}$ was obtained for the electrode with a high areal sulfur loading of $8.1 \mathrm{mg} \mathrm{cm}^{-2}$ [43]. A regenerative polysulfide-scavenging layer was designed by intertwining $\mathrm{V}_{2} \mathrm{O}_{5}$ nanowires with CNTs $\left(\mathrm{CNTs} / \mathrm{V}_{2} \mathrm{O}_{5}\right)$, which can dynamically suppress the diffusion of polysulfide species and regenerate themselves during cycling, resulting in dramatically extended cycling life with a high areal capacity of $>6 \mathrm{~mA} \mathrm{~h} \mathrm{~cm}^{-2}$ for 60 cycles.

Generally, 3D-based current collector cathodes possess unparalleled merits in terms of areal sulfur loading, $\mathrm{Li}^{+} /$ $\mathrm{e}^{-}$transport, and mechanical properties in comparison with their 2D counterparts [188]. However, they are still a long way from their practical application due to the following reasons. Firstly, the scaffolds of most cathodes are prepared via freeze-drying [88, 170], filtration [43, 186], chemical vapor deposition (CVD) [170, 189], and electrostatic spinning methods [68]. The cost and large-scale reliability should be taken into consideration for industrial application. Furthermore, a large amount of electrolyte is inevitably required for transporting $\mathrm{Li}^{+}$and wetting the porous architecture, which will no doubt decrease the mass and volumetric energy density. Additionally, welding of the current collector, tab and the cathode together is a critical issue that has not been solved for 3D-structured cathodes.

\subsubsection{Statistical Analysis of the Current Research on Li-S} Batteries with High Loadings Due to the fact that the energy density and cost are rarely mentioned in recent publications, herein, we investigate the factors related to the gravimetric energy density. As aforementioned, the high sulfur loading is essential to obtain a high areal energy density and a proper sulfur loading is in the range of $4-6 \mathrm{mg} \mathrm{cm}^{-2}$. Hence, we summarized the statistical information from 107 publications with high sulfur loadings greater than $4 \mathrm{mg} \mathrm{cm}^{-2}$ and the potential to deliver high energy densities of over $500 \mathrm{~W} \mathrm{~h} \mathrm{~kg}^{-1}$. The detailed information can be seen from Table 5, Figs. 9 and 10. As shown in Fig. 9, the number of publications has grown exponentially since 2011, meaning that high sulfur loading $\mathrm{Li}-\mathrm{S}$ cathodes have received increasing attention and have been one of the hottest topics in this area. Even in the first 3 months of 2018, there have been 13 publications focused on high sulfur loading electrodes. The sulfur loading in most publications (44.0\%) are in the optimized sulfur loading interval of $4-6 \mathrm{mg} \mathrm{cm}^{-2}$. $25.1 \%$ of publications have developed sulfur loading cathodes greater than $10 \mathrm{mg} \mathrm{cm}^{-2}$, which suggests that researchers have found effective methods to prepare high sulfur loading cathodes (Fig. 10a). In the 144 publications analyzed, nearly half (59 papers) of the studies did not provide any information about the $E / S$ ratio. Furthermore, in $53.9 \%$ of publications, the $E / S$ ratio in is more than $10 \mu \mathrm{L} \mathrm{mg}^{-1}$, corresponding to a weight ratio of electrolyte to sulfur higher than 10:1, which is considered to lower the energy density 


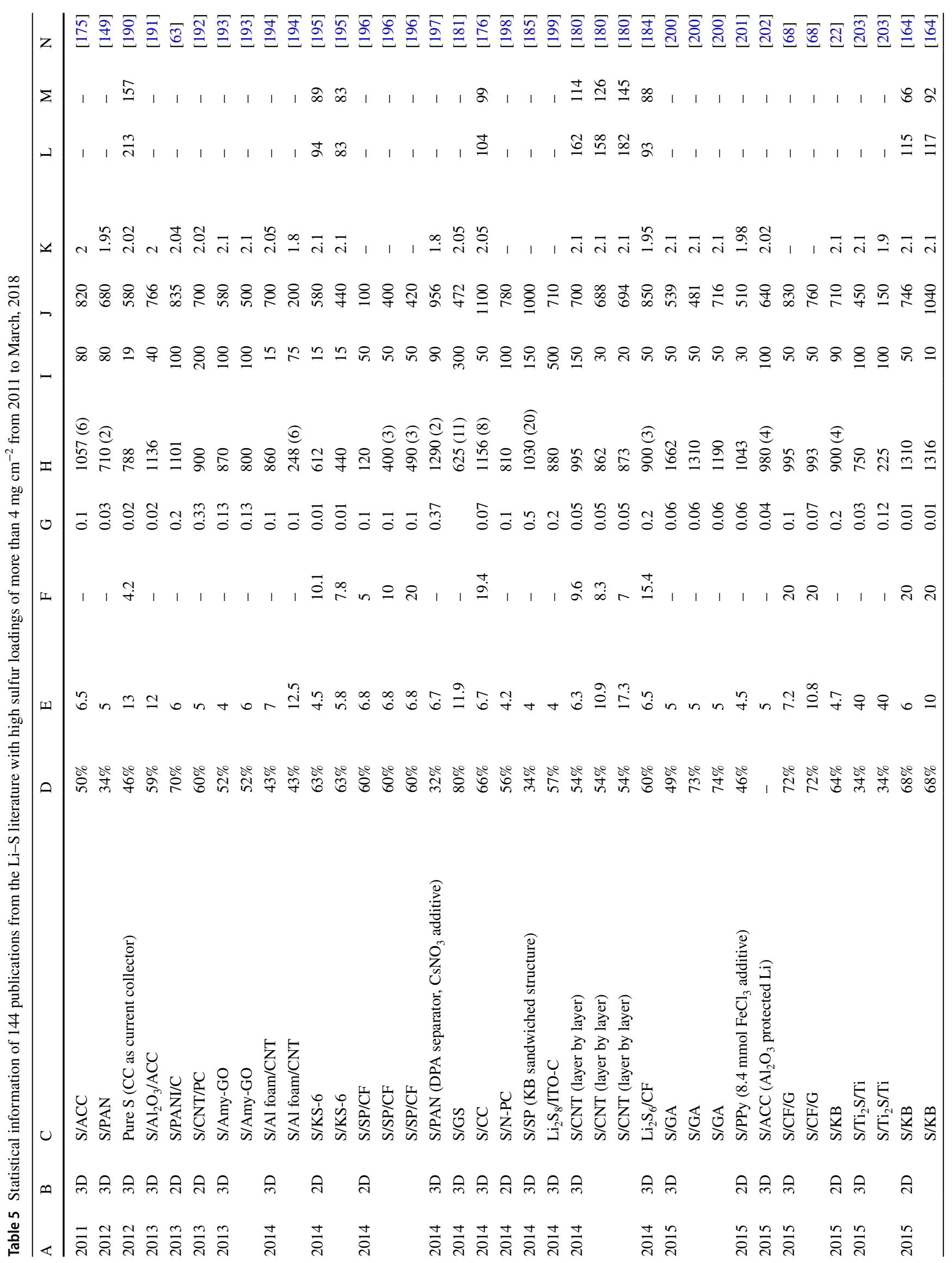




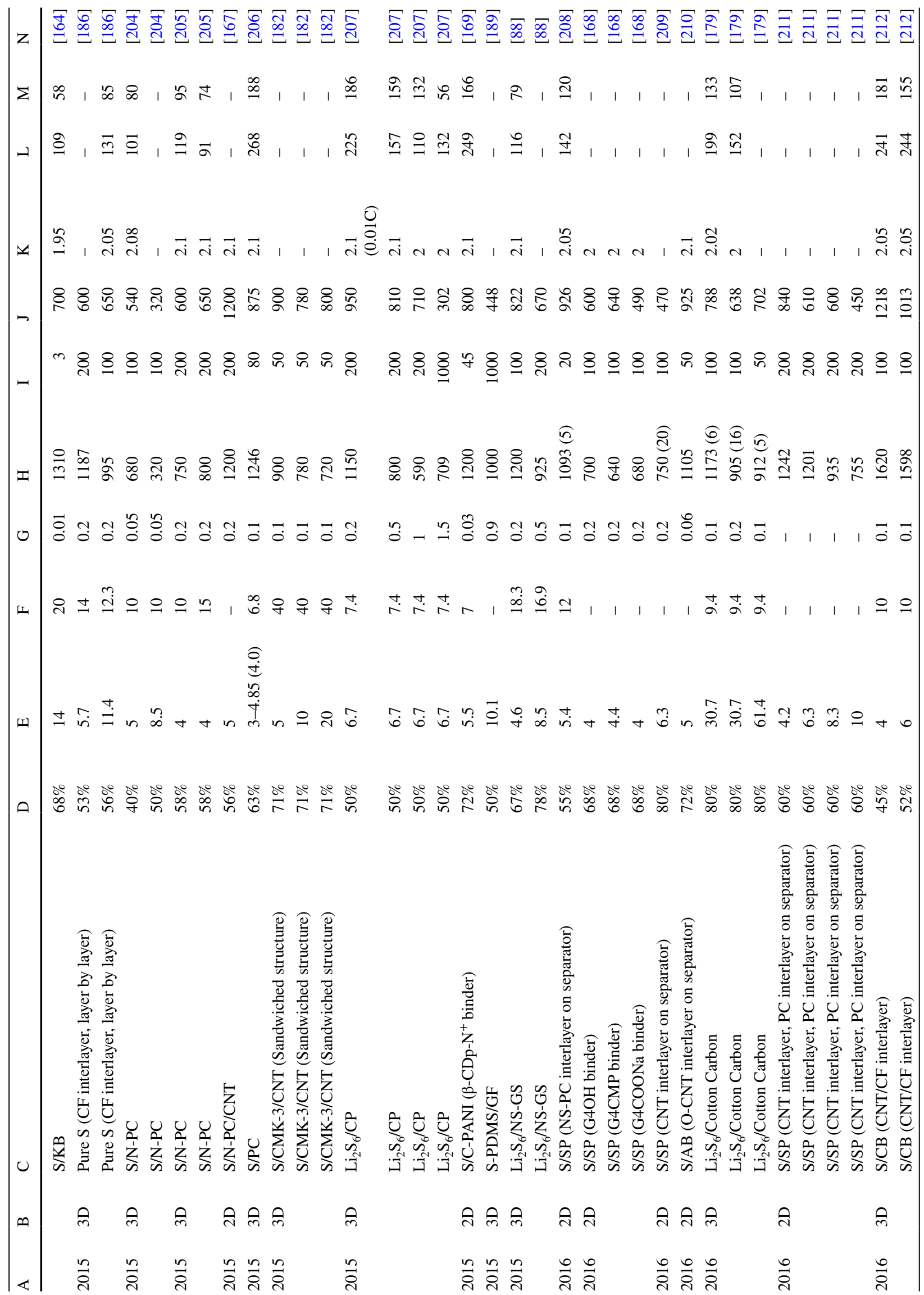




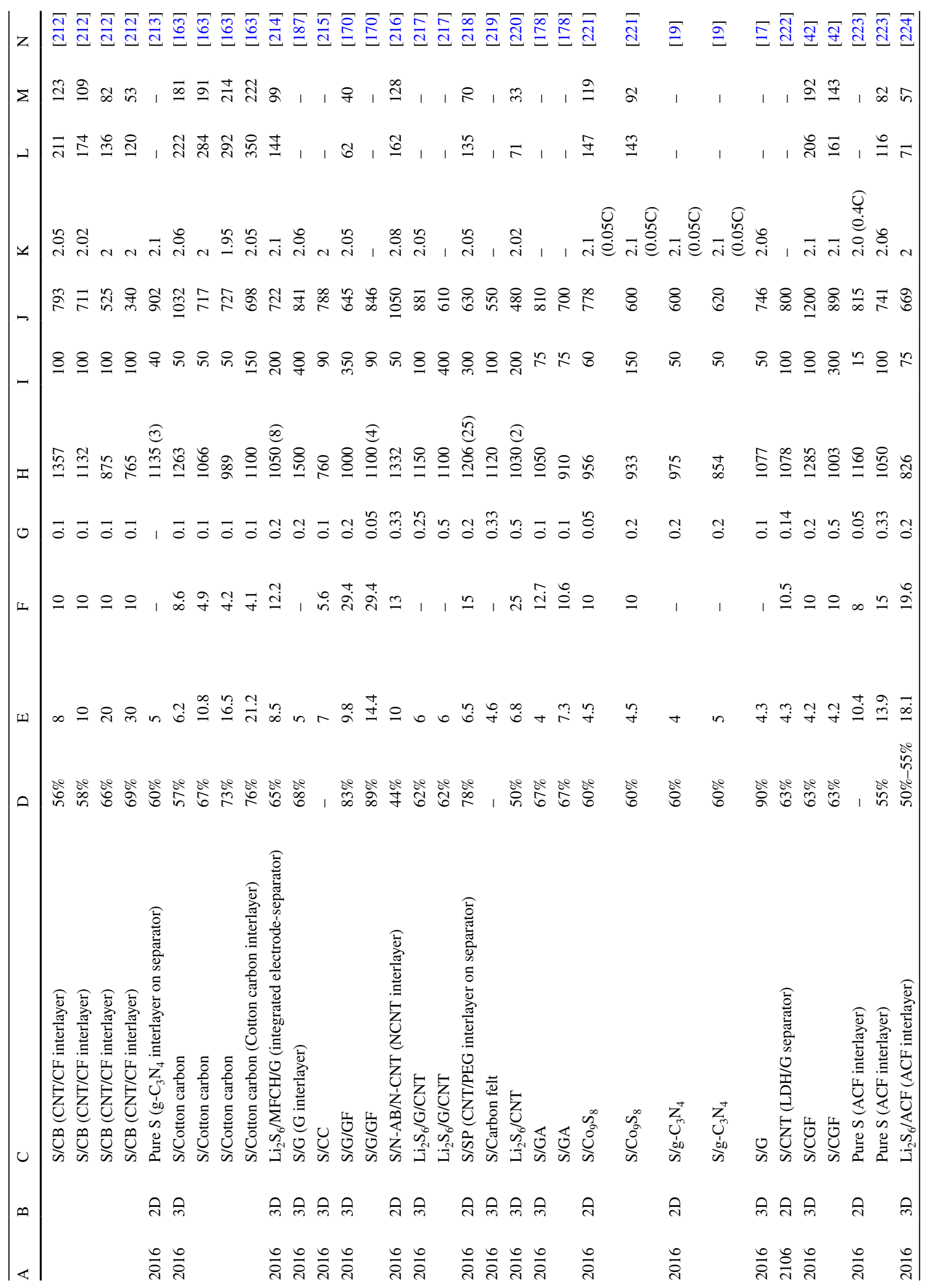




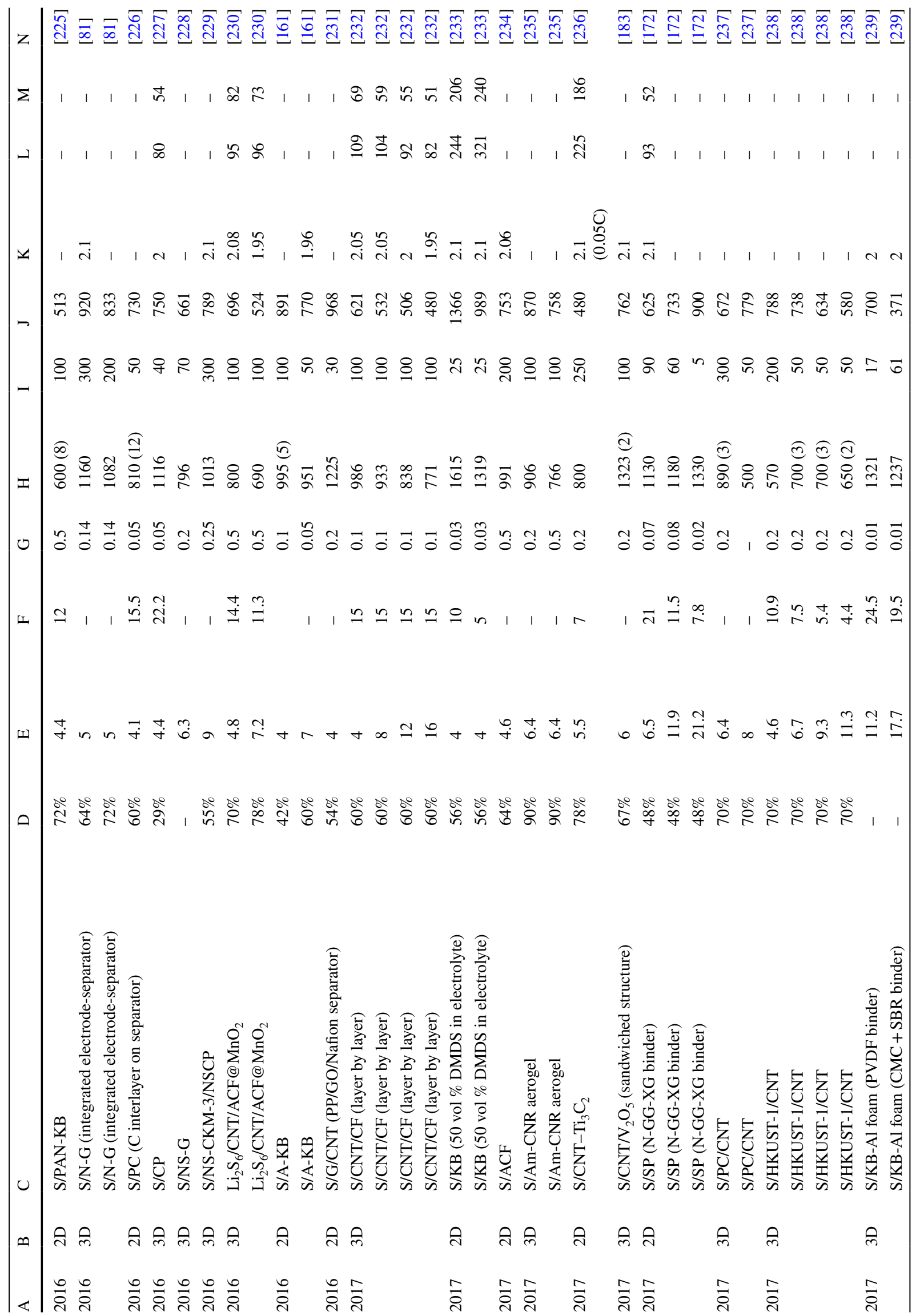




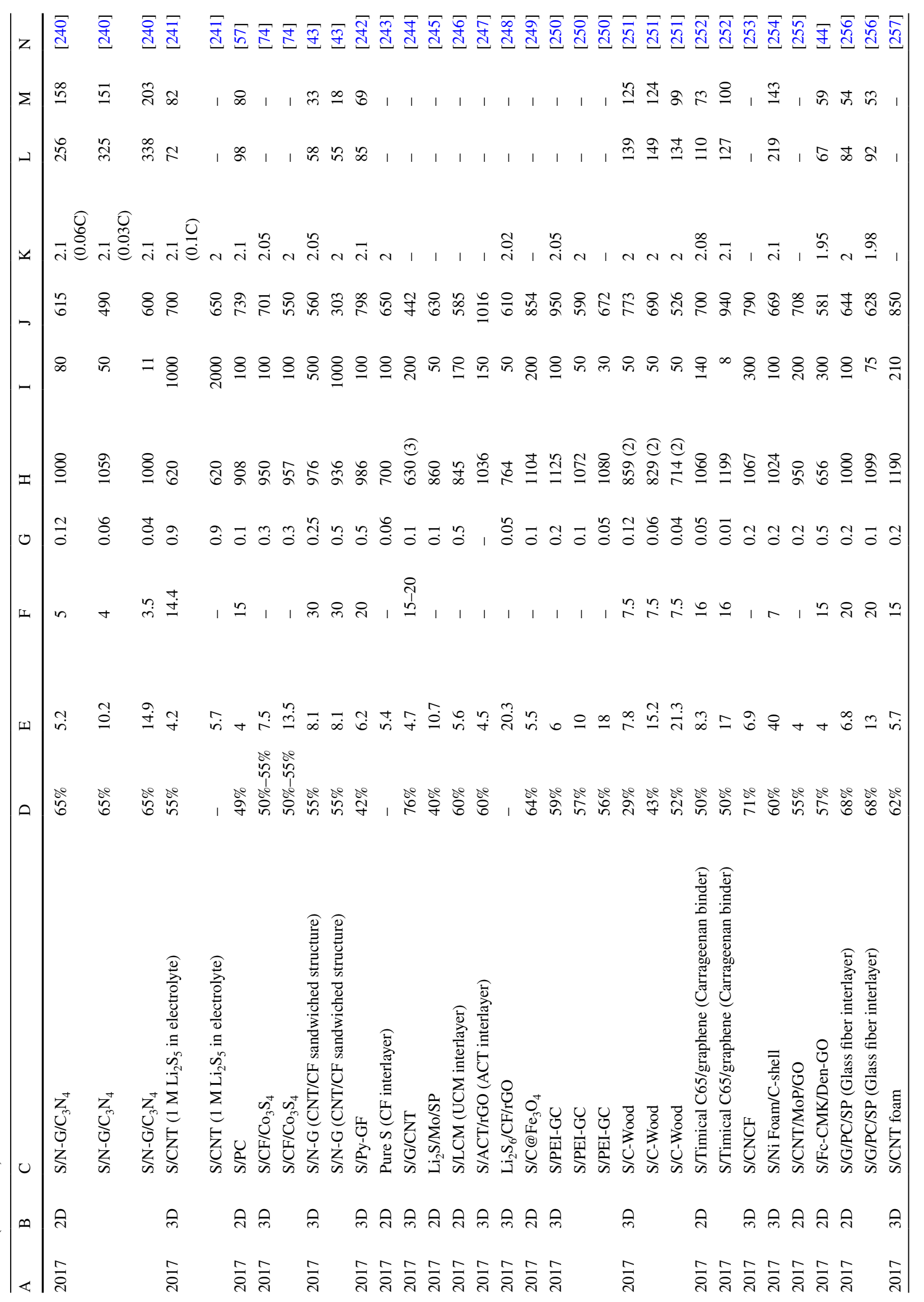




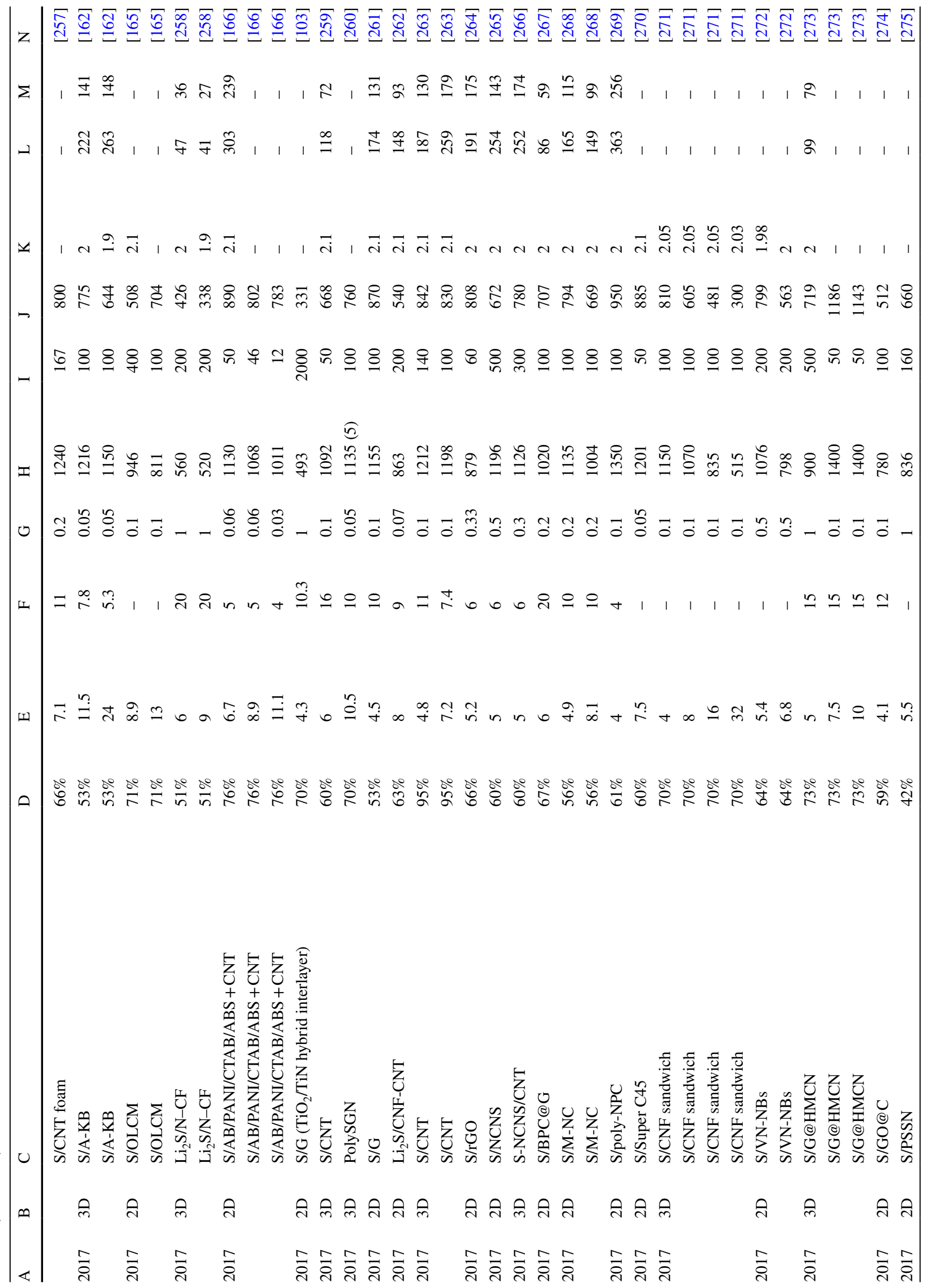




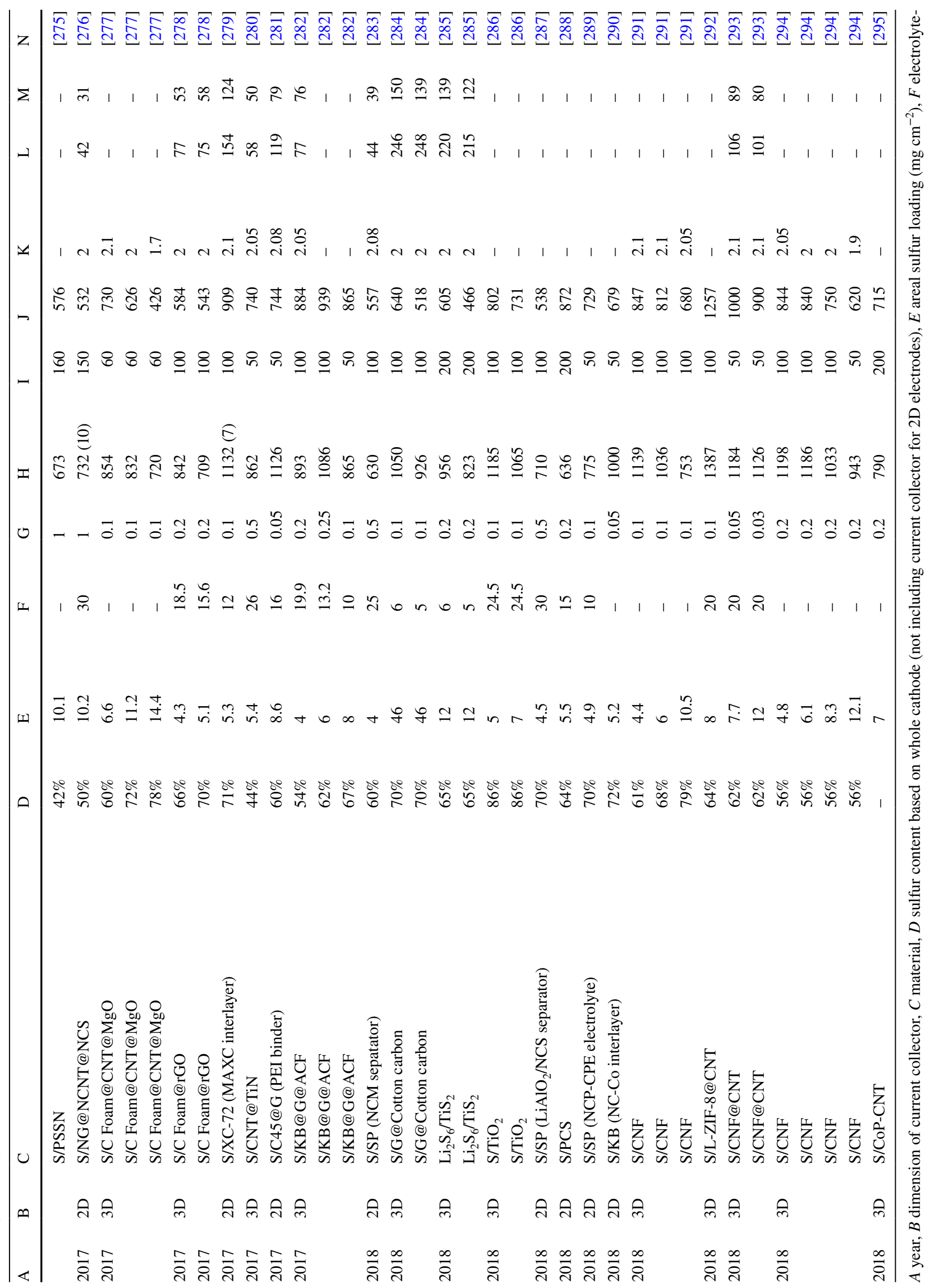




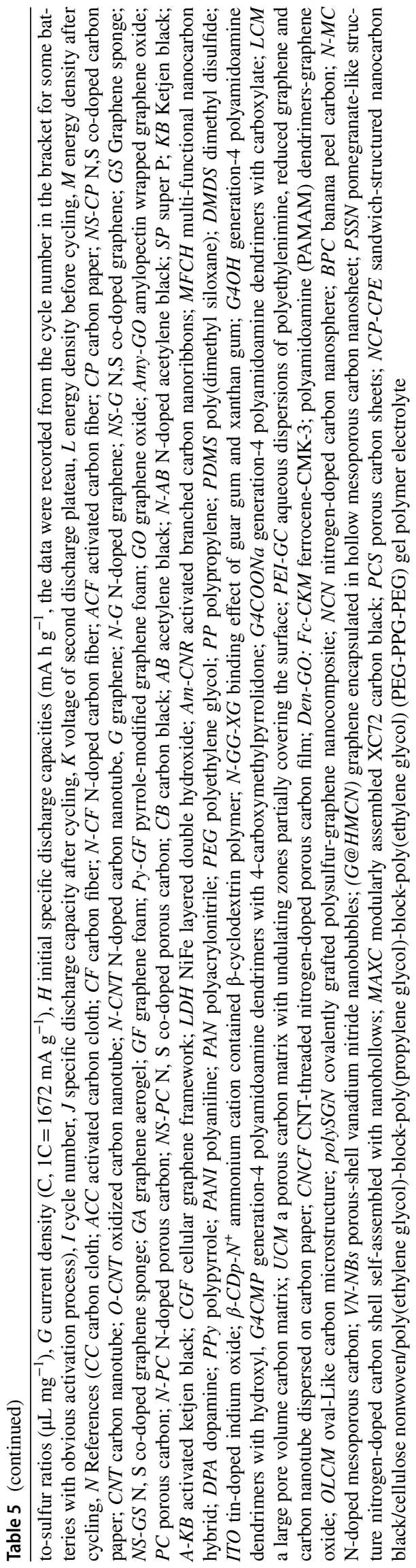

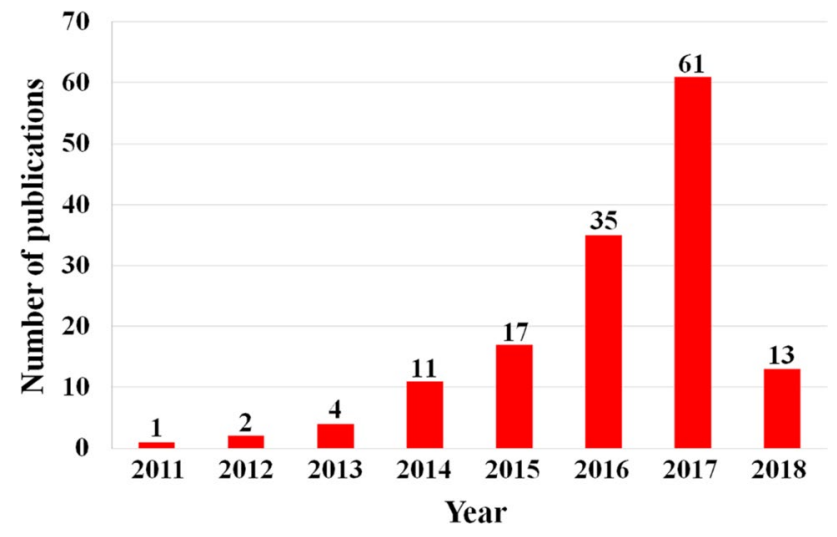

Fig. 9 Number of high loading Li-S publications from 2011 to March, 2018

to values less than $250 \mathrm{~W} \mathrm{~h} \mathrm{~kg}^{-1}$, even under the conditions of theoretical discharge capacity and voltage. The papers with a low $E / S$ ratio $\left(<4 \mu \mathrm{L} \mathrm{mg}^{-1}\right)$ occupy only $2.6 \%$ of the total publications (Fig. 10b), indicating that the $E / S$ ratio has not received enough attention despite its significance. Figure 10c shows the statistical information of the observed discharge voltages. Nearly half of the publications $(42.1 \%)$ present the second discharge voltage plateau over $2.05 \mathrm{~V}$, meaning that the overpotential in electrochemical reaction is not a significant problem. In addition, we find that the sulfur content in the whole electrodes (not including interlayer) rather than in the sulfur-containing composites is more reliable to evaluate the energy output of $\mathrm{Li}-\mathrm{S}$ batteries. Figure $8 \mathrm{~d}$ shows the calculated sulfur content among the 144 publications based on the whole electrodes (not including interlayer). More than $80 \%$ of publications present the sulfur cathodes with over $50 \mathrm{wt} \%$ sulfur contents, but only $20.0 \%$ of publications report the sulfur cathodes with high sulfur content of over $70 \mathrm{wt} \%$. In other words, constructing high sulfur loading electrodes with sulfur contents higher than $70 \mathrm{wt} \%$ is still a challenge due to the extremely high requirements of electronic conductivity. Compared with the sulfur content, the situation of cycling life and discharge capacity are even worse. Only $13.6 \%$ of the electrodes can deliver initial discharge capacities greater than $1200 \mathrm{~mA} \mathrm{~h} \mathrm{~g}^{-1}$ (Fig. 10e), which is far from that required for high-energy Li-S batteries. Moreover, only $28.0 \%$ of them achieved over 100 cycles, which can't meet the requirements for electric vehicles and have much lower cycle life than current Li-ion batteries. After cycling, the fraction of publications with discharge capacities remaining over $1000 \mathrm{~mA} \mathrm{~h} \mathrm{~g}^{-1}$ is only 5.3 and $72.8 \%$ of them are less than $800 \mathrm{~mA} \mathrm{~h} \mathrm{~g}^{-1}$, indicating the extremely poor cycling stability of high sulfur loading electrodes. Based on the aforementioned information, we have calculated the real energy densities of those publications based on the parameters of Li-S soft package (The 


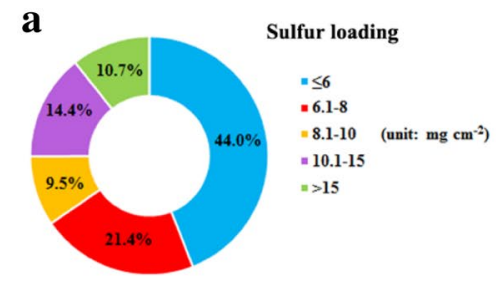

d
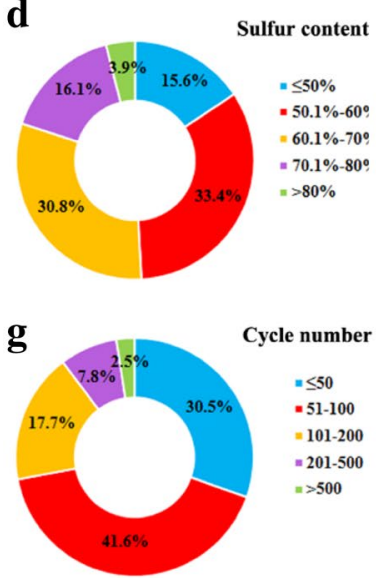

j

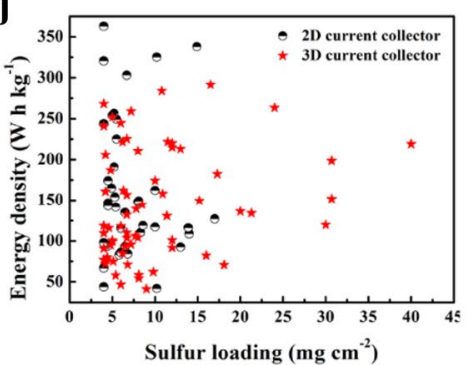

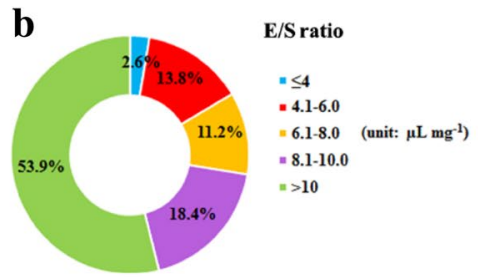

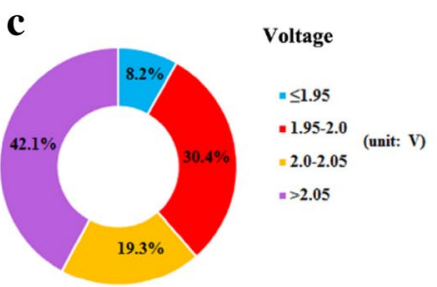

e
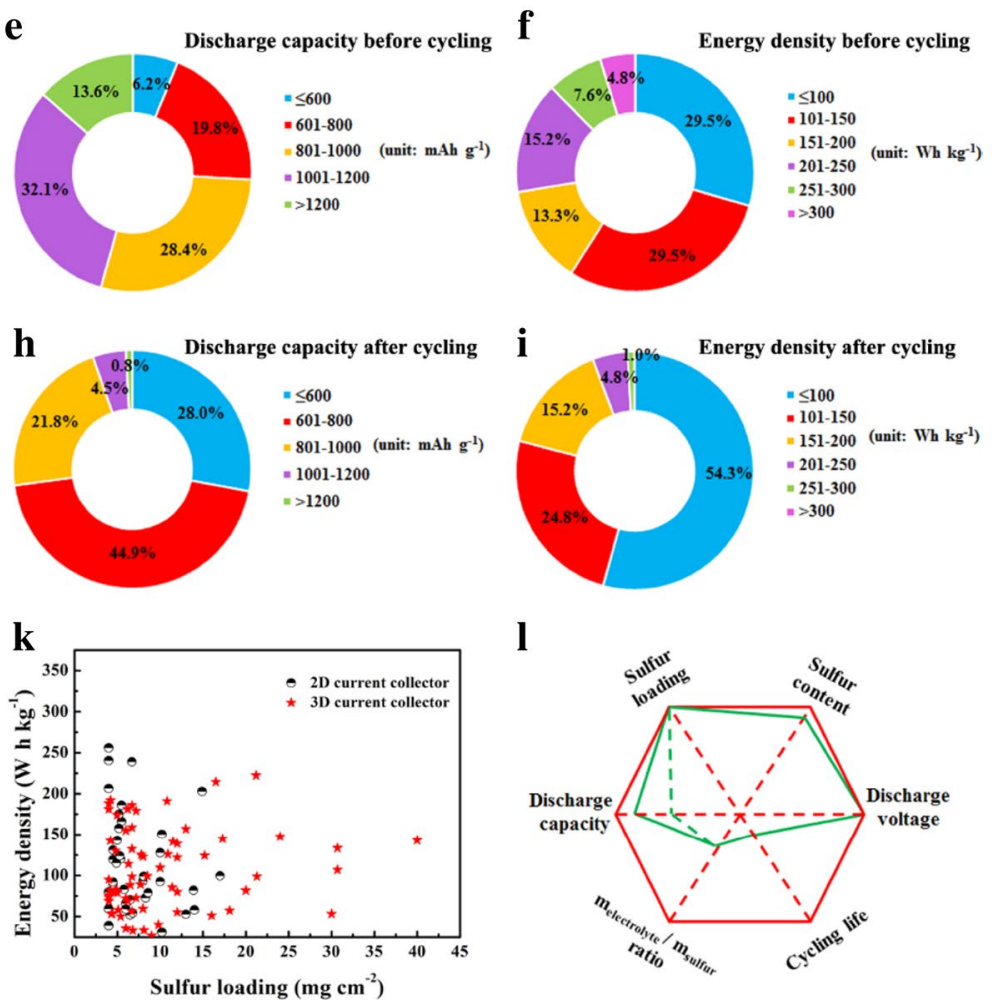

I

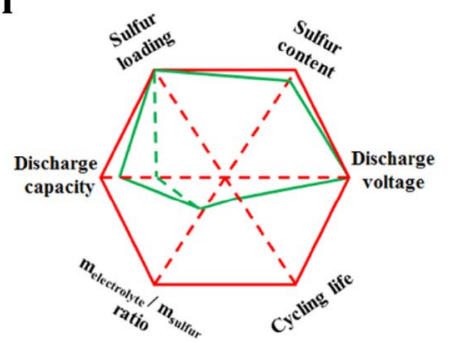

Fig. 10 Statistical analysis of a sulfur loading, b $E / S$ ratio, c discharge voltage of the second plateau d sulfur content, e discharge capacity before cycling, $\mathbf{f}$ energy density before cycling (calculated based on the discharge capacity and lower discharge voltage provided by the publications), $\mathbf{g}$ cycle number, $\mathbf{h}$ discharge capacity after cycling, $\mathbf{i}$ energy density after cycling (calculated based on the dis-

detailed information for 2D and 3D current collector cathodes can be seen from Tables 6 and 7, respectively), which are listed in Fig. 10f, i. Surprisingly, only $4.8 \%$ of them have the potential to deliver an energy density more than $300 \mathrm{~W} \mathrm{~h} \mathrm{~kg}^{-1}$. When taking these results into consideration, as illustrated by the spider picture in Fig. 101, the development of high sulfur loading electrodes with high capacity output and stabilized cycling performance under low $E / S$ ratio will be the main research direction in the future.

The energy density of 2D current collector-based Li-S batteries can be calculated as the following equation.

\subsection{Electrolyte}

As mentioned previously, the $E / S$ ratio plays a significant role in the electrochemical performance and energy density charge capacity and lower discharge voltage provided by the publications), $\mathbf{j}$ distribution of energy density before cycling for 2D and 3D current collector electrodes, $\mathbf{k}$ distribution of energy density after cycling for 2D and 3D current collector electrodes. I Spider chart displaying the state of current high loading sulfur cathodes

of $\mathrm{Li}-\mathrm{S}$ batteries. Low $E / S$ ratios, to some degree, can limit the dissolution of polysulfides and alleviate the "shuttle effect." On the contrary, it can also contribute to sluggish $\mathrm{Li}^{+}$transport and limit the C-rate performance. Furthermore, as the electrochemical reactions progress, the electrolyte is continuously consumed due to the side reactions between electrolyte and $\mathrm{Li}$ anode, leading to large overpotentials, low discharge voltage plateaus, low discharge capacity, and short cycling lives. Increasing the $E / S$ ratio is an effective strategy to solve the aforementioned problems but leads to an inevitable decrease in both the gravimetric and volumetric energy densities. Hence, optimization of the $E / S$ ratio is necessary and has been highlighted by several reports. Xiao et al. have investigated the relationship between the electrochemical performance of $\mathrm{S} / \mathrm{KB}$ electrodes and the electrolyte content. The results show that the optimized $E / S$ ratio 
Table 6 Simulated components of 2D current cllector based Li-S soft package

\begin{tabular}{ll}
\hline Components & Mass $\left(\mathrm{mg} \mathrm{cm}^{-2}\right)$ \\
\hline $\begin{array}{l}\text { Cathode current collector (alu- } \\
\text { minum foil, } 16 \mu \mathrm{m})\end{array}$ & 4.32 \\
$\quad \begin{array}{l}\text { Separator }(\text { Celgard 2325) } \\
\text { a }\end{array}$ & 1.80 \\
Sulfur $^{\mathrm{b}}$ & $2 x$ \\
${\text { Conductive additive }+ \text { binder }^{\mathrm{c}}}_{\text {Anode (lithium metal) }^{\mathrm{d}}}$ & $2 x(1-m) / m$ \\
Electrolyte $^{\mathrm{e}}$ & $1.31 x$ \\
Others (cathode tap, Anode tap, Al $^{\mathrm{f}}$ & $0.32+0.07 x+0.1 x / m+0.10 n x$ \\
$\quad$ laminate film, etc. & \\
Total $^{\mathrm{f}}$ & $6.40+1.38 x+2.10 x / m+2.10 n x$ \\
\hline
\end{tabular}

${ }^{a}$ Double layers of membranes per piece of cathode, the areal density of each layer of Clegard 2325 is $0.9 \mathrm{mg} \mathrm{cm}^{-2}$

${ }^{b}$ Slurry coated on both sides of cathode current collector with a sulfur loading of $x \mathrm{mg} \mathrm{cm}^{-2}$

${ }^{\mathrm{c}}$ Sulfur content in cathode is $m$

${ }^{\mathrm{d}} 50 \mathrm{wt} \%$ lithium excess accords to the stoichiometric ratio of sulfur

${ }^{\mathrm{e}}$ Mass ratio of electrolyte to sulfur is $n$

${ }^{\mathrm{f}}$ The mass ratio of such other components as cathode tap, anode tap, $\mathrm{Al}$ laminate film is $5 \mathrm{wt} \%$ of the whole $\mathrm{Li}-\mathrm{S}$ package

Table 7 Simulated components of 3D current collector-based Li-S soft package

\begin{tabular}{ll}
\hline Components & Mass $\left(\mathrm{mg} \mathrm{cm}^{-2}\right)$ \\
\hline Separator (Celgard 2325) $^{\mathrm{a}}$ & 0.9 \\
Sulfur $^{\mathrm{b}}$ & $x$ \\
Conductive additive $^{\mathrm{c}}$ & $x(1-m) / m$ \\
Anode (lithium metal) $^{\mathrm{d}}$ & $0.66 x$ \\
Electrolyte $^{\mathrm{e}}$ & $n x$ \\
Others (cathode tap, Anode tap, Al $_{\quad \text { laminate film, etc. })^{\mathrm{f}}}$ & $0.05+0.03 x+0.05 x / m+0.05 n x$ \\
Total & $0.95+0.69 x+1.05 x / m+1.05 n x$ \\
\hline
\end{tabular}

${ }^{\text {a }}$ The areal density of each layer of Clegard 2325 is $0.9 \mathrm{mg} \mathrm{cm}^{-2}$

${ }^{\mathrm{b}}$ Sulfur loading of $x \mathrm{mg} \mathrm{cm}^{-2}$

${ }^{\mathrm{c}}$ Sulfur content in cathode is $m$

${ }^{\mathrm{d}} 50 \mathrm{wt} \%$ lithium excess accords to the stoichiometric ratio of sulfur

${ }^{\mathrm{e}}$ Mass ratio of electrolyte to sulfur is $n$

${ }^{\mathrm{f}}$ The mass ratio of such other components as cathode tap, anode tap, Al laminate film is $5 \mathrm{wt} \%$ of the whole $\mathrm{Li}-\mathrm{S}$ package

is $20 \mu \mathrm{L} \mathrm{mg}^{-1}$ (corresponding to $50 \mathrm{~g} \mathrm{~L}^{-1}$ in Fig. $11 \mathrm{a}-\mathrm{c}$ ) after balancing the electrolyte viscosity, wetting ability, diffusion rate of polysulfide species, and nucleation/growth of short-chain $\mathrm{Li}_{2} \mathrm{~S} / \mathrm{Li}_{2} \mathrm{~S}_{2}$ along with largely reduced corrosion of the lithium metal anode [296]. The same optimized $E / S$ ratio of $20 \mu \mathrm{L} \mathrm{mg}^{-1}$ was also utilized by Kim et al. [297]. Chen et al. proposed a facile way to tune the polysulfide shuttling effect via adjusting the $E / S$ ratio. They found that the batteries with a $E / S$ ratio of $24.4 \mu \mathrm{L} \mathrm{mg}^{-1}$ (corresponding to $1.28 \mathrm{M}$ sulfur in DOL/DOM electrolyte in Fig. 11d) exhibited the best cycling performance and delivered a high initial discharge capacity of $1053 \mathrm{~mA} \mathrm{~h} \mathrm{~g}^{-1}$ at $1 \mathrm{C}$, in addition to a slow decay rate of $0.049 \%$ per cycle during 1000 cycles [298]. Recently, new research has revealed that the $\mathrm{Li}_{2} \mathrm{~S}$ nucleation and growth process is associated with the $E / S$ ratio [299]. At the highest $E / S$ ratio of $7.9 \mu \mathrm{L} \mathrm{mg}^{-1}$ (corresponding to $7.9 \mathrm{~mL} \mathrm{~g}^{-1}$ in this report), a typical twoplateaus charge/discharge profiles with a discharge capacity of $947 \mathrm{~mA} \mathrm{~h} \mathrm{~g}^{-1}$ was delivered. When the $E / S$ ratio was decreased to $4.2 \mu \mathrm{L} \mathrm{mg}^{-1}$, corresponding to $7.4 \mathrm{M}$ $\mathrm{S}$ (approximately the polysulfides saturation concentration at room temperature), the $\mathrm{Li}_{2} \mathrm{~S}$ nucleation and growth process become more sluggish, resulting in increased overpotential, lower discharge plateaus and decreased discharge capacity. Further decreasing the $E / S$ ratio to $2.4 \mu \mathrm{L} \mathrm{mg}^{-1}$ (13 M S in electrolyte) led to worse performance with a capacity of less than $60 \mathrm{~mA} \mathrm{~h} \mathrm{~g}^{-1}$. The above result further highlight the importance of electrolyte quantity in the electrochemical performance of $\mathrm{Li}-\mathrm{S}$ batteries. To date, the reported $E / S$ values for the best electrochemical performance are often higher than $7 \mu \mathrm{L} \mathrm{mg}^{-1}$, which can't meet the requirements of high energy density Li-S batteries with low $E / S$ ratios of less than $3 \mu \mathrm{L} \mathrm{mg}^{-1}$. There is still significant room for improvement and more efforts should be devoted to decreasing the value of the $E / S$ ratio.

The previously mentioned electrolytes are ether-based. For carbonate electrolytes, most efforts have been focused on increasing the sulfur content and loading of the cathodes, while few studies have been reported on the optimization of carbonate electrolytes. Hence, here we won't summarize the development of carbonate electrolytes. Some new electrolytes systems such as all-solid-state electrolytes will be further discussed in the section of solidstate $\mathrm{Li}-\mathrm{S}$ batteries.

\subsection{Lithium Protection}

High areal sulfur loading cathodes coupled with low electrolyt $E / S u l f u r$ ratios are vital to the success of highenergy $\mathrm{Li}-\mathrm{S}$ batteries. The electrolyte plays a crucial role in $\mathrm{Li}^{+}$transport and PS dissolution in ether-based electrolyte $\mathrm{Li}-\mathrm{S}$ batteries. Due to the low ionic conductivity of sulfur species, ether-based electrolyte is employed to force a "solid-liquid-solid" transfer process to increase the utilization of sulfur. Definite dissolution of PS is the key to ensure $\mathrm{Li}-\mathrm{S}$ batteries smoothly running in the operating voltage. There is no doubt that the dissolution of PS will lead to increased electrolyte viscosity and resistance, which is fatal for Li-S batteries with high sulfur loading cathodes and low E/S ratios. Hence, the Li-S batteries 
Fig. 11 a Charge-discharge profiles, $\mathbf{b}$ cycling performance and $\mathbf{c}$ Coulombic efficiency for $\mathrm{Li}-\mathrm{S}$ cells with different $S / E$ ratios at $0.2 \mathrm{C}$. Reprinted with permission from Ref. [296], copyright 2013, The Electrochemical Society. $\mathbf{d}$ The cycling performance of $\mathrm{Li}-\mathrm{S}$ cells with a sulfur loading of $1.28 \mathrm{M}$ [S] in the DOL/DME electrolyte at 1 C. Reprinted with permission from Ref. [298], copyright 2014, Elsevier
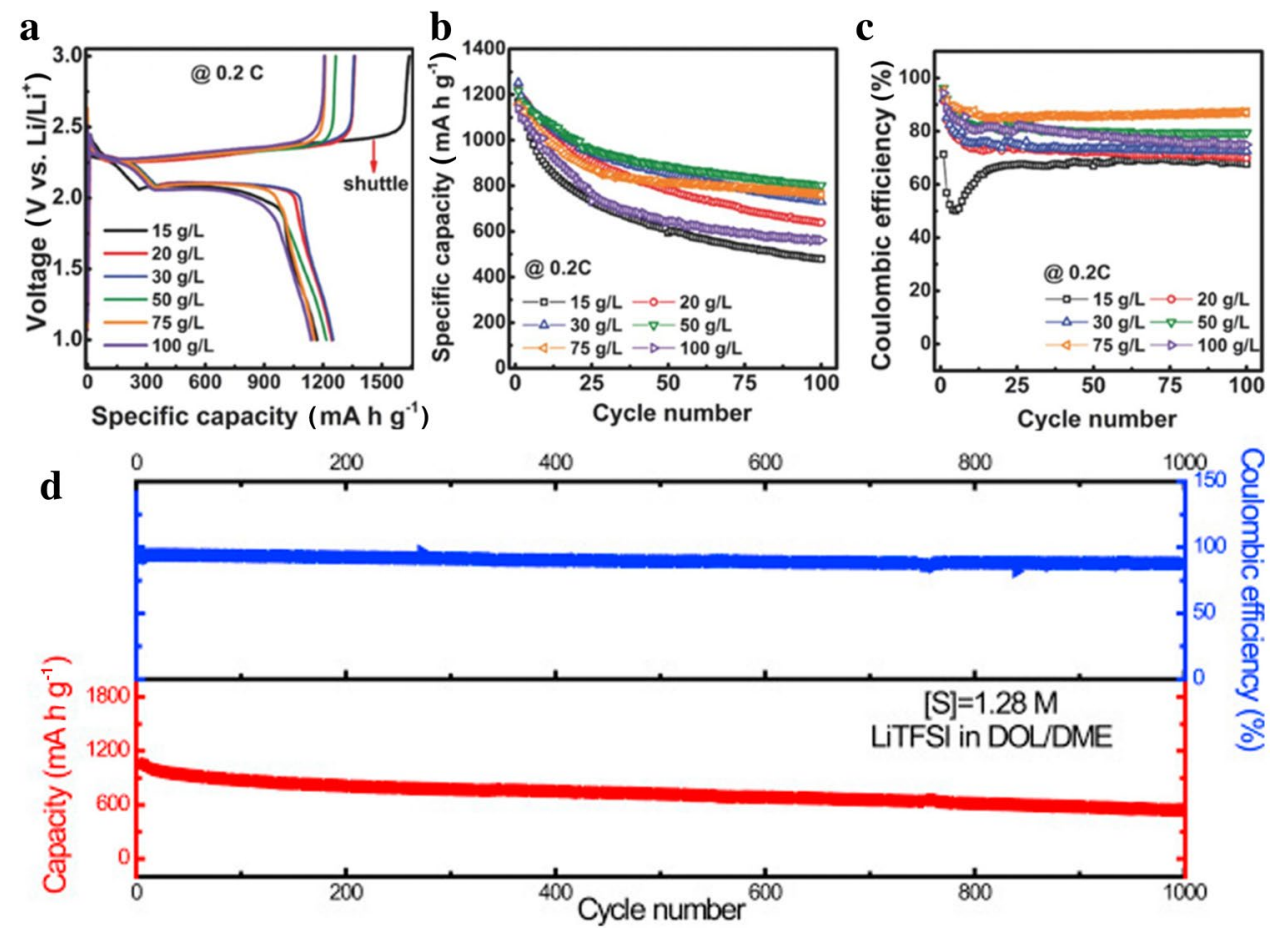

with high sulfur loading cathodes and low electrolyte ratios always show low discharge capacity output, low voltage plateaus and poor $\mathrm{C}$-rate performance. To date, it has been extremely difficult to achieve low $E / S$ ratios less than $1 \mu \mathrm{L} \mathrm{mg}^{-1}$ in current DOL/DME electrolyte systems. Hence, at this stage of research, it is more realistic to prolong the cycling life of Li-S batteries with high sulfur loading cathodes (sulfur loading: $4-6 \mathrm{mg} \mathrm{cm}^{-2}$ ) at a relatively low $E / S$ ratio of 2-3. Considering the non-uniform $\mathrm{Li}$ deposition and side reactions of the Li anode with electrolyte and dissolved polysulfide species, the stabilization of the lithium anode is a good choice in addressing both the safety hazards and cycling stability of high sulfur loading $\mathrm{Li}-\mathrm{S}$ batteries.

In this section, we review the strategies of lithium protection against lithium dendrite formation and/or dissolved PS. According to the protection mechanisms, these strategies can be classified into four parts: ex situ surface coating, in situ surface coating, solvent-in-salt, and other methods.

\subsubsection{Ex Situ Surface Coating}

One of the most effective and widely used methods to protect the lithium metal is to coat a protective layer on the surface to act as a physical barrier to against lithium dendrite formation and dissolved polysulfides [202, 300-304]. Porous $\mathrm{Al}_{2} \mathrm{O}_{3}$ with $0.23,0.58$ and $0.73 \mathrm{mg} \mathrm{cm}^{-2}$ coating layers were fabricated to suppress the side reactions between the $\mathrm{Li}$ anode and PS species by using a spin-coating method. It was found that the discharge capacity and capacity retention are sensitive to the coating density of $\mathrm{Al}_{2} \mathrm{O}_{3}$. A $0.23 \mathrm{mg} \mathrm{cm}^{-2}$ $\mathrm{Al}_{2} \mathrm{O}_{3}$ coating layer was found to be insufficient and could not form a complete physical barrier to effectively restrict PS dissolution, while electrolyte penetration and $\mathrm{Li}^{+}$diffusion were blocked by the $0.73 \mathrm{mg} \mathrm{cm}{ }^{-2} \mathrm{Al}_{2} \mathrm{O}_{3}$ coating layer. As a result, an optimized $0.58 \mathrm{mg} \mathrm{cm}^{-2} \mathrm{Al}_{2} \mathrm{O}_{3}$ coating layer was obtained and achieved the best battery performance, which enabled a capacity retention of $70 \%$ from the initial capacity of $1215 \mathrm{~mA} \mathrm{~h} \mathrm{~g}^{-1}$ at $160 \mathrm{~mA} \mathrm{~g}^{-1}$ after 50 cycles [303]. As another nanoscale coating technique, ALD is well known for enabling uniform thin-film deposition on substrates with high-aspect-ratio topography as well as controlling the thickness of thin films at atomic scale [305, 306]. Noked et al. deposited a 14-nm-thick $\mathrm{ALD} \mathrm{Al}_{2} \mathrm{O}_{3}$ layer on the surface of $\mathrm{Li}$ anode, which has been demonstrated to effectively reduce reactions between the $\mathrm{Li}$ anode and various corrosive species such as $\mathrm{H}_{2} \mathrm{O}, \mathrm{CO}_{2}$, sulfur and DME. In this regard, the $\mathrm{Li}-\mathrm{S}$ batteries assembled with ALD-coated anodes showed a high discharge capacity retention of around $90 \%$ over 100 cycles (calculated based on the initial discharge capacity of $\sim 1200 \mathrm{~mA} \mathrm{~h} \mathrm{~g}^{-1}$, sulfur loading $1.2 \mathrm{mg} \mathrm{cm}^{-2}$ ), while only $50 \%$ discharge capacity was retained for the unprotected $\mathrm{Li}$. Unfortunately, when the sulfur loading further increased to $5 \mathrm{mg} \mathrm{cm}^{-2}$, the Li-S cells with ALD-coated $\mathrm{Li}$ anode lost nearly $40 \%$ of their 4th cycle capacity after 100 cycles [202].

Considering that the non-ionic conductive coatings may impact the battery performance, more promising protective layers with high ionic conductivity were developed [300, 
Fig. 12 Schematic illustration of the designed $\mathrm{Li}-\mathrm{S}$ batteries $\mathbf{a}$ with and $\mathbf{b}$ without $\mathrm{Li}_{3} \mathrm{~N}$ as anode protection layer. c Comparison of the cycling performance of $\mathrm{Li}-\mathrm{S}$ batteries with and without $\mathrm{Li}_{3} \mathrm{~N}$ as anode protection layer. $\mathbf{d}, \mathbf{g}$ crosssectional morphologies and $\mathbf{e}$, $\mathbf{f}, \mathbf{h}, \mathbf{i}$ elemental mappings of a lithium metal anode with or without $\mathrm{Li}_{3} \mathrm{~N}$ protection after 100 cycles. Reprinted with permission from Ref. [300], copyright 2014, Royal Society of Chemistry a

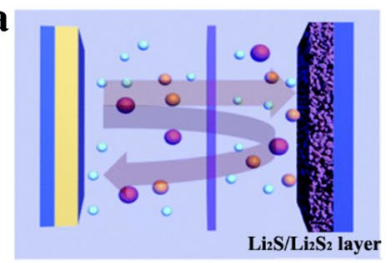

Lithium ions o Polysulfides ions b

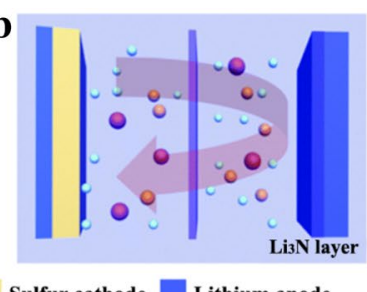

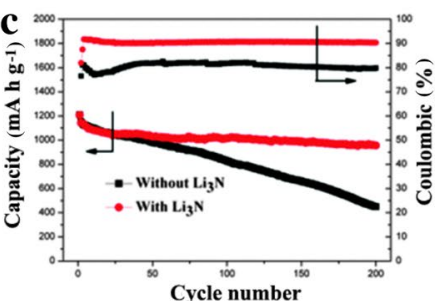

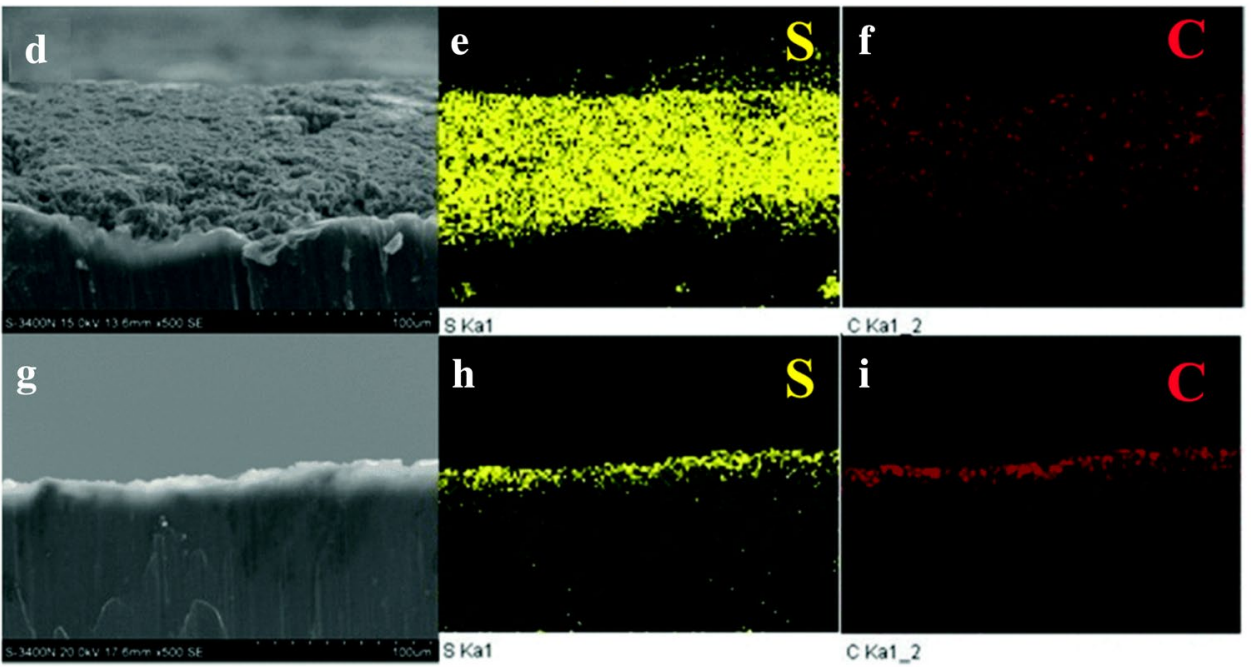

301]. $\mathrm{A} \mathrm{Li}_{3} \mathrm{~N}$ (approximately $10^{-3} \mathrm{~S} \mathrm{~cm}^{-1}$ ) layer with high $\mathrm{Li}^{+}$conductivity was fabricated via in situ reaction between $\mathrm{N}_{2}$ and Li anode (Fig. 12a). The Li-S batteries assembled with the protected anode delivered a Coulombic efficiency as high as $91.4 \%$ at $0.2 \mathrm{C}$ (Fig. 12c), which is over $10 \%$ higher than that of the corresponding bare $\mathrm{Li}$ anode. Moreover, even in $\mathrm{LiNO}_{3}$-free electrolyte, the $\mathrm{Li}-\mathrm{S}$ batteries still show a stable Coulombic efficiency of $92.3 \%$ and a high discharge capacity of $773 \mathrm{~mA} \mathrm{~h} \mathrm{~g}^{-1}$, corresponding to a $71 \%$ capacity retention for over 500 cycles at $0.5 \mathrm{C}$. As shown in Fig. $12 d-\mathrm{i}$, the protection effect of $\mathrm{Li}_{3} \mathrm{~N}$ was further demonstrated by the formation of a thinner lithium polysulfide layer on the surface of the protected $\mathrm{Li}$ anode compared with the bare counterpart (10 vs. $100 \mu \mathrm{m})$ [300]. Poly(3,4ethylenedioxythiophene)-co-poly (ethylene glycol) (PEDOTco-PEG), a member of the conductive polymer family, possesses a high ionic conductivity and strong adhesive force to Li metal and was employed as a coating layer by simply immersing Li metal into the polymer solution. The polymer layer not only acted as a selective film capable of inhibiting soluble lithium polysulfides diffusion and enabling $\mathrm{Li}^{+}$ to pass through, but also served as a shield to suppress the growth of lithium dendrites. The protection effect was confirmed by the electrochemical performance of the assembled $\mathrm{Li}-\mathrm{S}$ batteries and analysis of the anode morphology after cycling. The Li-S batteries with the protected anode maintained a high discharge capacity of $875.6 \mathrm{~mA} \mathrm{~h} \mathrm{~g}^{-1}$ at $0.2 \mathrm{C}$ after 200 cycles, corresponding to a high capacity retention of $73.45 \%$. Meanwhile, the batteries also achieved a high average Coulombic efficiency of $89.2 \%$ in a $\mathrm{LiNO}_{3}$-free electrolyte. Both the cycling performance and Coulombic efficiency are much higher than the unprotected counterpart (capacity retention: $32.8 \%$, Coulombic efficiency: $80.7 \%$ ). In addition to the electrochemical performance, the authors also observed the differences in morphology between the protected and unprotected anodes after cycling. It was found that the thickness of the $\mathrm{Li}_{2} \mathrm{~S}_{2} / \mathrm{Li}_{2} \mathrm{~S}$ layer formed on the unprotected anode is as high as $100 \mu \mathrm{m}$, while the thickness of the $\mathrm{Li}_{2} \mathrm{~S}_{2} / \mathrm{Li}_{2} \mathrm{~S}$ layer is only $40 \mu \mathrm{m}$ for the PEDOT-coPEG protected anode. Furthermore, the PEDOT-co-PEG with $10 \mu \mathrm{m}$ thickness was well-retained, suggesting that the coating layer is stable and can suppress the side reactions between lithium polysulfides and anode effectively.

In additional to aforementioned studies, the formation of other ex suit artificial SEI-protected Li anodes have also been reported, including the ionic liquid Py ${ }_{13}$ TFSI and ether solvent formed solid-state electrolyte interphase, lithium polysulfides and $\mathrm{LiNO}_{3}$ passivated implantable solid eletrolyte interphase, flexible solid electrolyte interphase via Li polyacrylic acid, and artificial soft-rigid protective layer composed by organic PVDF-HFP and inorganic LiF, etc [307-310]. These studies demonstrated effective methods for dendrite-free Li metal anodes and excellent performance in the Li-Li symmetric cells. It should be noted that some of these studies have not demonstrated the results in lithium-sulfur batteries or other Li metal-based batteries, which should be given in-depth insights in the real function of these protected Li metal anodes. 


\subsubsection{In Situ Surface Coating}

In situ formation of a stable SEI on the surface of the Li anode by introducing electrolyte additives is another strategy with more convenient processing and large-scale reliability. As a powerful electrolyte additive, lithium nitrate $\left(\mathrm{LiNO}_{3}\right)$ participates in forming a stable passivation layer that can avoid the direct contact of polysulfides with Li metal, enabling Li-S batteries with improved cycling stability and a high Coulombic efficiency of nearly $100 \%$ [311-313]. This discovery has been considered as a major breakthrough in this area and has been applied in most publications [24, 314]. Soon after, Aurbach et al. discovered the real role of $\mathrm{LiNO}_{3}$ in the $\mathrm{Li}-\mathrm{S}$ system with the use of X-ray photoelectron spectroscopy (XPS) and Fourier transform infrared spectroscopy (FT-IR). They found that $\mathrm{Li}_{x} \mathrm{NO}_{y}$ and $\mathrm{Li}_{x} \mathrm{SO}_{y}$ surface moieties derived from direct reduction in $\mathrm{LiNO}_{3}$ and sulfur species, respectively, are the main components of the passive layer, which remarkably reduced the side reactions between $\mathrm{Li}$ and lithium polysulfides as well as avoided overcharging of $\mathrm{Li}-\mathrm{S}$ batteries [313]. With the indepth studies, it has been found that the synergetic effect of $\mathrm{Li}_{2} \mathrm{~S}_{x}$, LiTFSI, and $\mathrm{LiNO}_{3}$ ternary salt in the electrolyte effectively constructs a stable and compact solid electrolyte interphase (SEI) layer to protect Li. Considering XAS, XPS, SEM, and other advanced characterizations, LiTFSI is proposed to afford a high $\mathrm{Li}^{+}$conductivity of the electrolyte in a working battery and the reactions between $\mathrm{LiNO}_{3}$ and $\mathrm{Li}_{2} \mathrm{~S}_{x}$ induce $\mathrm{Li}_{2} \mathrm{SO}_{3}$ formation, which is favorable to build protective SEI layer [315-318]. Afterward, some new electrolyte additives such as $\mathrm{CsNO}_{3}, \mathrm{LaNO}_{3}$ with similar roles but better electrochemical performances were also proposed [197, 319]. Despite their merit in improving Coulombic efficiency and cycling performance, the following issues should be taken into consideration. (1) All three additives are nitrate salts which show strong oxidizing properties and can potentially increase the safety issues [29]. (2) When the batteries operate at a voltage lower than $1.6 \mathrm{~V}$, the $\mathrm{LiNO}_{3}$ will be reduced to form some byproducts, leading to $\mathrm{LiNO}_{3}$ consumption and irreversible discharge capacity loss [314, 320]. These observations suggest that $\mathrm{Li}-\mathrm{S}$ batteries with $\mathrm{LiNO}_{3}$-containing electrolyte should be operated in a narrow voltage window, which undoubtedly affects the discharge capacity output. (3) The continuous consumption of $\mathrm{LiNO}_{3}$ can't be avoided during charge/discharge process following the decomposition/reformation process of SEI, leading to a fast capacity decay at later period of long-term cycling. Therefore, alternative and safer electrolyte additives were developed to alleviate the side reactions between $\mathrm{Li}$ anode and lithium polysulfides [321-324]. Liang et al. found that a passivating layer can be formed in situ on the surface of $\mathrm{Li}$ anode consisting of $\mathrm{Li}_{3} \mathrm{PS}_{4}$ after adding $\mathrm{P}_{2} \mathrm{~S}_{5}$ into electrolyte. This passive layer is dense and ionically conductive, which is able to conduct $\mathrm{Li}^{+}$while avoiding lithium polysulfide diffusion, attributing to a high reversible capacity (900-1350 $\mathrm{mA} \mathrm{h} \mathrm{g}^{-1}$ ) and a high Coulombic efficiency $(\geq 90 \%)$ over 40 cycles at $0.1 \mathrm{C}$ [321]. Lithium oxalyldifluoroborate (LiODFB) as an effective electrolyte additive was proposed to improve the cycling performance of $\mathrm{Li}-\mathrm{S}$ batteries and the mechanism was systemically studied via EDS, XPS, and density functional theory (DFT) calculation. Compared with the LiODFB-free electrolyte, LiODFB can

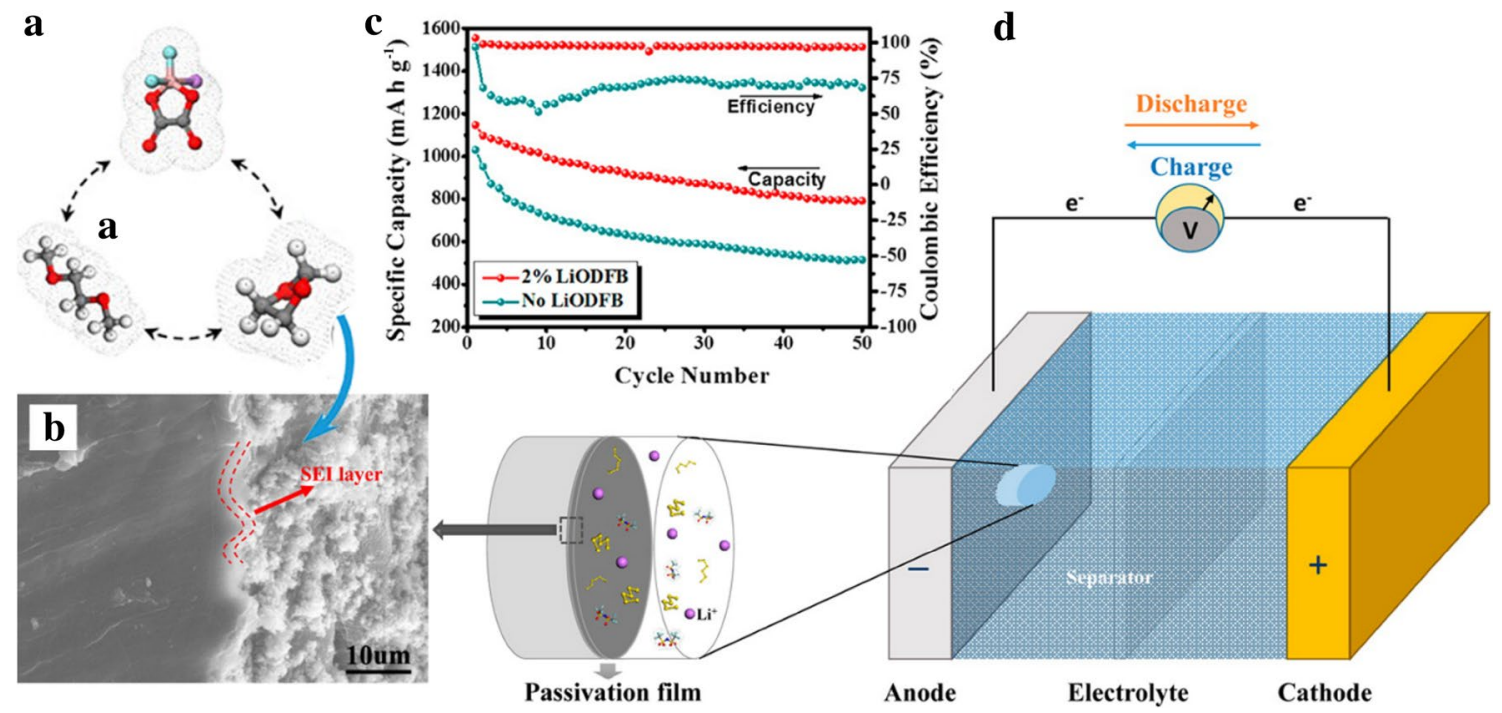

Fig. 13 a Formation mechanism of the passivation film with LiODFB additive. b Cross-section morphology of the lithium electrode with $2 \%$ LiODFB after 50 cycles. c Comparison of the cycle performance between cells with no and $2 \%$ LiODFB added. d Schematic configuration of the $\mathrm{Li}-\mathrm{S}$ cell. Reprinted with permission from Ref. [322], copyright 2014, American Chemical Society 
promote the formation of a high ionic conductivity LiF-rich SEI, promoting $\mathrm{Li}^{+}$transport while blocking PS shuttling (Fig. 13a, b). With the concentration of LiODFB increasing, the SEI resistance increased due to the thickness of the passivation layer, resulting in an optimized LiODFB concentration of $2 \mathrm{wt} \%$. The Li-S batteries with $2 \mathrm{wt} \%$ additive (Fig. 13d) presented a high discharge capacity of $1146.4 \mathrm{~mA} \mathrm{~h} \mathrm{~g}^{-1}$, an average Coulombic efficiency of $97 \%$, and a high capacity retention of $70 \%$ over 50 cycles at a current density of $100 \mathrm{~mA} \mathrm{~g}^{-1}$, which are great improvements compared with the electrolyte without LiODFB additive (initial discharge capacity: around $1000 \mathrm{~mA} \mathrm{~h} \mathrm{~g}^{-1}$, average Coulombic efficiency: $75 \%$, capacity retention: $50 \%$, shown in Fig. 13c) [322].

\subsubsection{Solvent-in-Salt}

Recently, a new method named "solvent-in-salt" has been explored and has demonstrated the ability to stabilize the surface of Li metal and enhance the cycling stability of $\mathrm{Li}-\mathrm{S}$ batteries [325]. Chen et al. investigated the lithium polysulfide dissolution behavior and $\mathrm{Li}$ anode morphology after cycling of Li-S batteries with different LiTFSI concentrations in a mixture of DOL/DME (v/v, 1:1). The authors found that no obvious polysulfides can be dissolved into the over-saturated 7 M LiTFSI solution, also called "solvent-insalt" electrolyte, thus eliminating Li anode corrosion by PS during the charge/discharge process. To demonstrate their concept, Li-S batteries assembled with $7 \mathrm{M}$ "solvent-in-salt" electrolyte were operated at $0.2 \mathrm{C}$ for 100 cycles. Results showed that the batteries presented a promising average
Coulombic efficiency of nearly $100 \%$ and a high initial discharge capacity of $1041 \mathrm{~mA} \mathrm{~h} \mathrm{~g}^{-1}$ with $74 \%$ capacity retention. In addition, the anode in the $\mathrm{Li}-\mathrm{Li}$ symmetric battery with $7 \mathrm{M}$ "solvent-in-salt" electrolyte exhibited the lowest surface roughness, further proving evidence of its capability in reducing the corrosion and suppression of lithium dendrite formation (Fig. 14).

In summary, ex situ surface coating and in situ SEI formation are among the most widely adopted strategies used to stabilize $\mathrm{Li}$ anodes against electrolyte and soluble lithium polysulfides. For the former strategy, the protective layer is one-off and not able to reform or repair during cycling and needs to be extremely stable during repeated cycling processes. Even though, the reported $\mathrm{Li}_{3} \mathrm{~N}, \mathrm{Al}_{2} \mathrm{O}_{3}$, PEDOT-co-PEG et al. are chemically stable in the $\mathrm{Li}-\mathrm{S}$ system, there are still some issues that should be mentioned. Inorganic coatings such as $\mathrm{Li}_{3} \mathrm{~N}$ and $\mathrm{Al}_{2} \mathrm{O}_{3}$ are hard, brittle, and non-flexible. They are easy to be broken and crack during repetitive folding in soft package assembly. Furthermore, $\mathrm{Al}_{2} \mathrm{O}_{3}$ is an ionically insulating material, and the battery performance is highly determined by the coating thickness. Most importantly, for practical application, the protected $\mathrm{Li}$ anode should be coupled with high sulfur loading cathodes. Therefore, whether the layer can tolerate the volumetric change from the large amount of Li deposition and dissolution should be further explored. Pure polymer coatings such as PEDOT-co-PEG are flexible and can accommodate the volumetric change to some extent. However, the Li-diffusion channels among the polymer chains should be enlarged due to the swelling effect of the polymer in the electrolyte, which will lead to
Fig. 14 Comparison of the properties between "salt-in-solvent" electrolyte and "solventin-salt" electrolyte, including the capability in suppressing shuttle of PS, solubility of PS and the morphology of Li metal anode after cycling (the scale bar is $60 \mu \mathrm{m})$. Reprinted with permission from Ref. [325], copyright 2013, Nature Publishing Group

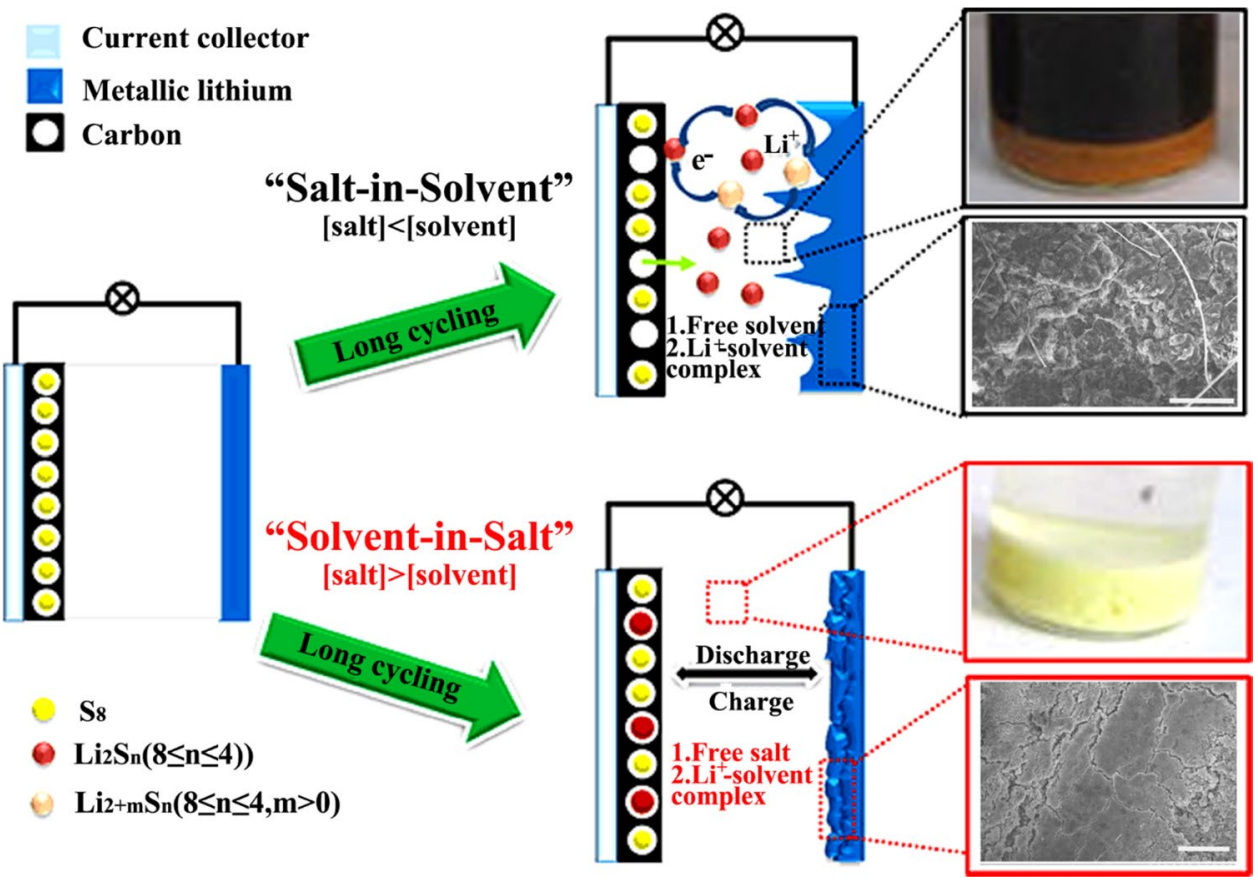


relatively poor protective properties and low Coulombic efficiency. For the latter case, even though it is a largescale reliable process and the SEI layers can be reformed/ repaired during cycling, the continuous consumption of electrolyte is still an unsolved issue. Especially when coupled with high sulfur loading electrodes, the situation worsens due to the large cycling capacity of lithium and further reactivity. Hence, seeking more stable and effective lithium protection methods is still critical for high sulfur loading batteries with low electrolyte/sulfur ratios. In our opinion, an ideal protective layer should meet the following requirements: inherent stability against $\mathrm{Li}$ metal, electrolyte, and soluble lithium polysulfides, being mechanically strong, uniform thickness, being flexible, and ionically conductive. Combining present techniques to fabricate hybrid protective layers is one of the best choices. These advanced hybrid systems should have the potential to provide flexibility capable of accommodating large volume changes, hardness to prevent dendrite growth, ionic conductivity to allow fast lithium transport, stability against electrolyte, and low cost with scalability.

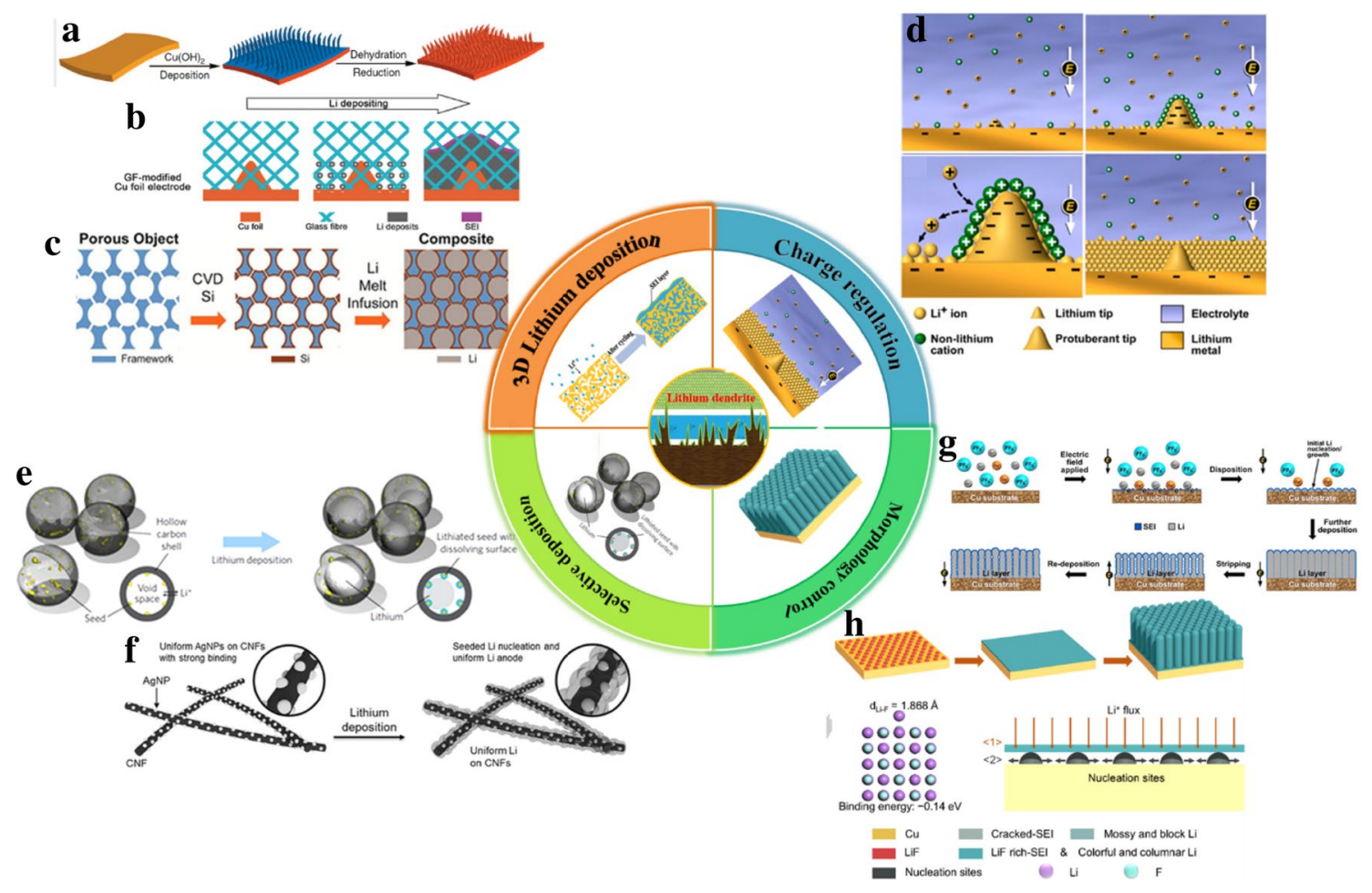

Fig. 15 Strategies for suppressing Li dendrites including 3D lithium deposition, charge regulation, selective deposition and morphology control. a Schematic diagram of the procedures to prepare a 3D porous $\mathrm{Cu}$ foil from a planar $\mathrm{Cu}$ foil. Reprinted with permission from Ref. [327], copyright 2015, Nature Publishing Group. b Li deposition behavior on the $\mathrm{Cu}$ substrate covered with a glass fiber cloth containing large quantities of polar functional groups. The protuberances on the $\mathrm{Cu}$ foil electrode are surrounded with evenly redistributed $\mathrm{Li}$ ions, enabling the dendrite-free Li deposits. Reprinted with permission from Ref. [38], copyright 2017, Wiley-VCH. c Schematic illustration of the design of a $\mathrm{Li}$-scaffold composite and Li melting process. Reprinted with permission from Ref. [332], copyright 2016, National Academy of Sciences of the United States of America. d Schematic illustration of $\mathrm{Li}$ deposition process with $\mathrm{Cs}^{+} / \mathrm{Rb}^{+}$additive based on the self-healing electrostatic shield (SHES) mechanism. Reprinted with permission from Ref. [333], copyright 2013, American Chemical Society. e Schematic illustration of Li metal nanocapsules design. $\mathrm{Au}$ nanoparticles are loaded inside hollow carbon spheres, where a large void space is reserved for $\mathrm{Li}$ metal. $\mathrm{Li}$ is expected to nucleate from the Au seed. Carbon shells provide both confinement and protection of the Li metal, as well as conduction channels for both electrons and Li metal. Reprinted with permission from Ref. [334], copyright 2016, Nature Publishing Group. f Schematic illustration of the strategy to uniformly deposit $\mathrm{Li}$ metal on 3D host materials via selective deposition. Li nucleation and growth are prominently occurred on Ag nanoparticles, which are homogeneously anchored on the CNF substrate via Joule heating. Li metal is thus directedly grow along the CNF forming an even $\mathrm{Li}$ anode. Reprinted with permission from Ref. [335], copyright 2017, Wiley-VCH. g Schematic of $\mathrm{Li}$ deposition and stripping processes with $\mathrm{Cs}^{+}$additive. Reprinted with permission from Ref. [336], copyright 2014, American Chemical Society. $\mathbf{h}$ Schematics for the Li plating morphologies on LiF-rich surface modified $\mathrm{Cu}$ substrate, including the binding energy of $\mathrm{Li}$ on LiF (100) surface and Li deposition mechanism. Reprinted with permission from Ref. [337], copyright 2017, Wiley-VCH 


\subsubsection{Other Methods}

In 4.3.1-4.3.3, we reviewed the efforts of lithium protection against lithium dendrite and dissolved PS that were directly applied in $\mathrm{Li}-\mathrm{S}$ batteries. There are some other methods that can provide protection for next-generation Li-metal-based batteries and have the potential to be used in $\mathrm{Li}-\mathrm{S}$ batteries, including 3D lithium deposition, charge regulation, selective deposition, and morphology control.

\section{A. 3D Lithium Deposition}

For a typical Li-based battery, a planar lithium foil is directly used as the anode. Due to the imperfect surface of $\mathrm{Li}$ foil, lithium is prone to deposit on the Li substrate at defect sites, resulting in lithium dendrite growth during plating, especially for the batteries operated at high current densities [326]. Deposition of Li inside a 3D skeleton has been demonstrated to be a promising strategy and has been widely used to prevent lithium dendrite growth. Yang et al. [327] have reported a 3D $\mathrm{Cu}$ foil with several submicron fibers that are roughly perpendicular to the surface (as shown in Fig. 15a), acting as the 3D current collector to suppress the lithium dendrite growth. For the original planar $\mathrm{Cu}$ foil, lithium is preferred to nucleate on the smooth surface and then grow as small lithium dendrites, which acts as charge centers as the charges accumulate at sharp ends in the electric field, resulting in subsequent amplification of the growth of the $\mathrm{Li}$ dendrites. On the contrary, for the 3D Cu foil, more submicron fiber tips are provided as the charge center and nucleation sites, enabling a more uniform electric field and charge distribution along the $\mathrm{Cu}$ skeleton. In this regard, lithium is therefore expected to nucleate and grow on the submicron $\mathrm{Cu}$ fibers with nanosized lumps, fill the pores of the 3D current collector, and eventually form a relatively smooth Li surface. With similar strategies but more scalable and feasible methods, Yang's group and Kim's group proposed alterative designs [328, 329]. In Yang's work, a 3D porous $\mathrm{Cu}$ current was obtained by simply dealloying $\mathrm{Zn}-\mathrm{Cu}$ alloy tape in an acid solution, which has been demonstrated to show a high Coulombic efficiency of $97 \%$ for 250 cycles at $0.5 \mathrm{~mA} \mathrm{~cm}^{-2}$ and for more than 140 cycles at $1.0 \mathrm{~mA} \mathrm{~cm}{ }^{-2}$ with significantly reduced polarization [328]. Kim et al. [329] directly used commercial stainless-steel fiber felt as the 3D current collector and showed a $75 \%$ Coulombic efficiency retention after 90 cycles, while the Coulombic efficiency retention of planar $\mathrm{Cu}$ foil is only $30 \%$ after 80 cycles (Current density $1 \mathrm{~mA} \mathrm{~cm}^{-2}$, capacity $1 \mathrm{~mA} \mathrm{~h} \mathrm{~cm}^{-2}$ ). Apart from the conductive metal-based and carbon-based $3 \mathrm{D}$ current collectors, nonconductive 3D micro-/nanostructured skeletons such as polymer nanofibers [330], glass fibers, [38], and $\mathrm{Li}_{7} \mathrm{~B}_{6}$ porous frameworks [331] have also been considered as promising current collectors. For instance, glass fibers with abundant polar functional groups ( $\mathrm{Si}-\mathrm{O}$, $\mathrm{O}-\mathrm{H}, \mathrm{O}-\mathrm{B}$ ) were employed on the surface of planar $\mathrm{Cu}$ foil as a $3 \mathrm{D}$ current collector. Considerable lithium ions could be adsorbed on the polar functional groups to compensate the electrostatic interactions between lithium ions and protuberances that formed on planar $\mathrm{Cu}$ foil during first plating. The electrode can avoid $\mathrm{Li}^{+}$accumulation around protuberances, thus leading to the even redistribution of $\mathrm{Li}^{+}$within the glass fiber framework (Fig. 15b).

3D current collectors not only play a role as the framework for Li deposition, but can also act as a porous network for fabricating Li-scaffolds through molten Li infusion. These 3D structures can possess a highly conductive surface area and excellent structural stability upon galvanostatic cycling via alleviating severe volumetric change during striping/plating and suppression of lithium dendrite growth. However, the design of a "lithiophilic" surface for Li impregnation is crucial to this strategy. Liu et al. [338] employed polyimide with a lithiophilic $\mathrm{ZnO}$ coating layer as a 3D scaffold for lithium infusion. Benefitting from the suppressed dendrite growth and alleviated volumetric expansion, a high current density of $5 \mathrm{~mA} \mathrm{~cm}{ }^{-2}$ in both carbonate and ether electrolytes was achieved. In order to further improve the conductivity of the composite anode, Y. Cui's group chose carbon frameworks and metal foams as the host materials and further transformed the "lithiophobic" surfaces into "lithiophilic" structures by coating a thin layer of Si to assist the melt-infusion process [332]. Before Si coating, the carbon framework and metal foam showed poor $\mathrm{Li}$ wettability due to the lack of bonding interactions between surface (carbon or $\mathrm{Cu}$ ) and molten Li. After Si modification, a binary alloy phase lithium silicide with some bonding interactions with pure $\mathrm{Li}$ was formed, guiding molten Li to wet the entire surface and fill in the porous structure (Fig. 15c). Benefiting from the highly conductive surface area, stable electrolyte/electrode interface, and negligible volume fluctuation, the carbon framework encapsulated with $\mathrm{Li}$ (labeled as $\mathrm{Li} / \mathrm{C}$ ) can operate for more than 80 cycles under a high current rate of $3 \mathrm{~mA} \mathrm{~cm} \mathrm{~cm}^{-2}$. Later, conductive rGO [339], Ni foam [340], and channel guided carbon [341] were also proposed as 3D lithiophilic scaffolds for lithium infusion due to the alloying reactions and lithiophilic surfaces. Recently, a nanoporous $\mathrm{Li}_{x} \mathrm{Si}-\mathrm{Li}_{2} \mathrm{O}$ composite with high ionic conductivity was obtained via mixing over stoichiometric amounts of molten $\mathrm{Li}$ and submicrometer-sized $\mathrm{SiO}$ powder at high temperature [342]. The $\mathrm{Li}_{x} \mathrm{Si}_{-}-\mathrm{Li}_{2} \mathrm{O}$ matrix acted as a protective layer that can prevent the direct contact between the embedded lithium domains and liquid electrolyte, enabling suppression of the severe side reactions between $\mathrm{Li}$ anode and electrolyte. Additionally, it is also a lithium ion conductive matrix that allows free $\mathrm{Li}^{+}$transport and maintains the electrochemical activity of the embedded lithium. 
The 3D current collectors can alleviate the infinite volumetric expansion of lithium as well as provide high specific surface area that can enable more stable lithium deposition at high rates and limit dendrite growth. Nevertheless, if they are coupled with Li-S batteries, the increased surface area of Li will be directly exposed to electrolyte, which will lead to more severe side reactions between $\mathrm{Li}$ and electrolyte/ polysulfides. Hence, coupling 3D current collector with protective layers (such as the $\mathrm{Li}_{x} \mathrm{Si}-\mathrm{Li}_{2} \mathrm{O}$ matrix) via a simple and scalable method will be more practical for liquid electrolyte $\mathrm{Li}-\mathrm{S}$ batteries, especially for the batteries with low $E / S$ ratios.

\section{B. Charge Regulation}

In Sect. 2.3.2, we have summarized some electrolyte additives that can form in situ protective layers to suppress side reactions between lithium and electrolyte/polysulfides. Nevertheless, as a part of the protective layer, they are eventually consumed and lose their function during long-term cycling. In 2013, Zhang's group discovered an effective electrolyte additive for $\mathrm{Li}$ dendrite suppression that was non-consumable for long-term cycling based on a good understanding of the charge regulation mechanism [333]. As shown in Fig. 15d, when low concentrations of cesium $\left(\mathrm{Cs}^{+}\right)$or rubidium $\left(\mathrm{Rb}^{+}\right)$ions were added into the electrolyte, they accumulated on the tips of the protuberances of the Li surface due to the relatively lower potential compared with the standard reduction potential of lithium ions. At this stage, the surrounding $\mathrm{Cs}^{+}$or $\mathrm{Rb}^{+}$served as a positively charged electrostatic shield which can effectively control the $\mathrm{Li}$ deposition by directing $\mathrm{Li}^{+}$to deposit on areas of lower local charge density, thus leading to a smooth surface. It should be clarified that the $\mathrm{Cs}^{+}$or $\mathrm{Rb}^{+}$species are not deposited or reduced during cycling, highlighting their long-term stability. In this consideration, a $\mathrm{Lili}_{4} \mathrm{Ti}_{5} \mathrm{O}_{12}$ cell with a high Coulombic efficiency of $99.86 \%$ and a stable capacity of around $160 \mathrm{~mA} \mathrm{~h} \mathrm{~g}^{-1}$ for 660 cycles was demonstrated through adding $0.05 \mathrm{M} \mathrm{Cs}^{+}$. A minor concern is that this strategy is only positioned to solve the battery shortcircuiting problems resulting from dendrite growth, while no difference was found for the Li deposition efficiency (a low Coulombic efficiency of 76.5\%) in a PC electrolyte with or without $\mathrm{Cs}^{+}$additive. Hence, in order to realize both high Coulombic efficiency and $\mathrm{Li}$ dendrite-free deposition, a good combination of the electrolyte solvent, salt, and additives is still urgently required.

\section{Selective Deposition}

Based on the deep understanding of the phase diagrams of $\mathrm{Li}$ with other metals, a selective deposition method was firstly proposed by Cui et al. [334]. They found that the nucleation and growth behavior of $\mathrm{Li}$ is a substrate-dependent process. On substrates such as $\mathrm{Au}, \mathrm{Ag}, \mathrm{Mg}, \mathrm{Al}$, and $\mathrm{Pt}$ materials that showed definite solubility of $\mathrm{Li}$, low overpotential and nucleation barriers were found for the Li deposition process, whereas appreciable nucleation barriers existed for metals $(\mathrm{Cu}, \mathrm{Ni}, \mathrm{C}, \mathrm{Sn}, \mathrm{Si})$ with negligible solubility. In other words, Li will selectively deposit on the surface of metals without nucleation barriers. Under the guidance of this concept, a nanocapsule structure consisting of hollow carbon with nanoparticle Au seeds embedded within (as shown in Fig. 15e) was designed for Li deposition. Interestingly, the $\mathrm{Li}$ was found to selectively nucleate and grow at the $\mathrm{Au}$ sites inside the hollow carbon spheres, which significantly suppressed the Li dendrite formation and improved the cycling stability. This idea was further accepted and developed by $\mathrm{L}$. Hu's group and Q. Zhang's group. In Hu's study, as shown in Fig. 15f, they modified the commercial carbon nanofiber $(\mathrm{CNF})$ with ultra-fine silver $(\mathrm{Ag})$ nanoparticles on the surface via a rapid Joule heating method, which served as a selective substrate for Li deposition [335]. Coinciding well with Cui's results, there is no nucleation overpotential for $\mathrm{Li}$ deposition on the Ag/CNF substrate and Li prominently nucleates and grows on the $\mathrm{Ag}$ nanoseeds, resulting in a uniform Li film along the CNFs during Li platting. Afterward, the materials options were further broadened by Zhang et al. In addition to metals, they found that different $\mathrm{Li}$ nucleation behavior can also be observed from other non-metallic materials such as carbon [343]. The results showed that negligible nucleation overpotential for Li deposition was observed on nitrogen-doped graphene (NG), while obvious nucleation overpotential was observed for its counterparts (graphene and $\mathrm{Cu}$ foil). As a result, the NG anode presented a dendritefree morphology as well as a high Coulombic efficiency of 98\% within around 200 cycles.

The selective deposition strategy has been demonstrated to be effective in prolonging the cycling stability by suppressing Li dendrite formation. Nevertheless, whether the nucleation overpotential difference between the two substrates is large enough to enable selective deposition at high current densities when it coupled with high sulfur loadings should be further studied. Furthermore, more attention should be paid to the side reactions between $\mathrm{Li}$ and electrolyte/polysulfides for the design of selective deposition substrates.

\section{Morphology Control}

The sharp tips of Li dendrites can pierce the separator, resulting in direct contact between the anode and cathode and short-circuiting. Passivating the sharp tip and controlling the morphology of Li deposition product seems to be a good method of protecting the Li anode. Zhang et al. [336] added an amount of $\mathrm{Cs}^{+}$into the $\mathrm{Li}^{+}$-containing 
electrolyte and surprisingly found that a self-aligned and highly compacted nanorod structure formed instead of Li dendrites. As shown in detail in Fig. 15g, at the early stage, both $\mathrm{Li}^{+}$and $\mathrm{Cs}^{+}$showed similar trends to the $\mathrm{Cu}$ substrate under the force of electric field. Afterward, due to the lower reduction potential of $\mathrm{Li}^{+}$compared with $\mathrm{Cs}^{+}$, the $\mathrm{Li}^{+}$was uniformly plating on the surface of $\mathrm{Cu}$ while the $\mathrm{Cs}^{+}$accumulated around the seeds/Li tips, acting as an electrostatic field to prevent accelerated dendrite growth. That is to say, the electric field directed $\mathrm{Li}$ growth along the applied electric field vertical to the $\mathrm{Cu}$ substrate at a constant rate, leading to a self-aligned $\mathrm{Li}$ nanorod structure. Directed by the same research group, trace amounts of water (25-50 ppm) were also found to play a similar role as $\mathrm{Cs}^{+}$and were introduced as electrolyte additives to control the morphology [344]. They found that the trace amount of HF formed from the side reactions of $\mathrm{LiPF}_{6}$ and $\mathrm{H}_{2} \mathrm{O}$ can facilitate the formation of uniform and dense LiF-rich SEI layers on the substrate. Such LiFrich SEI layers aid the uniform distribution of the electric field and thus lead to Li nanorod arrays aligned vertically to the substrate. Inspired by Zhang's work, Zhang et al. directly introduced the $\mathrm{LiF}$ on the $\mathrm{Cu}$ substrate, as shown in Fig. 15g. The Li-rich SEI layer was formed during the Li deposition, enabling a dendrite-free film with an aligned columnar structure [337]. Benefiting from the Li dendrite-free structure, the $\mathrm{Cu}$ modified with $\mathrm{LiF}$ showed a significant improvement in electrochemical performance including Coulombic efficiency and cycling life compared with the fresh $\mathrm{Cu}$.

Even though this method showed promising performance in suppressing Li dendrite growth during repeated cycling, the degradation and increasing roughness of the Li film resulting from the interactions between Li nanorods and electrolyte remain to be solved.

To summarize, Li protection shows great potential to improve the cycling life and decrease the $E / S$ ratio for highenergy Li-S batteries. Various strategies have been demonstrated to effectively improve the electrochemical performance of $\mathrm{Li}-\mathrm{S}$ batteries. However, the protective effects in most studies are obtained under relatively ideal conditions such as low sulfur loadings, large $E / S$ ratios and large excess of $\mathrm{Li}$. The performance needs to be further investigated from
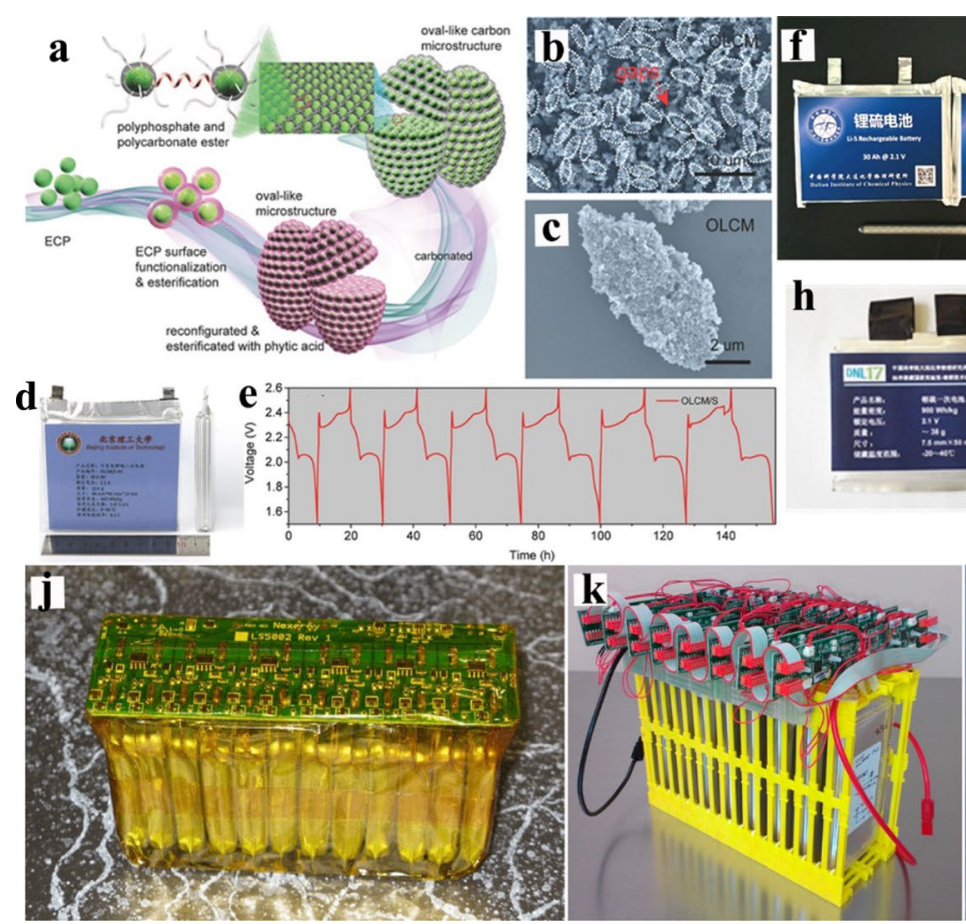
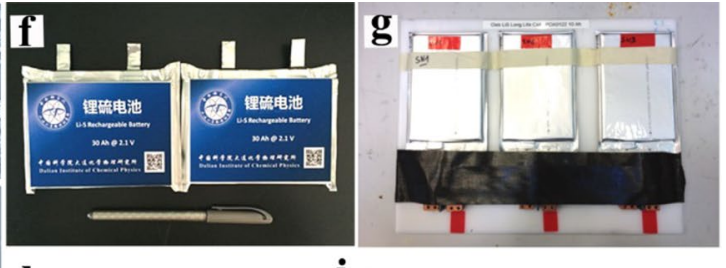

h
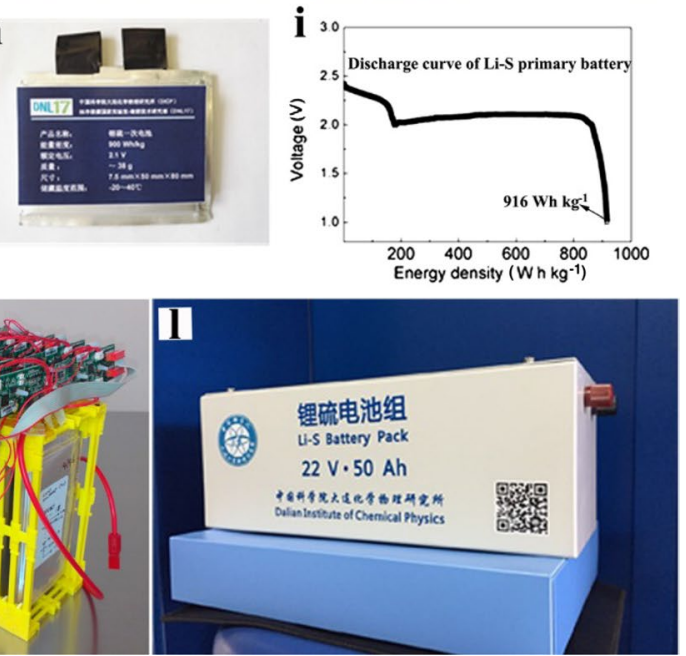

Fig. 16 a Schematic illustration of the synthesis process of the OLCMs. The morphology of OLMCs at $\mathbf{b}$ low and $\mathbf{c}$ high magnifications. $\mathbf{d}$ The photograph of Li-S soft package with S/OLCM cathode. e Discharge/charge voltage profiles of the Li-S soft package assembled with S/OLCM cathode for seven cycles. Reprinted with permission from Ref. [165], copyright 2017, Wiley-VCH. f The photograph of $550 \mathrm{~W} \mathrm{~h} \mathrm{~kg}^{-1} \mathrm{Li}-\mathrm{S}$ rechargeable soft package [349]. Reprinted with permission from J. Chen' Group. g POA0122 type of Li-S soft package designed by Oxis Energy Ltd [346]. Reprinted with permis- sion from Oxis Energy Ltd. h The photograph of $900 \mathrm{~W} \mathrm{~h} \mathrm{~kg}^{-1} \mathrm{Li}-\mathrm{S}$ primary battery and $\mathbf{i}$ their relative charge/discharge voltage profiles. Reprinted with permission from Ref. [49], copyright 2017. j Li-S battery packs designed by Sion Power Inc [347]. Reprinted with permission from Sion Power Inc. and k Oxis Energy Ltd. Reprinted with permission from Oxis Energy Ltd [348]. $11 \mathrm{~kW} \mathrm{~h} \mathrm{Li-S} \mathrm{battery} \mathrm{pack}$ with a high energy density of $330 \mathrm{~W} \mathrm{~h} \mathrm{~kg}^{-1}$ [349]. Reprinted with permission from J. Chen' Group 
the viewpoint of practical engineering designs for $\mathrm{Li}-\mathrm{S}$ batteries. Many novel Li protection methods have yet to be tested in $\mathrm{Li}-\mathrm{S}$ systems and should be further explored.

\subsection{Practical Li-S Battery Soft Packages}

It is important that researchers pursue a combination of fundamental research and industrial application to achieve high energy density Li-S soft package production. Since Sion Power company developed the first lithium-sulfur battery that can supply power to an unmanned aircraft for continuous flight for 14 days in 2010 [345], more and more Li-S batteries with high practical energy density were reported. Chen' group designed novel oval-like carbon microstructures (OLCMs) via assembling KB particles into micro-scale hosts and coated them on an Al film with a high sulfur loading double-sided electrode of $14.0 \mathrm{mg} \mathrm{cm}^{-2}$. The assembled Li-S soft package delivered a high capacity of $18.6 \mathrm{Ah}$ and an average voltage of $2.05 \mathrm{~V}$ with a low $E / S$ ratio of 2.7 . Furthermore, the soft package can run steadily for 7 cycles with a high practical energy density of $460 \mathrm{~W} \mathrm{~h} \mathrm{~kg}^{-1}$ [165]. Recently, as shown in Fig. 16f, Li-S rechargeable batteries with capacities/energy densities of $37 \mathrm{Ah} / 566 \mathrm{~W} \mathrm{~h} \mathrm{~kg}^{-1}$ at room temperature and $39 \mathrm{Ah} / 616 \mathrm{~W} \mathrm{~h} \mathrm{~kg}^{-1}$ at $50{ }^{\circ} \mathrm{C}$ were achieved by Chen et al. from Dalian Institute of Chemical Physics, which are the highest reported energy densities. Moreover, long-life soft package was also reported by OxisEnergy Ltd., the well-designed POA0122 type Li-S battery with a high capacity of $10 \mathrm{Ah}$ and an energy density of $152 \mathrm{~W} \mathrm{~h} \mathrm{~kg}^{-1}$ can stably run for more than 1400 cycles [346]. Besides, some Li-S battery packs shown in Fig. 16j-1 including several cells connected in series were developed by Sion Power Inc., Oxis Energy Ltd. and J Chen's group [347-349]. Oxis Energy Ltd. also developed a battery manage system, which is a distributed type with 16 small boards connected to each cell (Fig. 16k) [348]. The temperature, current and voltage of each cell were directly measured and controlled in such structure. Chen's group assembled a $1 \mathrm{~kW} \mathrm{~h} \mathrm{Li-S} \mathrm{battery} \mathrm{pack} \mathrm{with} \mathrm{a} \mathrm{capacity} \mathrm{of} 50 \mathrm{Ah}$ and the energy density can reach as high as $330 \mathrm{~W} \mathrm{~h} \mathrm{~kg}^{-1}$ (Fig. 161) [349]. Considering the reduced "shuttle effect" and relatively lower requirements in electrolyte and $\mathrm{Li}$ metal anode, primary Li-S batteries assembled with lower $E / S$ ratios and higher energy densities were developed by Zhang et al. As shown in Fig. 16h-i, the reported practical energy density can reach an ultra-high value of $916 \mathrm{~W} \mathrm{~h} \mathrm{~kg}^{-1}$ $\left(1000 \mathrm{~W} \mathrm{~h} \mathrm{~L}^{-1}\right)$, which stands out from recent Li-based primary systems such as $\mathrm{Li} / \mathrm{CF}_{4}, \mathrm{Li} / \mathrm{SOCl}_{2}, \mathrm{Li} / \mathrm{MnO}_{2}$, and $\mathrm{Li} /$ $\mathrm{SiO}_{2}$ batteries. These types of batteries are anticipated to be used in some special areas that need low power and long working time. All those achievements indicate promising prototypes of high energy density $\mathrm{Li}-\mathrm{S}$ batteries.

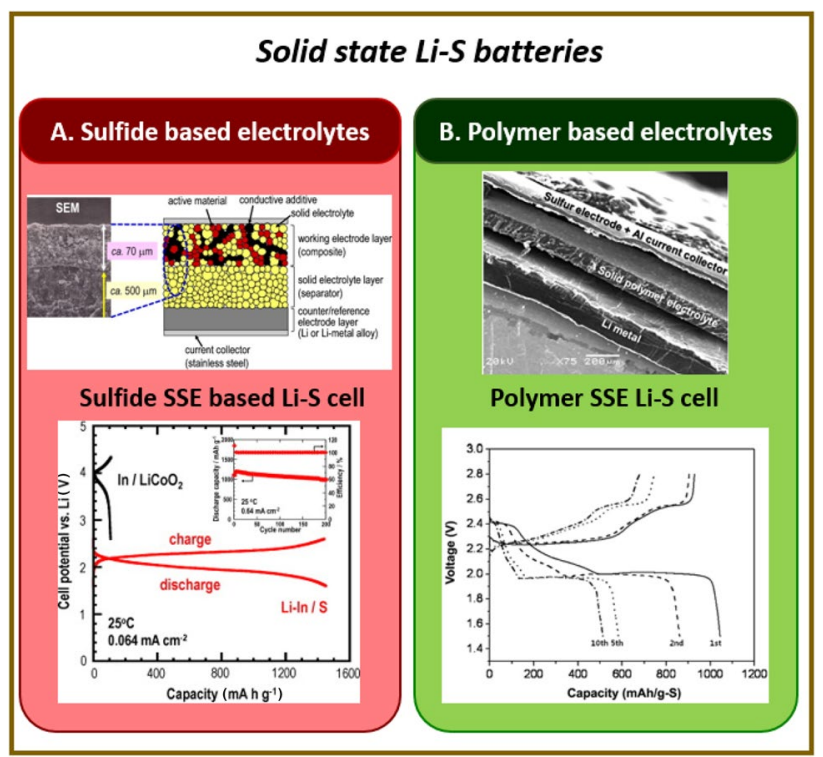

Fig. 17 Two main types of solid-state Li-S batteries with different cell configurations and discharge-charge profiles. Reprinted with permission from Ref. [358], copyright 2013, Elsevier B.V. Reprinted with permission from Ref. [359], copyright 2011, Elsevier B.V

\section{Next-Generation All-Solid-State Li-S Batteries}

The increasing demands of safety and concerns over flammable and toxic liquid electrolytes have promoted the development of safe and high-energy all-solid-state Li-based batteries [350, 351]. The first introduction of the all-solid-state Li-S battery system was as early as the 1990s [352]. However, the prosperity of Li-ion batteries at that time resulted in the stagnation of Li-S and all-solid-state (ASS) Li-S batteries [31, 353]. Since the early 2000s, with the increasing demand of higher energy density and the success of highly reversible liquid-based $\mathrm{Li}-\mathrm{S}$ batteries by Nazar's group, a significant amount of research has been dedicated to breaking through the limiting barriers of Li-S batteries [14, 354]. Furthermore, the successful development of high ionic conductivity solid-state electrolytes has improved the feasibility of high-energy solid-state Li-S batteries [355-357]. As shown in Fig. 17, there are mainly two types of developed all-solid-state $\mathrm{Li}-\mathrm{S}$ batteries which include sulfide-based electrolytes and polymer-based electrolytes. The differences of solid-state electrolytes (SSEs) in Li-S batteries determine the different material preparation, battery assembly processes, and electrochemical reaction routes. As shown in Fig. 17a, with the use of sulfide-based SSEs, the Li-S batteries are prepared into a sandwich-type structure. The electrochemical voltage profiles of sulfide-based $\mathrm{Li}-\mathrm{S}$ batteries is a pair of single discharge-charge plateaus, corresponding to the solid-phase $\mathrm{Li}-\mathrm{S}$ redox reaction mentioned in Sect. 1.1. 
On the other hand, the assembly of polymer-based Li-S batteries is closer to their liquid-based counterparts, which keep the layer-by-layer structure with the replacement of liquid electrolyte to a membrane polymer electrolyte. For the electrochemical reaction, as shown in Fig. 17b, polymer-based $\mathrm{Li}-\mathrm{S}$ batteries still demonstrate two-pair discharge-charge plateaus during cycling, which indicates that although the electrolyte is in solid state, the electrochemical reaction is still the solid-liquid dual-phase reaction. The development of all-solid-state Li-S batteries is in a start-up stage and the underlying mechanisms and battery structure optimization is still evolving. In this section, reported all-solid-state $\mathrm{Li}-\mathrm{S}$ batteries with different SSEs will be presented and future prospects will also be summarized.

\subsection{Sulfide-Based Electrolyte Li-S Batteries}

Sulfide-based solid-state electrolytes are the most popular SSEs employed in solid-state (SS) Li-S batteries [358, 360, 361]. Compared with other types of inorganic SSEs, sulfides have higher ionic conductivity and are well coordinated with sulfur and $\mathrm{Li}_{2} \mathrm{~S}$ cathodes, forming a stable interface [358, 360, 361]. Therefore, sulfide-based Li-S batteries are considered as the most promising all-solid-state batteries for real application. The cell configuration of inorganic SSE batteries is different from their liquid-based or polymer counterparts. In a typical battery assembly process, sulfur or $\mathrm{Li}_{2} \mathrm{~S}$ cathodic composites are mixed with sulfide SSE powder and then pressed into a pellet. The formed cathode pellet is then combined with a SSE pellet and anode to further form a sandwich-structured solid-state cell configuration. However, there are many challenges faced by sulfide-based all-solidstate $\mathrm{Li}-\mathrm{S}$ batteries. Firstly, the side reaction and high resistance at the interface between sulfide/cathode and sulfide/ $\mathrm{Li}$ metal seriously deteriorate the performance and cycle life of all-solid-state Li-S batteries [360, 362]. Secondly, the pellet press process during battery assembly makes it difficult to achieve commercialization [363, 364]. For the developed pouch cell of liquid-based batteries, flexible electrodes with controllable shape and size are essential for practical application, and are easy to assemble and transport. However, the currently employed synthetic techniques for sulfide electrolyte pellets are restricted by operation pressure and limited diameter. Furthermore, the fragile mechanical properties of the pellets hinder their practical application. Thirdly, the sulfide-based electrolytes are chemically and electrochemical unstable, which until now has been difficult to address for mass production [361, 365, 366]. Based on the aforementioned challenges, the development of novel nanomaterials and nanostructure in sulfide-based all-solidstate $\mathrm{Li}-\mathrm{S}$ is crucial in this field.

Early work has devoted significant efforts to cell configuration design and development of SSEs for $\mathrm{Li}-\mathrm{S}$ batteries.
As for preliminary research, amorphous sulfide SSEs were firstly attempted in $\mathrm{SS} \mathrm{Li}-\mathrm{S}$ batteries, such as $\mathrm{Li}_{2} \mathrm{~S}-\mathrm{SiS}_{2}$ glassy electrolytes and $\mathrm{Li}_{2} \mathrm{~S}-\mathrm{P}_{2} \mathrm{~S}_{5}$ glass-ceramic electrolytes [352]. In addition to the development of SSEs, investigation of cathode materials and an understanding of their electrochemical reactions in $\mathrm{Li}-\mathrm{S}$ batteries were also studied. Furthermore, investigation of the $\mathrm{P} / \mathrm{S}$ ratio of electrolytes on electrochemical performance, the cathode/electrolyte ratio effect on the electrochemical performance; ball milling time effect; and development of anodes with $\mathrm{Li}$ evaporation or Li-In alloys to pursue high cycling capability and stability have been explored [367-370]. As shown in Table 8, due to the low conductivity of sulfide electrolytes, the ratio of sulfur $/ \mathrm{Li}_{2} \mathrm{~S}$ in cathodic composite is very low to match the slow reaction kinetics. For electrochemical characterization, the batteries employ very low current densities and the cycle life of reported Li-S batteries are very limited. With the development of inorganic SSE, a variety of novel crystallized SSEs with high ionic conductivity have been applied to all-solid-state $\mathrm{Li}-\mathrm{S}$ batteries, such as thio-LiSICION Li ${ }_{10} \mathrm{GeP}_{2} \mathrm{~S}_{12}$, argyrodite $\mathrm{Li}_{6} \mathrm{PS}_{5} X(X=\mathrm{Cl}, \mathrm{Br})[355$, 371-374]. With the use of these novel SSEs, the developed $\mathrm{Li}-\mathrm{S}$ batteries can operate at higher current densities with improved cycle life at room temperature. On the other hand, it should be pointed out that these developed sulfide electrolytes are not chemically and electrochemically stable, triggering serious side reactions and increased resistance at the interfaces of cathode and anode materials [375]. To overcome the challenges of the interface between electrolyte and electrode materials, many novel nanostructured materials have been utilized. Liang et al. firstly reported the electrode/electrolyte interphase design with a $\mathrm{Li}_{3} \mathrm{PS}_{4}$ coating. The author successfully developed nanosize $\mathrm{Li}_{2} \mathrm{~S}$ with a $\mathrm{P}_{2} \mathrm{~S}_{5}$ coating to build a core-shell $\mathrm{Li}_{2} \mathrm{~S} @ \mathrm{Li}_{3} \mathrm{PS}_{4}$ cathode material. The high ionic conductivity of the $\mathrm{Li}_{3} \mathrm{PS}_{4}$ coating layer on the $\mathrm{Li}_{2} \mathrm{~S}$ nanoparticles enhanced the interphase connectivity and effectively reduced the ion diffusion path length [376, 377]. Despite the excellent electrochemical performance obtained from this cathode material, the active material loading was only $0.2-0.5 \mathrm{mg} \mathrm{cm}^{-2}$. Later, Wang's team developed a novel conductive $\mathrm{Li}_{2} \mathrm{~S}$ nanocomposite via a bottom-up method. The as-prepared $\mathrm{Li}_{2} \mathrm{~S}-\mathrm{Li}_{6} \mathrm{PS}_{5} \mathrm{Cl}-\mathrm{C}$ composites have demonstrated both high ionic and electric conductivity as cathode materials [378]. Another paper recent reported by Wang and Xu developed S-rGO- $\mathrm{Li}_{10} \mathrm{GeP}_{2} \mathrm{~S}_{12}$ composites with a similar structure to improve both the ionic and electronic conductivity of the cathode material. This study also introduced an attractive bi-layer sulfide electrolyte to improve the stability with reduced side reactions in Li-S batteries [379]. These studies give new insights into interface design and provide examples of how to reduce the interface resistance between sulfur/SSEs, creating a balance of ionic and electronic conductivity. 


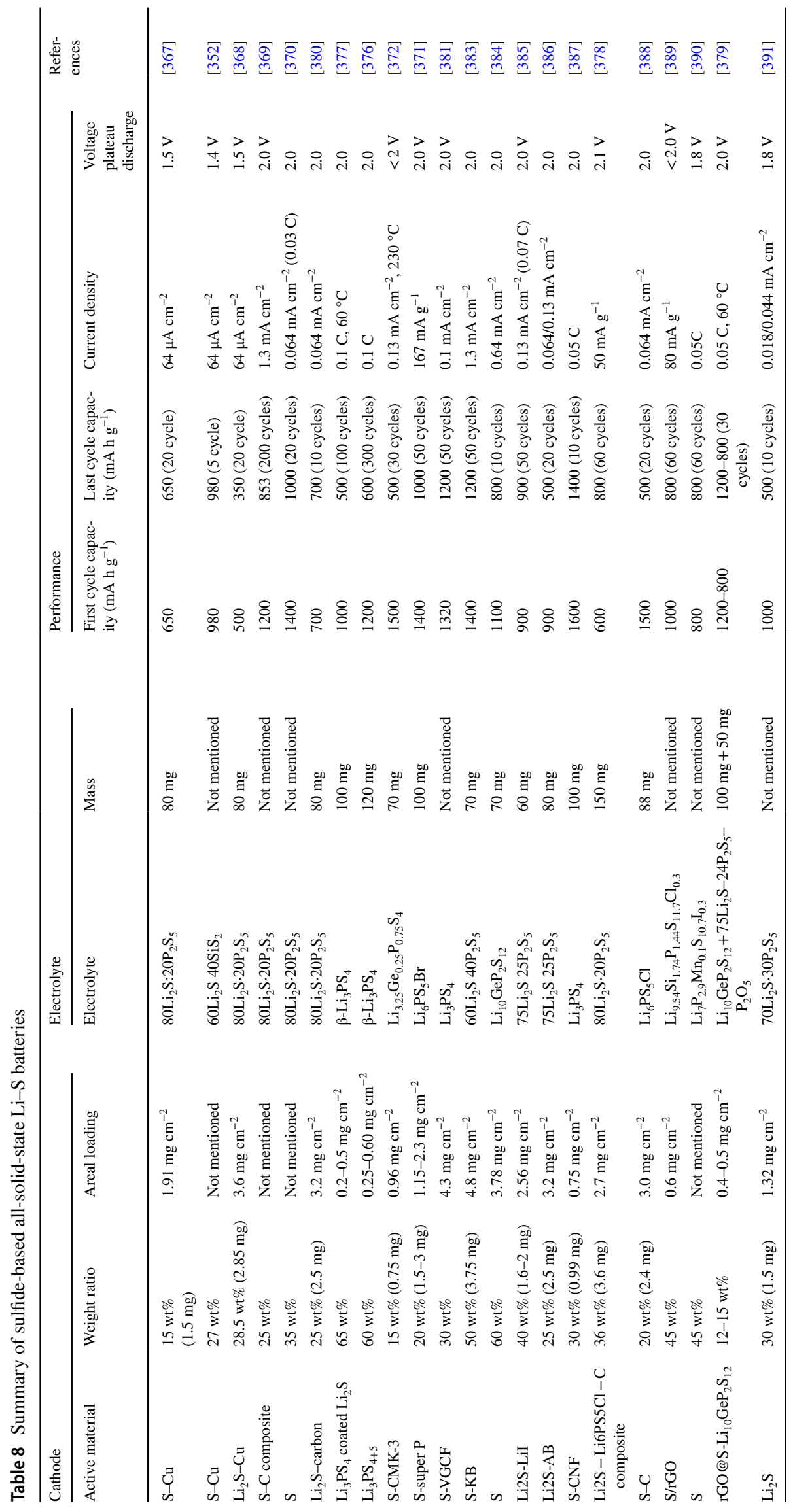




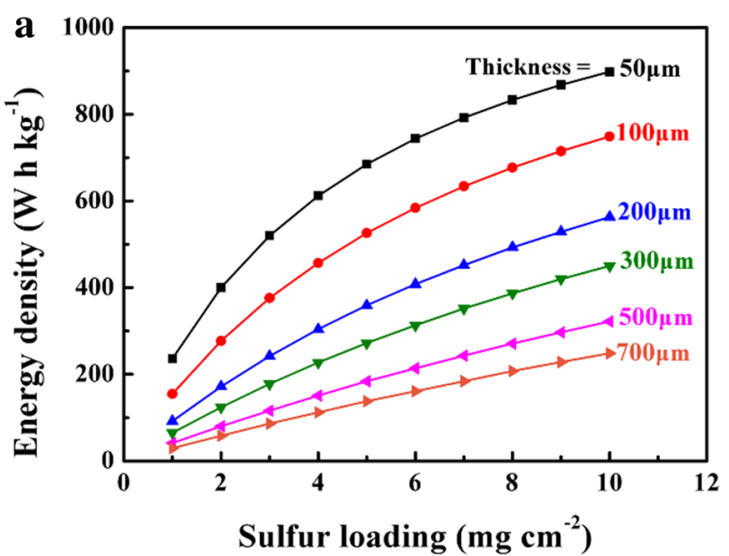

Fig. 18 Calculation and perspective on the gravimetric energy density of sulfide-based all-solid-state Li-S batteries. a Energy density calculated based on theoretical discharge capacity of $1672 \mathrm{~mA} \mathrm{~h} \mathrm{~g}^{-1}$ and average discharge voltage of $2.1 \mathrm{~V}$ as a function of sulfur loading for

Table 9 Simulated components of all-solid-state Li-S soft package

\begin{tabular}{|c|c|}
\hline Components & Mass $\left(\mathrm{mg} \mathrm{cm}^{-2}\right)$ \\
\hline $\begin{array}{l}\text { Cathode current collector (aluminum foil, } \\
16 \mu \mathrm{m} \text { ) }\end{array}$ & 4.32 \\
\hline Sulfur ${ }^{\mathrm{a}}$ & $x$ \\
\hline Other component in cathode ${ }^{b}$ & $x$ \\
\hline Anode (lithium metal) ${ }^{\mathrm{c}}$ & $0.65 x$ \\
\hline Electrolyte $^{\mathrm{d}}$ & $0.153 \underline{\mathrm{d}}$ \\
\hline $\begin{array}{l}\text { Others (Cathode tab, Anode tab, Al laminate } \\
\text { film, etc.) }{ }^{\mathrm{e}}\end{array}$ & $0.32+0.22 x+0.1 n x$ \\
\hline Total & $6.40+4.31 x+2.10 n x$ \\
\hline
\end{tabular}

${ }^{\text {a }}$ Sulfur loading is $x \mathrm{mg} \mathrm{cm}^{-2}$

${ }^{\mathrm{b}}$ The ratio of other component (conductive additive and electrolyte) in cathode is $50 \mathrm{wt} \%$

${ }^{\mathrm{c}} 50 \mathrm{wt} \%$ lithium excess accords to the stoichiometric ratio of sulfur

${ }^{\mathrm{d}}$ The density of the electrolyte is $1.7 \mathrm{mg} \mathrm{cm}^{-3}$ and the porosity is $10 \%, \mathrm{~d}$ is the thickness (unit: $\mu \mathrm{m}$ )

${ }^{\mathrm{e}}$ The mass ratio of such other components as cathode tap, anode tap, Al laminate film is $5 \mathrm{wt} \%$ of the whole $\mathrm{Li}-\mathrm{S}$ package

The developed nanomaterials and novel nanostructures can significantly improve the electrochemical performance of SS Li-S batteries. However, as shown in Table 8, the cathode loading and operating current densities in these developed all-solid-state batteries are very limited [371, $372,380-382]$. If calculating the ratio between cathode active material and total electrolyte, the value in most reported literature is less than $5 \mathrm{wt} \%$, which makes it difficult for all-solid-state batteries to achieve energy densities comparable to their liquid counterparts. To address the energy density concerns, we simulate a soft package sulfide-based all-solid-state $\mathrm{Li}-\mathrm{S}$ batteries to estimate the practical gravimetric energy density (here we use the

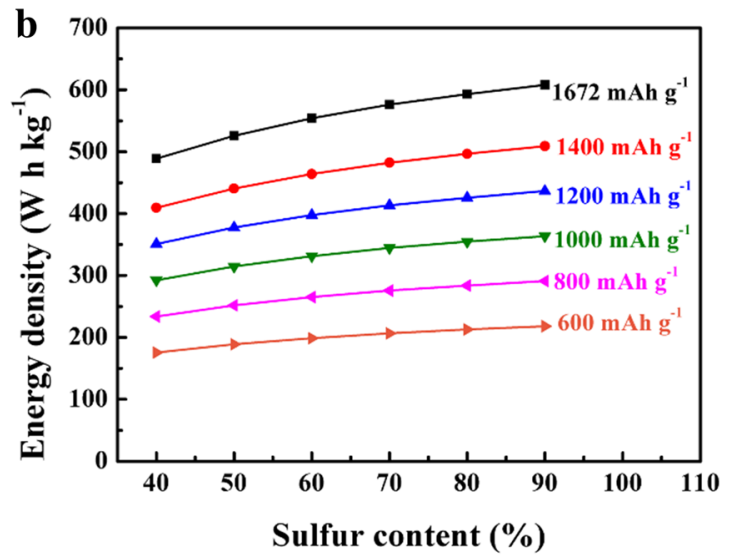

various thickness of electrolyte. $\mathbf{b}$ Energy density calculated based on a sulfur loading of $5 \mathrm{mg} \mathrm{cm}^{-2}$ and an electrolyte thickness of $100 \mu \mathrm{m}$ as a function of sulfur content for various discharge capacity

energy density instead), as shown in Fig. 18. The common materials, such as the cathode tab, anode tab, Al laminate film, etc. are same as the liquid-based $\mathrm{Li}-\mathrm{S}$ batteries shown in Fig. 18 and Table 9. Figure 18a demonstrates the energy density of Li-S batteries in terms of sulfur loading of cathodes with various electrolyte pellet thicknesses. The calculation employs a cathode with $50 \mathrm{wt} \%$ sulfur content which runs a theoretical discharge sulfur capacity of $1672 \mathrm{~mA} \mathrm{~h} \mathrm{~g}^{-1}$ and an average discharge voltage of $2.1 \mathrm{~V}$. As shown in Fig. 18a, the energy densities of the batteries increase with the sulfur loading. More importantly, with the same sulfur loading, the overall thickness reduction from the electrolyte pellet will dramatically improve the energy density. To reach a high energy density of $500 \mathrm{~W} \mathrm{~h} \mathrm{~kg}^{-1}$, the thickness of the electrolyte pellet should be less than $200 \mu \mathrm{m}(<30 \mathrm{mg})$. For most of the developed Li-S batteries as shown in Table 8 , the amount of electrolyte used is over $80 \mathrm{mg}$ and the thickness is around $600-700 \mu \mathrm{m}$. Therefore, the state-of-theart SS Li-S batteries, even with a high sulfur loading, have insufficiently low energy densities. Therefore, ultrathin and dense solid-state electrolyte films are critical for future application. Novel techniques, such as tape casting, PLD, and ALD are considered as promising candidates to achieve ultra-thin electrolytes. To further monitor the effect of the sulfur cathode performance on energy density, we fix the sulfur loading at $5 \mathrm{mg} \mathrm{cm}^{-2}$ and electrolyte thickness to $100 \mu \mathrm{m}$. Interestingly, the discharge performance of sulfur cathodes directly determines the energy density of battery. For instance, to reach an energy density of $300 \mathrm{~W} \mathrm{~h} \mathrm{~kg}^{-1}$, the sulfur cathode should achieve a discharge capacity over $1000 \mathrm{~mA} \mathrm{~h} \mathrm{~g}^{-1}$ during cycling. Based on these simulations, the ultra-thin solid-state electrolyte 
pellet and high-performance sulfur cathodes are two key factors in the development of sulfide-based $\mathrm{Li}-\mathrm{S}$ batteries.

In a brief summary, the development of inorganic electrolyte-based Li-S batteries is still at the primary stage [392, 393]. High ionic conductivity electrolytes with chemical stability will be crucial in this field, which directly determines the feasibility of high loading all-solid-state $\mathrm{Li}-\mathrm{S}$ batteries. Furthermore, the optimization of electrode/electrolyte is another challenge that needs to be addressed. The intimate electrode/electrolyte contact with small and stable interface resistance is also the key to achieve high-performance $\mathrm{Li}-\mathrm{S}$ batteries. Finally, according to the simulated results, fabrication of ultra-thin solid-state electrolyte films and employment of high-performance sulfur cathodes are two important strategies to improve the energy densities to the level required for next-generation batteries.

\subsection{Polymer Electrolyte-Based Li-S Batteries}

The structure of polymer-based all-solid-state Li-S batteries is very similar to their liquid counterparts, where the liquid electrolyte is replaced by a polymer electrolyte membrane, as shown in Fig. 17b [394, 395]. The most attractive advantage of polymer-based $\mathrm{Li}-\mathrm{S}$ batteries is the improved safety properties. By replacing the flammable liquid electrolyte, the battery exhibits dramatically reduced risks associated with explosion and ignition [359, 396, 397]. On the other hand, there are many challenges in polymer-based $\mathrm{Li}-\mathrm{S}$ batteries. Firstly, the developed polymer electrolytes have relatively low conductivity and can only be operated at high temperature $\left(>60{ }^{\circ} \mathrm{C}\right)$ [398-401]. Furthermore, due to the membrane structure, the ion diffusion path from polymer electrolyte to electrode is limited and therefore high loading sulfur cathodes are difficult to achieve [400, 401]. Finally, as mentioned before, polymer-based $\mathrm{Li}-\mathrm{S}$ batteries still undergo the solid-liquid dual-phase redox reaction, which indicates polysulfide dissolution and the accompanied shuttle effect is still a serious challenge. Based on the aforementioned challenges, the structure of polymer-based all-solid-state $\mathrm{Li}-\mathrm{S}$ batteries is simple and easy to fabricate; however, the development and progress are limited. Preliminary research has developed a variety of polymers such as PEO, PEMO, and PEGDME and investigate the electrochemical performance with these SSEs in Li-S batteries [359, 402-407]. Furthermore, novel polymer electrolytes with nanostructure design, improved ionic conductivity and advanced characterizations were also conducted [396, 408, 409]. Many polymer electrolytes possess significant advantages in flexibility and chemical compatibility that are unrivaled by other SSEs. Among them, Fan et al. [410] reported a novel nanostruture polymer-in-salt polysiloxane electrolyte applied to all-solid-state $\mathrm{Li}-\mathrm{S}$ batteries. The developed polymer-based SSEs demonstrated high ionic conductivity and good accommodation with Li metal anode which breaks the bottleneck that allow the polymer-based ASS Li-S batteries operating at ambient temperature. Many groups have attempted to develop hybrid electrolytes with the combination of polymer and oxide-based electrolytes, which demonstrated enhanced stability and conductivity [411-415]. Despite the excellent electrochemical performance, the loading of these sulfur and $\mathrm{Li}_{2} \mathrm{~S}$-based cathodes are unsatisfactory and unsuitable for commercial application.

To summarize, the development of polymer-based allsolid-state Li-S batteries still have a long way to go. The low conductivity of polymer SSEs, high interface resistance between cathodes and SSE, and dissolution of polysulfides lead to unsatisfactory cycle capacity and cell life. However, polymer-based SSEs have their own positive characteristics, such as superior flexibility, controllable size and shape, and low cost, making them promising candidates for future $\mathrm{Li}$ metal batteries. From the authors' view, the development of highly conductive polymer-based SSEs, the design of novel nanostructured SSEs and electrodes are still prominent issues that need further investigation.

\subsection{Summary and Perspective of All-Solid-State Li-S Batteries}

All-solid-state Li-S batteries have been attracting extensive interests for future application due to their high energy density and improved safety properties. In this section, we summarize the two types of all-solid-state $\mathrm{Li}-\mathrm{S}$ batteries, sulfide-based $\mathrm{Li}-\mathrm{S}$ batteries, and polymer-based $\mathrm{Li}-\mathrm{S}$ batteries, with their cell configurations, electrochemical mechanisms, application challenges and advantages, recently developed studies, and future perspectives.

Firstly, the electrochemical mechanism of polymer-based and sulfide-based all-solid-state $\mathrm{Li}-\mathrm{S}$ batteries are different. From our knowledge, polymer-based $\mathrm{Li}-\mathrm{S}$ batteries follow solid-liquid dual-phase $\mathrm{Li}-\mathrm{S}$ redox reaction (two-pair plateaus in discharge-charge profiles), which cannot avoid the dissolution of polysulfides. On the other hand, sulfide electrolyte $\mathrm{Li}-\mathrm{S}$ batteries undergo solid-phase $\mathrm{Li}-\mathrm{S}$ redox reactions (one pair of plateaus in discharge-charge profiles), which indicates the occurence of an alternative electrochemical route. However, the detailed electrochemical route of the solid-phase $\mathrm{Li}-\mathrm{S}$ redox reaction is still unclear and needs further in-depth investigation to reveal the mechanism behind it.

Secondly, there are still many challenges that hinder the practical application of the two types of all-solid-state $\mathrm{Li}-\mathrm{S}$ batteries. For sulfide electrolyte all-solid-state $\mathrm{Li}-\mathrm{S}$ batteries, the sulfur/ $\mathrm{Li}_{2} \mathrm{~S}$ loadings are particularly low and far from achieving high-energy Li-S batteries. Furthermore, the state-of-the-art batteries need to add a high content of SSEs to obtain good ionic conductivity, which undoubtedly 
decrease the ratio of cathode and electrolyte, leading to an overall low energy density battery system. Additionally, the synthesis of sulfide electrolytes, battery assembly, and interface design of sulfide-based Li-S batteries are still ongoing and need further exploration. The future development of $\mathrm{Li}-\mathrm{S}$ batteries needs to address multiple issues including: (1) the development of stable, highly conductive, and low-cost sulfide electrolytes. The ionic conductivity directly determines the affordable cathode loading and current density of the batteries. (2) Considering the battery structure and assembly, novel electrolyte/electrode structure with facile synthetic processes are an important step to overcome the bottleneck of Li-S battery application. The currently employed fragile pellet structure can only accommodate very small size batteries. A flexible and dense electrode/ electrolyte film with high mechanical strength is the ideal structure for future all-solid-state $\mathrm{Li}-\mathrm{S}$ batteries. (3) Stable and high-energy lithium-based anode is another key factor to achieve successful all-solid-state $\mathrm{Li}-\mathrm{S}$ batteries. The most prevailing anode employed in developed $\mathrm{Li}-\mathrm{S}$ batteries is the Li-In alloy anode. Despite the indium enabling an improved anode stability during cycling, the mass of the additional indium metal layer sacrifices the gravimetric and volumetric energy density of the batteries. As mentioned in the previous section, many novel studies have developed safe and high-energy Li metal anodes in liquid electrolytes. These advanced design can be applied in all-solid-state $\mathrm{Li}-\mathrm{S}$ batteries in future investigations. (4) The electrochemical reaction route of the single plateau solid-state $\mathrm{Li}-\mathrm{S}$ batteries is still not clear. Revealing the underlying mechanisms of sulfidebased all-solid-state Li-S batteries with in-operando studies will air the design of electrolyte and electrode materials.

Polymer-based all-solid-state Li-S batteries also need long-term exploration. (1) Development of high ionic conductivity polymer SSEs is the bottleneck in this field. The state-of-the-art $\mathrm{Li}-\mathrm{S}$ batteries with polymer electrolytes still need to operate at high temperature. Therefore, developing hybrid polymer-inorganic electrolytes is an important direction for future application. (2) Detailed studies on the energy density simulation of polymer-based Li-S batteries are still in its infancy. For most reported polymerbased all-solid-state $\mathrm{Li}-\mathrm{S}$ batteries, the parameters of the employed polymer membrane, such as mass, density, and thickness, are all unknown, which make it hard to calculate and simulate a precise value of the energy density of these batteries. (3) Similar to liquid-based Li-S batteries, polymer-based all-solid-state $\mathrm{Li}-\mathrm{S}$ batteries also suffer from the shuttle effect from dissolved polysulfides and severe Li dendrite growth, which will require significant attention to novel nanomaterials and nanostructure design to overcome these issues.

In summary, safe and high-energy $\mathrm{Li}-\mathrm{S}$ batteries have received a great amount of attention in recent years. Based on the safety concerns for real application of Li-S systems, all-solid-state $\mathrm{Li}-\mathrm{S}$ batteries have been considered to be the most promising candidate for future application. Nonetheless, there are still many issues and large room for improvement in battery performance. On the one hand, the synthesis of highly conductive solid-state electrolytes with improved chemical stability, economic price and potential for mass production is a big challenge for battery fabrication. On the other hand, battery structure and electrolyte/electrolyte interface design are still ongoing issues that will need to be addressed in order to achieve facile, dense, and high mechanical strength batteries. Another prominent concern is the design of safe and high-energy Li metal anodes, which is critical to achieve high-energy Li-S batteries. Meanwhile, the underlying mechanisms of all-solid-state $\mathrm{Li}-\mathrm{S}$ batteries are still calling for deeper understanding to support the design of better batteries.

\section{Conclusion and Perspective}

In this review, several important parameters such as sulfur loading, $E / S$ ratio, Li excess percentage, capacity output, and sulfur content that affect the cost, gravimetric, and volumetric energy density were systemically studied and reviewed from an engineering perspective for the fabrication of practical $\mathrm{Li}-\mathrm{S}$ batteries. Based on the assumed conditions and relative data, it is found that the achievement of low-cost engineering $\mathrm{Li}-\mathrm{S}$ batteries with both high gravimetric and volumetric energy densities (500 $\mathrm{W} \mathrm{h} \mathrm{kg}^{-1}$ and $500 \mathrm{~W} \mathrm{~h} \mathrm{~L}^{-1}$, respectively) should meet several requirements including high sulfur content ( $\geq 70 \mathrm{wt} \%$ ) based on the whole cathode, high specific capacities ( $\left.\geq 1400 \mathrm{~mA} \mathrm{~h} \mathrm{~g}^{-1}\right)$, high areal sulfur loadings around $5 \mathrm{mg} \mathrm{cm}^{-2}$, low $E / S$ ratios $\left(\leq 3 \mu \mathrm{L} \mathrm{mg}^{-1}\right)$, high average voltages of approximately $2.15 \mathrm{~V}$, low electrode porosity $(\leq 40 \%)$, and low $\mathrm{Li}$ excess $(\leq 50 \mathrm{wt} \%)$. With the exception of the $\mathrm{Li}$ excess and electrode porosity factors which have been greatly neglected in research, the statistical information collected from 107 publications with high sulfur loadings of more than $4 \mathrm{mg} \mathrm{cm}^{-2}$ showed that the capacity output, cycling life, and $E / S$ ratio are the main shortcomings that limit the practical application of $\mathrm{Li}-\mathrm{S}$ batteries. In other words, solving these problems, or at least reducing their effect, is critical to paving the way for large-scale engineering of $\mathrm{Li}-\mathrm{S}$ batteries. Some suggestions with respect to solving the issues mentioned above and to propel the development of high-energy density and low-cost $\mathrm{Li}-\mathrm{S}$ batteries are as follows:

\subsection{Sulfur Cathode}

For achieving high-loading, high capacity output and long cycling life $\mathrm{Li}-\mathrm{S}$ cathodes, novel conductive hosts need to be designed with high electrical conductivity, fast $\mathrm{Li}^{+}$ transport channels, and the capability to confine the lithium 
polysulfide shuttling effect. For thick cathodes, the top-down design of a conductive network with unrestricted $\mathrm{Li}^{+}$transport channels during long-term cycling should also be taken into consideration. Scale-up of readily available and lowcost cathode fabrication strategies should also be explored. Considering the fact that large $E / S$ ratios lead to low practical mass and volumetric energy densities, the development of cathodes with low porosities of less than $40 \%$ should be a priority for the next stage of research. Furthermore, the binder is an important component of the cathode which plays an important role in connecting the active materials and current collectors, while occasionally acting as a polysulfide immobilizer as well. As an inactive and nonconductive component of the cathode, decreasing its ratio without breaking the binding effect will no doubt improve the conductivity of the whole cathode and increase the energy density. Hence, developing low-cost binders with high bonding strength and good capability in suppressing lithium polysulfides shuttle is extremely meaningful, especially for the practical engineering of $\mathrm{Li}-\mathrm{S}$ batteries. For cathodes in carbonate electrolytes, such as the most reported PAN-S and small molecular sulfur-based cathodes, the sulfur contents based on the whole cathode are less than $40 \mathrm{wt} \%$ which correlates to gravimetric energy densities lower than $300 \mathrm{~W} \mathrm{~h} \mathrm{~kg}^{-1}$. Hence, increasing the sulfur content is one of the primary objectives in achieving acceptable energy densities. Some new methods such as MLD coating can make it possible to operate the high sulfur content cathodes (more than $60 \mathrm{wt} \%$ ) in carbonate-based electrolytes, and the mechanism behind the improved performance should be further clarified to facilitate the development of strategies for carbonate-based Li-S systems. Moreover, the electrochemical performance should be further improved to meet the demand of high-energy Li-S batteries. For all-solid-state $\mathrm{Li}-\mathrm{S}$ batteries, most research has been focused on improving the ionic conductivity of the electrolytes, reducing the resistance of $\mathrm{Li}^{+}$transport at the interface, and alleviating the side reactions between the electrolyte and active materials. Developing high sulfur loading cathodes with excellent electrochemical performance is also significant for the liquid electrolyte-based Li-S batteries.

\subsection{Electrolytes}

Choosing appropriate electrolytes, including the chemical type, concentration, and volume (the thickness of solid-state electrolyte) for various $\mathrm{Li}-\mathrm{S}$ batteries systems plays an important role in developing commercial Li-S batteries. Currently, significant challenges remain for all ether-based electrolytes, carbonate-based electrolytes, and solid-sate electrolytes. For the choice of electrolytes, it would be better to weigh the pros and cons of different electrolytes in order to achieve high energy density, low cost, and improved safety. For ether-based electrolytes, especially for the most used DOL/DME (v/v, 1/1, LiTFSI as the Li salt) electrolyte, the shuttle effect of polysulfides has received great attention and been, to some extent, alleviated in last few years. However, the "disproportionation" of polysulfides, leading to irreversible capacity decay, has been largely ignored in coin cells with high $E / S$ ratios and should be emphasized, especially for the engineering of Li-S soft packages with low $E / S$ ratios [416]. Further optimization of the Li salt concentration and developing new Li salts are necessary to decrease the cost of electrolyte and improve both the gravimetric energy density and volumetric energy density. For carbonate-based electrolytes, the high active materials utilization and avoidance of "shuttle" effect are significant merits. The development of readily available high sulfur content cathodes is more realistic at this research stage. Of course, the electrochemical performance of high sulfur-loading cathodes in carbonate electrolytes coupled with low $E / S$ ratios also need to be developed at the same time. The potential safety hazards resulting from lithium dendrite formation in such liquid electrolytes (carbonate-based electrolytes and ether-based electrolytes) are still big stumbling blocks for commercialization of $\mathrm{Li}-\mathrm{S}$ batteries. Electrolyte additives used for stabilizing the Li surface and reducing side reactions between electrolytes/polysulfides and Li anode, as well as suppressing dendrite formation are still urgently needed.

More attention should be focused on the solid-state electrolyte systems to address the concerns of safety. Sulfidebased all-solid-state electrolytes, as one of the most promising candidates with high ionic conductivities at room temperature, shows great potential to be applied in $\mathrm{Li}-\mathrm{S}$ batteries. Currently, the high interfacial resistance and the capacity decay resulting from the side reactions between electrolytes and active materials are the primary issues in the all-solid-state systems. In the long-term, low $E / S$ ratio cathodes, ultra-thin and dense electrolytes should be further explored in order to achieve high energy densities comparable to liquid electrolytes. Also, aiming toward practical application, feasible and low-cost electrolyte synthesis methods are needed. Additionally, the instability in air and brittleness of the all-solid-state electrolytes put forward higher demands for transferring electrolytes and assembling batteries. Due to the low ionic conductivity of polymer-based electrolytes, most batteries need to be operated at high temperatures. More work should be concentrated on improving the ionic conductivity at lower temperatures, especially at room temperature.

\subsection{Anodes}

Despite the high discharge capacity and high energy density of metallic $\mathrm{Li}$, issues such as $\mathrm{Li}$ dendrite growth and side reactions with liquid electrolyte have become the most crucial 
bottlenecks of $\mathrm{Li}-\mathrm{S}$ systems. Recently, tremendous efforts and innovations have been concentrated on solving Li dendrite formation and great progress has been made in both cycling stability and rate performance. Some of them have demonstrated their positive effect on prolonging the cycling life of $\mathrm{Li}-\mathrm{S}$ batteries via suppressing the $\mathrm{Li}$ dendrite formation and side reactions between $\mathrm{Li}$ anode and electrolytes/polysulfides. However, the fundamental understanding of the SEI formation/ decomposition mechanism and the evolution of both structure and component during repetitive charge/discharge process are still inadequate. Furthermore, practical $\mathrm{Li}-\mathrm{S}$ batteries with high energy density and low cost should be coupled with high sulfur loading cathodes, low $E / S$ ratios and low Li excess percentage. The $\mathrm{Li}$ excess percentage should be optimized to balance the electrochemical performance and energy density. $\mathrm{Li}$ protection techniques need to be further investigated under the aforementioned conditions.

Overall, $\mathrm{Li}-\mathrm{S}$ batteries are promising energy storage devices but need to meet specific requirements before largescale production. Many factors affecting their performance and fabrication, such as gravimetric energy density, volumetric energy density, cost, cycle life, shelf life and safety, need to be addressed. Recently, there has been great progress on the efforts of improving energy density and cycling life, however, more detailed performance studies should be systemically investigated and structures should be designed for practical and commercial engineering targets. In other words, the commercialization of Li-S batteries is still far away. More studies in both fundamental research and technical development need to be done to help researchers gain a deeper understanding on the internal reaction mechanisms, develop new materials/ structures and technologies to achieve breakthroughs for the large-scale development of Li-S technology.

Acknowledgements This research was supported by the Natural Science and Engineering Research Council of Canada (NSERC), the Canada Research Chair Program (CRC), the Canada Foundation for Innovation (CFI), and the University of Western Ontario (UWO), National Natural Science Foundation of China (Nos. 51403209, 51677176, 51673199, 21406221, 51177156/E0712), Youth Innovation Promotion Association (2015148), Natural Sciences Foundation of Liaoning Province of China (2013020126), Youth Innovation Foundation of Dalian Institute of Chemical Physics (201307), Xiaofei Yang is supported by the Chinese Scholarship Council.

Open Access This article is distributed under the terms of the Creative Commons Attribution 4.0 International License (http://creativeco mmons.org/licenses/by/4.0/), which permits use, duplication, adaptation, distribution and reproduction in any medium or format, as long as you give appropriate credit to the original author(s) and the source, provide a link to the Creative Commons license and indicate if changes were made.

\section{References}

1. Liang, J., Sun, Z.H., Li, F., et al.: Carbon materials for Li-S batteries: functional evolution and performance improvement. Energy Storage Mater. 2, 76-106 (2016)

2. Bruce, P.G., Freunberger, S.A., Hardwick, L.J., et al.: Li-O and $\mathrm{Li}-\mathrm{S}$ batteries with high energy storage. Nat. Mater. 11, 19-29 (2012)

3. Li, Z., Huang, Y., Yuan, L., et al.: Status and prospects in sulfur-carbon composites as cathode materials for rechargeable lithium-sulfur batteries. Carbon 92, 41-63 (2015)

4. Zhang, S., Ueno, K., Dokko, K., et al.: Recent advances in electrolytes for lithium-sulfur batteries. Adv. Energy Mater. 5, 1500117 (2015)

5. Peng, H.J., Huang, J.Q., Zhang, Q.: A review of flexible lithium-sulfur and analogous alkali metal-chalcogen rechargeable batteries. Chem. Soc. Rev. 46, 5237-5288 (2017)

6. Ogoke, O., Wu, G., Wang, X., et al.: Effective strategies for stabilizing sulfur for advanced lithium-sulfur batteries. J. Mater. Chem. A 5, 448-469 (2017)

7. Xu, Z.L., Kim, J.K., Kang, K.: Carbon nanomaterials for advanced lithium sulfur batteries. Nano Today 19, 84-107 (2018)

8. Li, L., Chen, C., Yu, A.: New electrochemical energy storage systems based on metallic lithium anode-the research status, problems and challenges of lithium-sulfur, lithium-oxygen and all solid state batteries. Sci. China Chem. 60, 1402-1412 (2017)

9. Wang, T., Kretschmer, K., Choi, S., et al.: Fabrication methods of porous carbon materials and separator membranes for lithium-sulfur batteries: development and future perspectives. Small Methods 1, 1700089 (2017)

10. Zhang, G., Zhang, Z.W., Peng, H.J., et al.: A toolbox for lithium-sulfur battery research: methods and protocols. Small Methods 1, 1700134 (2017)

11. Zhou, W., Yu, Y., Chen, H., et al.: Yolk-shell structure of polyaniline-coated sulfur for lithium-sulfur batteries. J. Am. Chem. Soc. 135, 16736-16743 (2013)

12. Zhou, G., Pei, S., Li, L., et al.: A graphene-pure-sulfur sandwich structure for ultrafast, long-life lithium-sulfur batteries. Adv. Mater. 26, 625-631 (2014)

13. Yang, X., Yu, Y., Yan, N., et al.: 1-D oriented cross-linking hierarchical porous carbon fibers as a sulfur immobilizer for high performance lithium-sulfur batteries. J. Mater. Chem. A 4, 5965-5972 (2016)

14. Ji, X., Lee, K.T., Nazar, L.F.: A highly ordered nanostructured carbon-sulphur cathode for lithium-sulphur batteries. Nat. Mater. 8, 500-506 (2009)

15. Chen, H., Wang, C., Dong, W., et al.: Monodispersed sulfur nanoparticles for lithium-sulfur batteries with theoretical performance. Nano Lett. 15, 798-802 (2015)

16. Guo, Z., Zhang, B., Li, D., et al.: A mixed microporous/lowrange mesoporous composite with high sulfur loading from hierarchically-structured carbon for lithium-sulfur batteries. Electrochim. Acta 230, 181-188 (2017)

17. Papandrea, B., Xu, X., Xu, Y., et al.: Three-dimensional graphene framework with ultra-high sulfur content for a robust lithium-sulfur battery. Nano Res. 9, 240-248 (2016)

18. Miao, L.X., Wang, W.K., Wang, A.B., et al.: A high sulfur content composite with core-shell structure as cathode material for Li-S batteries. J. Mater. Chem. A 1, 11659-11664 (2013)

19. Pang, Q., Nazar, L.F.: Long-life and high-areal-capacity Li-s batteries enabled by a light-weight polar host with intrinsic polysulfide adsorption. ACS Nano 10, 4111-4118 (2016)

20. Lu, S., Cheng, Y., Wu, X., et al.: Significantly improved longcycle stability in high-rate $\mathrm{Li}-\mathrm{S}$ batteries enabled by coaxial 
graphene wrapping over sulfur-coated carbon nanofibers. Nano Lett. 13, 2485-2489 (2013)

21. Moon, S., Jung, Y.H., Jung, W.K., et al.: Encapsulated monoclinic sulfur for stable cycling of $\mathrm{Li}-\mathrm{S}$ rechargeable batteries. Adv. Mater. 25, 6547-6553 (2013)

22. Lv, D., Zheng, J., Li, Q., et al.: High energy density lithiumsulfur batteries: challenges of thick sulfur cathodes. Adv. Energy Mater. 5, 1402290 (2015)

23. Pope, M.A., Aksay, I.A.: Structural design of cathodes for Li-S batteries. Adv. Energy Mater. 5, 1500124 (2015)

24. Ma, Z., Li, Z., Hu, K., et al.: The enhancement of polysulfide absorbsion in $\mathrm{Li}-\mathrm{S}$ batteries by hierarchically porous $\mathrm{CoS}_{2} /$ carbon paper interlayer. J. Power Sources 325, 71-78 (2016)

25. Li, Z., Yin, L.: Nitrogen-doped MOF-derived micropores carbon as immobilizer for small sulfur molecules as a cathode for lithium sulfur batteries with excellent electrochemical performance. ACS Appl. Mater. Interfaces 7, 4029-4038 (2015)

26. Yang, X., Yan, N., Zhou, W., et al.: Sulfur embedded in onedimensional French fries-like hierarchical porous carbon derived from a metal-organic framework for high performance lithium-sulfur batteries. J. Mater. Chem. A 3, 15314-15323 (2015)

27. Yang, X., Dong, B., Zhang, H., et al.: Sulfur impregnated in a mesoporous covalent organic framework for high performance lithium-sulfur batteries. RSC Adv. 5, 86137-86143 (2015)

28. Liu, J., Sun, X.: Elegant design of electrode and electrode/electrolyte interface in lithium-ion batteries by atomic layer deposition. Nanotechnology 26, 024001 (2015)

29. Zhang, S.S.: Liquid electrolyte lithium/sulfur battery: fundamental chemistry, problems, and solutions. J. Power Sources 231, 153-162 (2013)

30. Zhang, S.S.: Sulfurized carbon: a class of cathode materials for high performance lithium/sulfur batteries. Front. Energy Res. 1, 10 (2013)

31. Yin, Y.X., Xin, S., Guo, Y.G., et al.: Lithium-sulfur batteries: electrochemistry, materials, and prospects. Angew. Chem. Int. Ed. 52, 13186-13200 (2013)

32. Wei Seh, Z., Li, W., Cha, J.J., et al.: Sulphur-TiO ${ }_{2}$ yolk-shell nanoarchitecture with internal void space for long-cycle lithiumsulphur batteries. Nat. Commun. 4, 1331 (2013)

33. Wang, D.W., Zeng, Q., Zhou, G., et al.: Carbon-sulfur composites for Li-S batteries: status and prospects. J. Mater. Chem. A 1, 9382-9394 (2013)

34. Helen, M., Reddy, M.A., Diemant, T., et al.: Single step transformation of sulphur to $\mathrm{Li}_{2} \mathrm{~S}_{2} / \mathrm{Li}_{2} \mathrm{~S}$ in Li-S batteries. Sci. Rep. 5 , 12146 (2015)

35. Zhang, K., Zhao, Q., Tao, Z., et al.: Composite of sulfur impregnated in porous hollow carbon spheres as the cathode of $\mathrm{Li}-\mathrm{S}$ batteries with high performance. Nano Res. 6, 38-46 (2013)

36. Kim, J.S., Kim, D.W., Jung, H.T., et al.: Controlled lithium dendrite growth by a synergistic effect of multilayered graphene coating and an electrolyte additive. Chem. Mater. 27, 2780-2787 (2015)

37. Jozwiuk, A., Berkes, B.B., Weiß, T., et al.: The critical role of lithium nitrate in the gas evolution of lithium-sulfur batteries. Energy Environ. Sci. 9, 2603-2608 (2016)

38. Cheng, X.B., Hou, T.Z., Zhang, R., et al.: Dendrite-free lithium deposition induced by uniformly distributed lithium ions for efficient lithium metal batteries. Adv. Mater. 28, 2888-2895 (2016)

39. Hagen, M., Hanselmann, D., Ahlbrecht, K., et al.: Lithium-sulfur cells: the gap between the state-of-the-art and the requirements for high energy battery cells. Adv. Energy Mater. 5, 1401986 (2015)

40. Fang, R., Zhao, S., Sun, Z., et al.: More reliable lithium-sulfur batteries: status, solutions and prospects. Adv. Mater. 29, 1606823 (2017)
41. Peng, H.J., Huang, J.Q., Cheng, X.B., et al.: Review on highloading and high-energy lithium-sulfur batteries. Adv. Energy Mater. 7, 1700260 (2017)

42. Peng, H.J., Xu, W.T., Zhu, L., et al.: 3D carbonaceous current collectors: the origin of enhanced cycling stability for highsulfur-loading lithium-sulfur batteries. Adv. Funct. Mater. 26, 6351-6358 (2016)

43. Yu, M., Ma, J., Xie, M., et al.: Freestanding and sandwichstructured electrode material with high areal mass loading for long-life lithium-sulfur batteries. Adv. Energy Mater. 7, 1602347 (2017)

44. Mi, Y., Liu, W., Wang, Q., et al.: A pomegranate-structured sulfur cathode material with triple confinement of lithium polysulfides for high-performance lithium-sulfur batteries. J. Mater. Chem. A 5, 11788-11793 (2017)

45. Hwang, J.Y., Kim, H.M., Sun, Y.K.: Controlling the wettability between freestanding electrode and electrolyte for high energy density lithium-sulfur batteries. J. Electrochem. Soc. 165, A5006-A5013 (2018)

46. Li, H., Tao, Y., Zhang, C., et al.: Dense graphene monolith for high volumetric energy density Li-S batteries. Adv. Energy Mater (2018). https://doi.org/10.1002/aenm.201703438

47. Cheng, X.B., Huang, J.Q., Zhang, Q., et al.: Aligned carbon nanotube/sulfur composite cathodes with high sulfur content for lithium-sulfur batteries. Nano Energy 4, 65-72 (2014)

48. Eroglu, D., Zavadil, K.R., Gallagher, K.G.: Critical link between materials chemistry and cell-level design for high energy density and low cost lithium-sulfur transportation battery. J. Electrochem. Soc. 162, A982-A990 (2015)

49. Chen, Y., Yang, X., Yu, Y., et al.: Key materials and technology research progress of lithium-sulfur batteries. Energy Storage Sci. Tech. 6, 169-189 (2017)

50. Wu, J., Liu, P., Hu, Y., et al.: Calculation on energy densities of lithium ion batteries and metallic lithium ion batteries. Energy Storage Sci. Technol. 5, 443-453 (2016)

51. Liang, C., Dudney, N.J., Howe, J.Y.: Hierarchically structured sulfur/carbon nanocomposite material for high-energy lithium battery. Chem. Mater. 21, 4724-4730 (2009)

52. Agrawal, M., Choudhury, S., Gruber, K., et al.: Porous carbon materials for $\mathrm{Li}-\mathrm{S}$ batteries based on resorcinol-formaldehyde resin with inverse opal structure. J. Power Sources 261, 363-370 (2014)

53. Wang, M., Zhang, H., Wang, Q., et al.: Steam-etched spherical carbon/sulfur composite with high sulfur capacity and long cycle life for Li/S battery application. ACS Appl. Mater. Interfaces 7, 3590-3599 (2015)

54. Li, G., Sun, J., Hou, W., et al.: Three-dimensional porous carbon composites containing high sulfur nanoparticle content for highperformance lithium-sulfur batteries. Nat. Commun. 7, 10601 (2016)

55. Li, X., Sun, Q., Liu, J., et al.: Tunable porous structure of metal organic framework derived carbon and the application in lithium-sulfur batteries. J. Power Sources 302, 174-179 (2016)

56. Wang, M., Zhang, H., Zhou, W., et al.: Rational design of a nested pore structure sulfur host for fast $\mathrm{Li} / \mathrm{S}$ batteries with a long cycle life. J. Mater. Chem. A 4, 1653-1662 (2016)

57. Peng, X.X., Lu, Y.Q., Zhou, L.L., et al.: Graphitized porous carbon materials with high sulfur loading for lithium-sulfur batteries. Nano Energy 32, 503-510 (2017)

58. Sun, Q., He, B., Zhang, X.Q., et al.: Engineering of hollow coreshell interlinked carbon spheres for highly stable lithium-sulfur batteries. ACS Nano 9, 8504-8513 (2015)

59. Zheng, G., Yang, Y., Cha, J.J., et al.: Hollow carbon nanofiberencapsulated sulfur cathodes for high specific capacity rechargeable lithium batteries. Nano Lett. 11, 4462-4467 (2011) 
60. Fu, Y., Manthiram, A.: Core-shell structured sulfur-polypyrrole composite cathodes for lithium-sulfur batteries. RSC Adv. 2, 5927-5929 (2012)

61. Chen, H., Dong, W., Ge, J., et al.: Ultrafine sulfur nanoparticles in conducting polymer shell as cathode materials for high performance lithium/sulfur batteries. Sci. Rep. 3, 1910 (2013)

62. Wang, C., Wan, W., Chen, J.T., et al.: Dual core-shell structured sulfur cathode composite synthesized by a one-pot route for lithium sulfur batteries. J. Mater. Chem. A 1, 1716-1723 (2013)

63. Wang, M., Wang, W., Wang, A., et al.: A multi-core-shell structured composite cathode material with a conductive polymer network for Li-S batteries. Chem. Commun. 49, 10263-10265 (2013)

64. Zhang, Y., Zhao, Y., Konarov, A., et al.: One-pot approach to synthesize PPy@S core-shell nanocomposite cathode for Li/S batteries. J. Nanoparticle Res. 15, 2007 (2013)

65. Ma, G., Wen, Z., Jin, J., et al.: Hollow polyaniline sphere @ sulfur composites for prolonged cycling stability of lithium-sulfur batteries. J. Mater. Chem. A 2, 10350-10354 (2014)

66. Zhou, W., Xiao, X., Cai, M., et al.: Polydopamine-coated, nitrogen-doped, hollow carbon-sulfur double-layered core-shell structure for improving lithium-sulfur batteries. Nano Lett. 14, 5250-5256 (2014)

67. Li, Z., Zhang, J., Lou, X.W.: Hollow carbon nanofibers filled with $\mathrm{MnO}_{2}$ nanosheets as efficient sulfur hosts for lithium-sulfur batteries. Angew. Chem. Int. Ed. 54, 12886-12890 (2015)

68. Li, Z., Zhang, J.T., Chen, Y.M., et al.: Pie-like electrode design for high-energy density lithium-sulfur batteries. Nat. Commun. 6, $8850(2015)$

69. Zhang, J., Yang, N., Yang, X., et al.: Hollow sulfur@graphene oxide core-shell composite for high-performance $\mathrm{Li}-\mathrm{S}$ batteries. J. Alloys Compd. 650, 604-609 (2015)

70. Li, X., Chu, L., Wang, Y., et al.: Anchoring function for polysulfide ions of ultrasmall $\mathrm{SnS}_{2}$ in hollow carbon nanospheres for high performance lithium-sulfur batteries. Mater. Sci. Eng. B 205, 46-54 (2016)

71. Li, Z., Zhang, J., Guan, B., et al.: A sulfur host based on titanium monoxide@carbon hollow spheres for advanced lithium-sulfur batteries. Nat. Commun. 7, 13065 (2016)

72. Zhang, J., Hu, H., Li, Z., et al.: Double-shelled nanocages with cobalt hydroxide inner shell and layered double hydroxides outer shell as high-efficiency polysulfide mediator for lithium-sulfur batteries. Angew. Chem. Int. Ed. 55, 3982-3986 (2016)

73. Chiochan, P., Phattharasupakun, N., Wutthiprom, J., et al.: Coredouble shell sulfur@carbon black nanosphere@ oxidized carbon nanosheet composites as the cathode materials for $\mathrm{Li}-\mathrm{S}$ batteries. Electrochim. Acta 237, 78-86 (2017)

74. Xu, H., Manthiram, A.: Hollow cobalt sulfide polyhedra-enabled long-life, high areal-capacity lithium-sulfur batteries. Nano Energy 33, 124-129 (2017)

75. Yang, Y., Yu, G., Cha, J.J., et al.: Improving the performance of lithium-sulfur batteries by conductive polymer coating. ACS Nano 5, 9187-9193 (2011)

76. Ai, W., Zhou, W., Du, Z., et al.: Nitrogen and phosphorus codoped hierarchically porous carbon as an efficient sulfur host for Li-S batteries. Energy Storage Mater. 6, 112-118 (2017)

77. Cai, W., Zhou, J., Li, G., et al.: B, N-co-doped graphene supported sulfur for superior stable $\mathrm{Li}-\mathrm{S}$ half cell and $\mathrm{Ge}-\mathrm{S}$ full battery. ACS Appl. Mater. Interfaces 8, 27679-27687 (2016)

78. Gu, X., Tong, C.J., Lai, C., et al.: A porous nitrogen and phosphorous dual doped graphene blocking layer for high performance Li-S batteries. J. Mater. Chem. A 3, 16670-16678 (2015)

79. Kim, K.Y., Jung, Y., Kim, S.: Study on urea precursor effect on the electroactivities of nitrogen-doped graphene nanosheets electrodes for lithium cells. Carbon Lett. 19, 40-46 (2016)
80. Liu, X., Huang, W., Wang, D., et al.: A nitrogen-doped 3D hierarchical carbon/sulfur composite for advanced lithium sulfur batteries. J. Power Sources 355, 211-218 (2017)

81. Song, J., Yu, Z., Gordin, M.L., et al.: Advanced sulfur cathode enabled by highly crumpled nitrogen-doped graphene sheets for high-energy-density lithium-sulfur batteries. Nano Lett. 16, 864-870 (2016)

82. Wu, F., Li, J., Tian, Y., et al.: 3D coral-like nitrogen-sulfur codoped carbon-sulfur composite for high performance lithiumsulfur batteries. Sci. Rep. 5, 13340 (2015)

83. Wu, H., Huang, Y., Xu, S., et al.: Fabricating three-dimensional hierarchical porous $\mathrm{N}$-doped graphene by a tunable assembly method for interlayer assisted lithium-sulfur batteries. Chem. Eng. J. 327, 855-867 (2017)

84. Wu, X., Fan, L., Wang, M., et al.: Long-life lithium-sulfur battery derived from nori-based nitrogen and oxygen dual-doped 3D hierarchical biochar. ACS Appl. Mater. Interfaces 9, 1888918896 (2017)

85. Zegeye, T.A., Tsai, M.C., Cheng, J.H., et al.: Controllable embedding of sulfur in high surface area nitrogen doped three dimensional reduced graphene oxide by solution drop impregnation method for high performance lithium-sulfur batteries. J. Power Sources 353, 298-311 (2017)

86. Zhang, M., Yu, C., Yang, J., et al.: Nitrogen-doped tubular/porous carbon channels implanted on graphene frameworks for multiple confinement of sulfur and polysulfides. J. Mater. Chem. A 5, 10380-10386 (2017)

87. Zhao, Y., Bakenova, Z., Zhang, Y., et al.: High performance sulfur/nitrogen-doped graphene cathode for lithium/sulfur batteries. Ionics 21, 1925-1930 (2015)

88. Zhou, G., Paek, E., Hwang, G.S., et al.: Long-life Li/polysulphide batteries with high sulphur loading enabled by lightweight three-dimensional nitrogen/sulphur-codoped graphene sponge. Nat. Commun. 6, 7760 (2015)

89. Zhou, X., Liao, Q., Bai, T., et al.: Rational design of graphene @ nitrogen and phosphorous dual-doped porous carbon sandwichtype layer for advanced lithium-sulfur batteries. J. Mater. Sci. 52, 7719-7732 (2017)

90. Liu, J., Li, W., Duan, L., et al.: A graphene-like oxygenated carbon nitride material for improved cycle-life lithium/sulfur batteries. Nano Lett. 15, 5137-5142 (2015)

91. Chang, Z., Dou, H., Ding, B., et al.: $\mathrm{Co}_{3} \mathrm{O}_{4}$ nanoneedle arrays as a multifunctional "super-reservoir" electrode for long cycle life Li-S batteries. J. Mater. Chem. A 5, 250-257 (2017)

92. Dirlam, P.T., Park, J., Simmonds, A.G., et al.: Elemental sulfur and molybdenum disulfide composites for $\mathrm{Li}-\mathrm{S}$ batteries with long cycle life and high-rate capability. ACS Appl. Mater. Interfaces 8, 13437-13448 (2016)

93. Hwang, J.Y., Kim, H.M., Lee, S.K., et al.: High-energy, highrate, lithium-sulfur batteries: synergetic effect of Hollow $\mathrm{TiO}_{2}$-webbed carbon nanotubes and a dual functional carbonpaper interlayer. Adv. Energy Mater. 6, 1501480 (2016)

94. Li, W., Hicks-Garner, J., Wang, J., et al.: $\mathrm{V}_{2} \mathrm{O}_{5}$ polysulfide anion barrier for long-lived Li-S batteries. Chem. Mater. 26, 34033410 (2014)

95. Li, X., Lu, Y., Hou, Z., et al.: $\mathrm{SnS}_{2}$-compared to $\mathrm{SnO}_{2}$-stabilized $\mathrm{S} / \mathrm{C}$ composites toward high-performance lithium sulfur batteries. ACS Appl. Mater. Interfaces 8, 19550-19557 (2016)

96. Li, Y., Cai, Q., Wang, L., et al.: Mesoporous $\mathrm{TiO}_{2}$ nanocrystals/ graphene as an efficient sulfur host material for high-performance lithium-sulfur batteries. ACS Appl. Mater. Interfaces 8, 23784 $23792(2016)$

97. Li, Y., Ye, D., Liu, W., et al.: A $\mathrm{MnO}_{2}$ /graphene oxide/multiwalled carbon nanotubes-sulfur composite with dual-efficient polysulfide adsorption for improving lithium-sulfur batteries. ACS Appl. Mater. Interfaces 8, 28566-28573 (2016) 
98. Liang, X., Hart, C., Pang, Q., et al.: A highly efficient polysulfide mediator for lithium-sulfur batteries. Nat. Commun. 6, 5682 (2015)

99. Pang, Q., Kundu, D., Cuisinier, M., et al.: Surface-enhanced redox chemistry of polysulphides on a metallic and polar host for lithium-sulphur batteries. Nat. Commun. 5, 4759 (2014)

100. Yu, M., Ma, J., Song, H., et al.: Atomic layer deposited $\mathrm{TiO}_{2}$ on a nitrogen-doped graphene/sulfur electrode for high performance lithium-sulfur batteries. Energy Environ. Sci. 9, 1495-1503 (2016)

101. Yuan, Z., Peng, H.J., Hou, T.Z., et al.: Powering lithium-sulfur battery performance by propelling polysulfide redox at sulfiphilic hosts. Nano Lett. 16, 519-527 (2016)

102. Zheng, C., Niu, S., Lv, W., et al.: Propelling polysulfides transformation for high-rate and long-life lithium-sulfur batteries. Nano Energy 33, 306-312 (2017)

103. Zhou, T., Lv, W., Li, J., et al.: Twinborn $\mathrm{TiO}_{2}-\mathrm{TiN}$ heterostructures enabling smooth trapping-diffusion-conversion of polysulfides towards ultralong life lithium-sulfur batteries. Energy Environ. Sci. 10, 1694-1703 (2017)

104. Al Salem, H., Babu, G., Rao, C.V., et al.: Electrocatalytic polysulfide traps for controlling redox shuttle process of $\mathrm{Li}-\mathrm{S}$ batteries. J. Am. Chem. Soc. 137, 11542-11545 (2015)

105. Zhang, Q., Wang, Y., Seh, Z.W., et al.: Understanding the anchoring effect of two-dimensional layered materials for lithium-sulfur batteries. Nano Lett. 15, 3780-3786 (2015)

106. Fang, X., Peng, H.: A revolution in electrodes: recent progress in rechargeable lithium-sulfur batteries. Small 11, 1488-1511 (2015)

107. Gu, X., Zhang, S., Hou, Y.: Graphene-based sulfur composites for energy storage and conversion in $\mathrm{Li}-\mathrm{S}$ batteries. Chin. J. Chem. 34, 13-31 (2016)

108. Imtiaz, S., Zhang, J., Zafar, Z.A., et al.: Biomass-derived nanostructured porous carbons for lithium-sulfur batteries. Sci. China Mater. 59, 389-407 (2016)

109. Lee, S.K., Lee, Y.J., Sun, Y.K.: Nanostructured lithium sulfide materials for lithium-sulfur batteries. J. Power Sources 323, 174-188 (2016)

110. Li, Z., Wu, H.B., Lou, X.W.: Rational designs and engineering of hollow micro-/nanostructures as sulfur hosts for advanced lithium-sulfur batteries. Energy Environ. Sci. 9, 3061-3070 (2016)

111. Liu, M., Ye, F., Li, W., et al.: Chemical routes toward long-lasting lithium/sulfur cells. Nano Res. 9, 94-116 (2016)

112. Liu, X., Huang, J.Q., Zhang, Q., et al.: Nanostructured metal oxides and sulfides for lithium-sulfur batteries. Adv. Mater. 29, 1601759 (2017)

113. Pang, Q., Liang, X., Kwok, C.Y., et al.: Review-the importance of chemical interactions between sulfur host materials and lithium polysulfides for advanced lithium-sulfur batteries. J. Electrochem. Soc. 162, A2567-A2576 (2015)

114. Wang, J.G., Xie, K., Wei, B.: Advanced engineering of nanostructured carbons for lithium-sulfur batteries. Nano Energy 15, 413-444 (2015)

115. Wu, S., Ge, R., Lu, M., et al.: Graphene-based nano-materials for lithium-sulfur battery and sodium-ion battery. Nano Energy 15, 379-405 (2015)

116. Zhang, J., Gu, P., Xu, J., et al.: High performance of electrochemical lithium storage batteries: $\mathrm{ZnO}$-based nanomaterials for lithium-ion and lithium-sulfur batteries. Nanoscale 8, 1857818595 (2016)

117. Zhang, S.S.: Heteroatom-doped carbons: synthesis, chemistry and application in lithium/sulphur batteries. Inorg. Chem. Front. 2, 1059-1069 (2015)

118. Li, X., Sun, X.: Nitrogen-doped carbons in Li-S batteries: materials design and electrochemical mechanism. Front. Energy Res. 2, 49 (2014)
119. Barré, A., Deguilhem, B., Grolleau, S., et al.: A review on lithium-ion battery ageing mechanisms and estimations for automotive applications. J. Power Sources 241, 680-689 (2013)

120. Lu, L., Han, X., Li, J., et al.: A review on the key issues for lithium-ion battery management in electric vehicles. J. Power Sources 226, 272-288 (2013)

121. Goodenough, J.B., Kim, Y.: Challenges for rechargeable batteries. J. Power Sources 196, 6688-6694 (2011)

122. Song, R., Fang, R., Wen, L., et al.: A trilayer separator with dual function for high performance lithium-sulfur batteries. J. Power Sources 301, 179-186 (2016)

123. Barchasz, C., Leprêtre, J.C., Patoux, S., et al.: Electrochemical properties of ether-based electrolytes for lithium/sulfur rechargeable batteries. Electrochim. Acta 89, 737-743 (2013)

124. Yim, T., Park, M.S., Yu, J.S., et al.: Effect of chemical reactivity of polysulfide toward carbonate-based electrolyte on the electrochemical performance of $\mathrm{Li}-\mathrm{S}$ batteries. Electrochim. Acta 107, 454-460 (2013)

125. Gao, J., Lowe, M.A., Kiya, Y., et al.: Effects of liquid electrolytes on the charge-discharge performance of rechargeable lithium/sulfur batteries: electrochemical and in-situ X-ray absorption spectroscopic studies. J. Phys. Chem. C 115, 25132-25137 (2011)

126. Xin, S., Gu, L., Zhao, N.H., et al.: Smaller sulfur molecules promise better lithium-sulfur batteries. J. Am. Chem. Soc. 134, 18510-18513 (2012)

127. Fanous, J., Wegner, M., Grimminger, J., et al.: Structurerelated electrochemistry of sulfur-poly(acrylonitrile) composite cathode materials for rechargeable lithium batteries. Chem. Mater. 23, 5024-5028 (2011)

128. Xu, Z., Wang, J., Yang, J., et al.: Enhanced performance of a lithium-sulfur battery using a carbonate-based electrolyte. Angew. Chem. Int. Ed. 55, 10372-10375 (2016)

129. Li, X., Lushington, A., Sun, Q., et al.: Safe and durable hightemperature lithium-sulfur batteries via molecular layer deposited coating. Nano Lett. 16, 3545-3549 (2016)

130. Zheng, W., Liu, Y.W., Hu, X.G., et al.: Novel nanosized adsorbing sulfur composite cathode materials for the advanced secondary lithium batteries. Electrochim. Acta 51, 1330-1335 (2006)

131. Lai, C., Gao, X.P., Zhang, B., et al.: Synthesis and electrochemical performance of sulfur/highly porous carbon composites. J. Phys. Chem. C 113, 4712-4716 (2009)

132. Zhang, B., Qin, X., Li, G.R., et al.: Enhancement of long stability of sulfur cathode by encapsulating sulfur into micropores of carbon spheres. Energy Environ. Sci. 3, 1531-1537 (2010)

133. Yang, C.P., Yin, Y.X., Guo, Y.G., et al.: Electrochemical (de) lithiation of 1D sulfur chains in Li-S batteries: a model system study. J. Am. Chem. Soc. 137, 2215-2218 (2015)

134. Wu, H.B., Wei, S., Zhang, L., et al.: Embedding sulfur in MOFderived microporous carbon polyhedrons for lithium-sulfur batteries. Chem. Eur. J. 19, 10804-10808 (2013)

135. Zhang, W., Qiao, D., Pan, J., et al.: $\mathrm{A} \mathrm{Li}^{+}$-conductive microporous carbon-sulfur composite for $\mathrm{Li}-\mathrm{S}$ batteries. Electrochim. Acta 87, 497-502 (2013)

136. Niu, S., Zhou, G., Lv, W., et al.: Sulfur confined in nitrogendoped microporous carbon used in a carbonate-based electrolyte for long-life, safe lithium-sulfur batteries. Carbon 109, 1-6 (2016)

137. $\mathrm{Hu}, \mathrm{L} ., \mathrm{Lu}, \mathrm{Y} ., \mathrm{Li}, \mathrm{X}$., et al.: Optimization of microporous carbon structures for lithium-sulfur battery applications in carbonatebased electrolyte. Small 13, 1603533 (2017)

138. Hu, L., Lu, Y., Zhang, T., et al.: Ultramicroporous carbon through an activation-free approach for $\mathrm{Li}-\mathrm{S}$ and $\mathrm{Na}-\mathrm{S}$ batteries in carbonate-based electrolyte. ACS Appl. Mater. Interfaces 9, 13813-13818 (2017) 
139. Zhu, Q., Zhao, Q., An, Y., et al.: Ultra-microporous carbons encapsulate small sulfur molecules for high performance lithium-sulfur battery. Nano Energy 33, 402-409 (2017)

140. Du, W.C., Zhang, J., Yin, Y.X., et al.: Sulfur confined in subnanometer-sized 2D graphene interlayers and its electrochemical behavior in lithium-sulfur batteries. Chem. Asian J. 11, 26902694 (2016)

141. Fu, C., Wong, B.M., Bozhilov, K.N., et al.: Solid state lithiation-delithiation of sulphur in sub-nano confinement: a new concept for designing lithium-sulphur batteries. Chem. Sci. 7, 1224-1232 (2016)

142. Markevich, E., Salitra, G., Talyosef, Y., et al.: Review-on the mechanism of quasi-solid-state lithiation of sulfur encapsulated in microporous carbons: is the existence of small sulfur molecules necessary? J. Electrochem. Soc. 164, A6244-A6253 (2017)

143. Li, Z., Yuan, L., Yi, Z., Sun, Y., Liu, Y., Jiang, Y., Shen, Y., Xin, Y., Zhang, Z., Huang, Y.: Insight into the electrode mechanism in lithium-sulfur batteries with ordered microporous carbon confined sulfur as the cathode. Adv. Energy Mater. 4(7), 1301473 (2014)

144. Li, X., Liang, J., Zhang, K., et al.: Amorphous S-rich $\mathrm{S}_{1-x} \mathrm{Se}_{x} / \mathrm{C}$ $(x \leq 0.1)$ composites promise better lithium-sulfur batteries in a carbonate-based electrolyte. Energy Environ. Sci. 8, 3181-3186 (2015)

145. Zheng, S., Yi, F., Li, Z., et al.: Copper-stabilized sulfur-microporous carbon cathodes for Li-S batteries. Adv. Funct. Mater. 24, 4156-4163 (2014)

146. Wang, D.W., Zhou, G., Li, F., et al.: A microporous-mesoporous carbon with graphitic structure for a high-rate stable sulfur cathode in carbonate solvent-based Li-S batteries. Phys. Chem. Chem. Phys. 14, 8703-8710 (2012)

147. Li, G., Jing, H., Li, H., et al.: Sulfur/microporous carbon composites for Li-S battery. Ionics 21, 2161-2170 (2015)

148. Wang, J., Yang, J., Xie, J., et al.: A novel conductive polymersulfur composite cathode material for rechargeable lithium batteries. Adv. Mater. 14, 963-965 (2002)

149. Wang, L., He, X., Li, J., et al.: Charge/discharge characteristics of sulfurized polyacrylonitrile composite with different sulfur content in carbonate based electrolyte for lithium batteries. Electrochim. Acta 72, 114-119 (2012)

150. Luo, C., Zhu, Y., Wen, Y., et al.: Carbonized polyacrylonitrilestabilized $\mathrm{S}_{\mathrm{e}} \mathrm{S}_{x}$ cathodes for long cycle life and high power density lithium ion batteries. Adv. Funct. Mater. 24, 4082-4089 (2014)

151. Chen, H., Wang, C., Hu, C., et al.: Vulcanization accelerator enabled sulfurized carbon materials for high capacity and high stability of lithium-sulfur batteries. J. Mater. Chem. A 3, 1392$1395(2015)$

152. Ye, J., He, F., Nie, J., et al.: Sulfur/carbon nanocomposite-filled polyacrylonitrile nanofibers as a long life and high capacity cathode for lithium-sulfur batteries. J. Mater. Chem. A 3, 7406-7412 (2015)

153. Frey, M., Zenn, R.K., Warneke, S., et al.: Easily accessible, textile fiber-based sulfurized poly(acrylonitrile) as $\mathrm{Li} / \mathrm{S}$ cathode material: correlating electrochemical performance with morphology and structure. ACS Energy Lett. 2, 595-604 (2017)

154. Lin, F., Wang, J., Jia, H., et al.: Nonflammable electrolyte for rechargeable lithium battery with sulfur based composite cathode materials. J. Power Sources 223, 18-22 (2013)

155. Wu, B., Chen, F., Mu, D., et al.: Cycleability of sulfurized polyacrylonitrile cathode in carbonate electrolyte containing lithium metasilicate. J. Power Sources 278, 27-31 (2015)

156. Zheng, S., Han, P., Han, Z., et al.: High performance C/S composite cathodes with conventional carbonate-based electrolytes in Li-S battery. Sci. Rep. 4, 4842 (2014)
157. Xu, Y., Wen, Y., Zhu, Y., et al.: Confined sulfur in microporous carbon renders superior cycling stability in $\mathrm{Li} / \mathrm{S}$ batteries. Adv. Funct. Mater. 25, 4312-4320 (2015)

158. Wei, S., Ma, L., Hendrickson, K.E., et al.: Metal-sulfur battery cathodes based on PAN-sulfur composites. J. Am. Chem. Soc. 137, 12143-12152 (2015)

159. Wang, M., Zhang, H., Zhou, W., et al.: Rational design of a nested pore structure sulfur host for fast $\mathrm{Li} / \mathrm{S}$ batteries with a long cycle life. J. Mater. Chem. A. 4, 1653-1662 (2016)

160. Zhong, Y., Wang, S., Sha, Y., et al.: Trapping sulfur in hierarchically porous, hollow indented carbon spheres: a high-performance cathode for lithium-sulfur batteries. J. Mater. Chem. A. 4, 9526-9535 (2016)

161. Yang, X., Chen, Y., Wang, M., et al.: Phase inversion: a universal method to create high-performance porous electrodes for nanoparticle-based energy storage devices. Adv. Funct. Mater. 26, 8427-8434 (2016)

162. Yang, X., Zhang, H., Chen, Y., et al.: Shapeable electrodes with extensive materials options and ultra-high loadings for energy storage devices. Nano Energy 39, 418-428 (2017)

163. Fang, R., Zhao, S., Hou, P., et al.: 3D interconnected electrode materials with ultrahigh areal sulfur loading for $\mathrm{Li}-\mathrm{S}$ batteries. Adv. Mater. 28, 3374-3382 (2016)

164. Ma, Y., Zhang, H., Wu, B., et al.: Lithium sulfur primary battery with super high energy density: based on the cauliflower-like structured C/S cathode. Sci. Rep. 5, 14949 (2015)

165. Ye, Y., Wu, F., Liu, Y., et al.: Toward practical high-energy batteries: a modular-assembled oval-like carbon microstructure for thick sulfur electrodes. Adv. Mater. 29, 1700598 (2017)

166. Zeng, F., Wang, A., Wang, W., et al.: Strategies of constructing stable and high sulfur loading cathodes based on the bladecasting technique. J. Mater. Chem. A 5, 12879-12888 (2017)

167. Song, J., Gordin, M.L., Xu, T., et al.: Strong lithium polysulfide chemisorption on electroactive sites of nitrogen-doped carbon composites for high-performance lithium-sulfur battery cathodes. Angew. Chem. Int. Ed. 54, 4325-4329 (2015)

168. Bhattacharya, P., Nandasiri, M.I., Lv, D., et al.: Polyamidoamine dendrimer-based binders for high-loading lithium-sulfur battery cathodes. Nano Energy 19, 176-186 (2016)

169. Zeng, F., Wang, W., Wang, A., et al.: Multidimensional polycation beta-cyclodextrin polymer as an effective aqueous binder for high sulfur loading cathode in lithium-sulfur batteries. ACS Appl. Mater. Interfaces 7, 26257-26265 (2015)

170. $\mathrm{Hu}, \mathrm{G} ., \mathrm{Xu}, \mathrm{C}$., Sun, Z., et al.: 3D graphene-foam-reducedgraphene-oxide hybrid nested hierarchical networks for highperformance Li-S batteries. Adv. Mater. 28, 1603-1609 (2016)

171. Li, G., Wang, C., Cai, W., et al.: The dual actions of modified polybenzimidazole in taming the polysulfide shuttle for long-life lithium-sulfur batteries. NPG Asia Mater. 8, e317 (2016)

172. Liu, J., Galpaya, D.G.D., Yan, L., et al.: Exploiting a robust biopolymer network binder for an ultrahigh-areal-capacity $\mathrm{Li}-\mathrm{S}$ battery. Energy Environ. Sci. 10, 750-755 (2017)

173. Zhang, H., Zhang, H., Li, X., et al.: Nanofiltration (NF) membranes: the next generation separators for all vanadium redox flow batteries (VRBs)? Energy Environ. Sci. 4, 1676 (2011)

174. Zhao, Y., Li, M., Yuan, Z., et al.: Advanced charged sponge-like membrane with ultrahigh stability and selectivity for vanadium flow batteries. Adv. Funct. Mater. 26, 210-218 (2016)

175. Elazari, R., Salitra, G., Garsuch, A., et al.: Sulfur-impregnated activated carbon fiber cloth as a binder-free cathode for rechargeable Li-S batteries. Adv. Mater. 23, 5641-5644 (2011)

176. Miao, L., Wang, W., Yuan, K., et al.: A lithium-sulfur cathode with high sulfur loading and high capacity per area: a binderfree carbon fiber cloth-sulfur material. Chem. Commun. 50, 13231-13234 (2014) 
177. Qiu, Y., Li, W., Zhao, W., et al.: High-rate, ultralong cycle-life lithium/sulfur batteries enabled by nitrogen-doped graphene. Nano Lett. 14, 4821-4827 (2014)

178. Nitze, F., Agostini, M., Lundin, F., et al.: A binder-free sulfur/ reduced graphene oxide aerogel as high performance electrode materials for lithium sulfur batteries. Sci. Rep. 6, 39615 (2016)

179. Chung, S.H., Chang, C.H., Manthiram, A.: A carbon-cotton cathode with ultrahigh-loading capability for statically and dynamically stable lithium-sulfur batteries. ACS Nano 10, 10462-10470 (2016)

180. Yuan, Z., Peng, H.J., Huang, J.Q., et al.: Hierarchical freestanding carbon-nanotube paper electrodes with ultrahigh sulfur-loading for lithium-sulfur batteries. Adv. Funct. Mater. 24, 6105-6112 (2014)

181. Lu, S., Chen, Y., Wu, X., et al.: Three-dimensional sulfur/graphene multifunctional hybrid sponges for lithium-sulfur batteries with large areal mass loading. Sci. Rep. 4, 4629 (2014)

182. Sun, Q., Fang, X., Weng, W., et al.: An aligned and laminated nanostructured carbon hybrid cathode for high-performance lithium-sulfur batteries. Angew. Chem. Int. Ed. 54, 10539-10544 (2015)

183. Liu, F., Xiao, Q., Wu, H.B., et al.: Regenerative polysulfide-scavenging layers enabling lithium-sulfur batteries with high energy density and prolonged cycling life. ACS Nano 11, 2697-2705 (2017)

184. Zu, C., Manthiram, A.: High-performance Li/dissolved polysulfide batteries with an advanced cathode structure and high sulfur content. Adv. Energy Mater. 4, 1400897 (2014)

185. Song, J., Yu, Z., Xu, T., et al.: Flexible freestanding sandwichstructured sulfur cathode with superior performance for lithiumsulfur batteries. J. Mater. Chem. A 2, 8623-8627 (2014)

186. Qie, L., Manthiram, A.: A facile layer-by-layer approach for high-areal-capacity sulfur cathodes. Adv. Mater. 27, 1694-1700 (2015)

187. Fang, R., Zhao, S., Pei, S., et al.: Toward more reliable lithiumsulfur batteries: an all-graphene cathode structure. ACS Nano 10, 8676-8682 (2016)

188. Pang, Q., Liang, X., Kwok, C.Y., et al.: Advances in lithium-sulfur batteries based on multifunctional cathodes and electrolytes. Nat Energy 1, 16132 (2016)

189. Zhou, G., Li, L., Ma, C., et al.: A graphene foam electrode with high sulfur loading for flexible and high energy $\mathrm{Li}-\mathrm{S}$ batteries. Nano Energy 11, 356-365 (2015)

190. Zhang, S.S., Tran, D.T.: A proof-of-concept lithium/sulfur liquid battery with exceptionally high capacity density. J. Power Sources 211, 169-172 (2012)

191. Han, X., Xu, Y., Chen, X., et al.: Reactivation of dissolved polysulfides in $\mathrm{Li}-\mathrm{S}$ batteries based on atomic layer deposition of $\mathrm{Al}_{2} \mathrm{O}_{3}$ in nanoporous carbon cloth. Nano Energy 2, 1197-1206 (2013)

192. Xu, T., Song, J., Gordin, M.L., et al.: Mesoporous carbon-carbon nanotube-sulfur composite microspheres for high-areal-capacity lithium-sulfur battery cathodes. ACS Appl. Mater. Interfaces 5, 11355-11362 (2013)

193. Zhou, W., Chen, H., Yu, Y., et al.: Amylopectin wrapped graphene oxide/sulfur for improved cyclability of lithium-sulfur battery. ACS Nano 7, 8801-8808 (2013)

194. Cheng, X.B., Peng, H.J., Huang, J.Q., et al.: Three-dimensional aluminum foam/carbon nanotube scaffolds as long- and shortrange electron pathways with improved sulfur loading for high energy density lithium-sulfur batteries. J. Power Sources 261, 264-270 (2014)

195. Ding, N., Chien, S.W., Hor, T.S.A., et al.: Key parameters in design of lithium sulfur batteries. J. Power Sources 269, 111-116 (2014)
196. Kang, S.H., Zhao, X., Manuel, J., et al.: Effect of sulfur loading on energy density of lithium sulfur batteries. Phys. Status Solidi A 211, 1895-1899 (2014)

197. Kim, J.S., Hwang, T.H., Kim, B.G., et al.: A lithium-sulfur battery with a high areal energy density. Adv. Funct. Mater. 24, 5359-5367 (2014)

198. Song, J., Xu, T., Gordin, M.L., et al.: Nitrogen-doped mesoporous carbon promoted chemical adsorption of sulfur and fabrication of high-areal-capacity sulfur cathode with exceptional cycling stability for lithium-sulfur batteries. Adv. Funct. Mater. 24, 1243-1250 (2014)

199. Yao, H., Zheng, G., Hsu, P.C., et al.: Improving lithium-sulphur batteries through spatial control of sulphur species deposition on a hybrid electrode surface. Nat. Commun. 5, 3943 (2014)

200. Jiang, Y., Lu, M., Ling, X., et al.: One-step hydrothermal synthesis of three-dimensional porous graphene aerogels/sulfur nanocrystals for lithium-sulfur batteries. J. Alloys Compd. 645, 509-516 (2015)

201. Hyun, J.E., Lee, P.C., Tatsumi, I.: Preparation and electrochemical properties of sulfur-polypyrrole composite cathodes for electric vehicle applications. Electrochim. Acta 176, 887-892 (2015)

202. Kozen, A.C., Lin, C.F., Pearse, A.J., et al.: Next-generation lithium metal anode engineering via atomic layer deposition. ACS Nano 9, 5884-5892 (2015)

203. Ma, L., Wei, S., Zhuang, H.L., et al.: Hybrid cathode architectures for lithium batteries based on $\mathrm{TiS}_{2}$ and sulfur. J. Mater. Chem. A 3, 19857-19866 (2015)

204. Schneider, A., Suchomski, C., Sommer, H., et al.: Free-standing and binder-free highly N-doped carbon/sulfur cathodes with tailorable loading for high-areal-capacity lithium-sulfur batteries. J. Mater. Chem. A 3, 20482-20486 (2015)

205. Schneider, A., Weidmann, C., Suchomski, C., et al.: Ionic liquidderived nitrogen-enriched carbon/sulfur composite cathodes with hierarchical microstructure-a step toward durable high-energy and high-performance lithium-sulfur batteries. Chem. Mater. 27, 1674-1683 (2015)

206. Strubel, P., Thieme, S., Biemelt, T., et al.: ZnO hard templating for synthesis of hierarchical porous carbons with tailored porosity and high performance in lithium-sulfur battery. Adv. Funct. Mater. 25, 287-297 (2015)

207. Yan, J., Liu, X., Qi, H., et al.: High-performance lithium-sulfur batteries with a cost-effective carbon paper electrode and high sulfur-loading. Chem. Mater. 27, 6394-6401 (2015)

208. Balach, J., Singh, H.K., Gomoll, S., et al.: Synergistically enhanced polysulfide chemisorption using a flexible hybrid separator with $\mathrm{N}$ and $\mathrm{S}$ dual-doped mesoporous carbon coating for advanced lithium-sulfur batteries. ACS Appl. Mater. Interfaces 8, 14586-14595 (2016)

209. Chang, C.H., Chung, S.H., Manthiram, A.: Effective stabilization of a high-loading sulfur cathode and a lithium-metal anode in Li-S batteries utilizing SWCNT-modulated separators. Small 12, 174-179 (2016)

210. Cheng, X., Wang, W., Wang, A., et al.: Oxidized multiwall carbon nanotube modified separator for high performance lithiumsulfur batteries with high sulfur loading. RSC Adv. 6, $89972-$ 89978 (2016)

211. Chung, S.H., Chang, C.-H., Manthiram, A.: Hierarchical sulfur electrodes as a testing platform for understanding the high-loading capability of Li-S batteries. J. Power Sources 334, 179-190 (2016)

212. Chung, S.H., Chang, C.H., Manthiram, A.: A core-shell electrode for dynamically and statically stable $\mathrm{Li}-\mathrm{S}$ battery chemistry. Energy Environ. Sci. 9, 3188-3200 (2016)

213. Fan, C.Y., Yuan, H.Y., Li, H.H., et al.: the effective design of a polysulfide-trapped separator at the molecular level for high 
energy density Li-S batteries. ACS Appl. Mater. Interfaces 8, 16108-16115 (2016)

214. Fang, R., Zhao, S., Pei, S., et al.: An integrated electrode/separator with nitrogen and nickel functionalized carbon hybrids for advanced lithium/polysulfide batteries. Carbon 109, 719-726 (2016)

215. He, N., Zhong, L., Xiao, M., et al.: Foldable and high sulfur loading $3 \mathrm{~d}$ carbon electrode for high-performance Li-S battery application. Sci. Rep. 6, 33871 (2016)

216. Kim, H.M., Sun, H.H., Belharouak, I., et al.: An alternative approach to enhance the performance of high sulfur-loading electrodes for Li-S batteries. ACS Energy Lett. 1, 136-141 (2016)

217. Li, X., Pu, X., Han, S., et al.: Enhanced performances of Li/ polysulfide batteries with 3D reduced graphene oxide/carbon nanotube hybrid aerogel as the polysulfide host. Nano Energy 30, 193-199 (2016)

218. Luo, L., Chung, S.H., Manthiram, A.: A trifunctional multiwalled carbon nanotubes/polyethylene glycol (MWCNT/PEG)coated separator through a layer-by-layer coating strategy for high-energy Li-S batteries. J. Mater. Chem. A 4, 16805-16811 (2016)

219. Milroy, C., Manthiram, A.: An elastic, conductive, electroactive nanocomposite binder for flexible sulfur cathodes in lithium-sulfur batteries. Adv. Mater. 28(44), 9744-9751 (2016)

220. Milroy, C., Manthiram, A.: Printed microelectrodes for scalable, high-areal-capacity lithium-sulfur batteries. Chem. Commun. 52, 4282-4285 (2016)

221. Pang, Q., Kundu, D., Nazar, L.F.: A graphene-like metallic cathode host for long-life and high-loading lithium-sulfur batteries. Mater. Horiz. 3, 130-136 (2016)

222. Peng, H.J., Zhang, Z.W., Huang, J.Q., et al.: A cooperative interface for highly efficient lithium-sulfur batteries. Adv. Mater. 28, 9551-9558 (2016)

223. Qie, L., Manthiram, A.: High-energy-density lithium-sulfur batteries based on blade-cast pure sulfur electrodes. ACS Energy Lett. 1, 46-51 (2016)

224. Qie, L., Zu, C., Manthiram, A.: A high energy lithium-sulfur battery with ultrahigh-loading lithium polysulfide cathode and its failure mechanism. Adv. Energy Mater. 6, 1502459 (2016)

225. Sohn, H., Gordin, M.L., Regula, M., et al.: Porous spherical polyacrylonitrile-carbon nanocomposite with high loading of sulfur for lithium-sulfur batteries. J. Power Sources 302, 70-78 (2016)

226. Sun, K., Liu, H., Gan, H.: Cathode loading effect on sulfur utilization in lithium-sulfur battery. J. Electrochem. Energy Convers. Storage 13, 021002 (2016)

227. Walus, S., Barchasz, C., Bouchet, R., et al.: Investigation of non-woven carbon paper as a current collector for sulfur positive electrode-understanding of the mechanism and potential applications for Li/S batteries. Electrochim. Acta 211, 697-703 (2016)

228. Wang, J., Cheng, S., Li, W., et al.: Simultaneous optimization of surface chemistry and pore morphology of 3D graphene-sulfur cathode via multi-ion modulation. J. Power Sources 321, 193200 (2016)

229. Wang, X., Gao, T., Han, F., et al.: Stabilizing high sulfur loading $\mathrm{Li}-\mathrm{S}$ batteries by chemisorption of polysulfide on three-dimensional current collector. Nano Energy 30, 700-708 (2016)

230. Xu, H., Qie, L., Manthiram, A.: An integrally-designed, flexible polysulfide host for high-performance lithium-sulfur batteries with stabilized lithium-metal anode. Nano Energy 26, 224-232 (2016)

231. Zhuang, T.Z., Huang, J.Q., Peng, H.J., et al.: Rational integration of polypropylene/graphene oxide/nafion as ternary-layered separator to retard the shuttle of polysulfides for lithium-sulfur batteries. Small 12, 381-389 (2016)
232. Chang, C.H., Chung, S.H., Manthiram, A.: Highly flexible, freestanding tandem sulfur cathodes for foldable $\mathrm{Li}-\mathrm{S}$ batteries with a high areal capacity. Mater. Horiz. 4, 249-258 (2017)

233. Chen, S., Gao, Y., Yu, Z., et al.: High capacity of lithiumsulfur batteries at low electrolyte/sulfur ratio enabled by an organosulfide containing electrolyte. Nano Energy 31, 418-423 (2017)

234. Lee, J.S., Kim, W., Jang, J., et al.: Sulfur-embedded activated multichannel carbon nanofiber composites for long-life, highrate lithium-sulfur batteries. Adv. Energy Mater. 7, 1601943 (2017)

235. Li, S., Mou, T., Ren, G., et al.: Gel based sulfur cathodes with a high sulfur content and large mass loading for highperformance lithium-sulfur batteries. J. Mater. Chem. A 5, 1650-1657 (2017)

236. Liang, X., Rangom, Y., Kwok, C.Y., et al.: Interwoven MXene nanosheet/carbon-nanotube composites as $\mathrm{Li}-\mathrm{S}$ cathode hosts. Adv. Mater. 29, 1603040 (2017)

237. Liu, Y., Li, G., Fu, J., et al.: Strings of porous carbon polyhedrons as self-standing cathode host for high-energy-density lithium-sulfur batteries. Angew. Chem. Int. Ed. 56, 6176-6180 (2017)

238. Mao, Y., Li, G., Guo, Y., et al.: Foldable interpenetrated metalorganic frameworks/carbon nanotubes thin film for lithium-sulfur batteries. Nat. Commun. 8, 14628 (2017)

239. Nara, H., Yokoshima, T., Mikuriya, H., et al.: The potential for the creation of a high areal capacity lithium-sulfur battery using a metal foam current collector. J. Electrochem. Soc. 164, A5026A5030 (2017)

240. Pang, Q., Liang, X., Kwok, C.Y., et al.: A comprehensive approach toward stable lithium-sulfur batteries with high volumetric energy density. Adv. Energy Mater. 7, 1601630 (2017)

241. Peng, H.J., Huang, J.Q., Liu, X.Y., et al.: Healing high-loading sulfur electrodes with unprecedented long cycling life: spatial heterogeneity control. J. Am. Chem. Soc. 139, 8458-8466 (2017)

242. Zhang, K., Xie, K., Yuan, K., et al.: Enabling effective polysulfide trapping and high sulfur loading via a pyrrole modified graphene foam host for advanced lithium-sulfur batteries. J. Mater. Chem. A 5, 7309-7315 (2017)

243. Zhang, Y., Li, K., Li, H., et al.: High sulfur loading lithium-sulfur batteries based on a upper current collector electrode with lithium-ion conductive polymers. J. Mater. Chem. A 5, 97-101 (2017)

244. Zhang, Z., Kong, L.L., Liu, S., et al.: A high-efficiency sulfur/ carbon composite based on 3D graphene nanosheet@carbon nanotube matrix as cathode for lithium-sulfur battery. Adv. Energy Mater. 7, 1602543 (2017)

245. Balach, J., Jaumann, T., Giebeler, L.: Nanosized $\mathrm{Li}_{2} \mathrm{~S}$-based cathodes derived from $\mathrm{MoS}_{2}$ for high-energy density $\mathrm{Li}-\mathrm{S}$ cells and $\mathrm{Si}-\mathrm{Li}_{2} \mathrm{~S}$ full cells in carbonate-based electrolyte. Energy Storage Mater. 8, 209-216 (2017)

246. Cui, Y., Wu, X., Wu, J., et al.: An interlayer with architecture that limits polysulfides shuttle to give a stable performance $\mathrm{Li}-\mathrm{S}$ battery. Energy Storage Mater. 9, 1-10 (2017)

247. Gao, Z., Zhang, Y., Song, N., et al.: Towards flexible lithiumsulfur battery from natural cotton textile. Electrochim. Acta 246, 507-516 (2017)

248. Han, S., Pu, X., Li, X., et al.: High areal capacity of Li-S batteries enabled by freestanding $\mathrm{CNF} / \mathrm{rGO}$ electrode with high loading of lithium polysulfide. Electrochim. Acta 241, 406-413 (2017)

249. He, J., Luo, L., Chen, Y., et al.: Yolk-shelled $\mathrm{C} @ \mathrm{Fe}_{3} \mathrm{O}_{4}$ nanoboxes as efficient sulfur hosts for high-performance lithium-sulfur batteries. Adv. Mater. 29, 1702707 (2017)

250. Hong, X., Jin, J., Wu, T., et al.: A rGO-CNT aerogel covalently bonded with a nitrogen-rich polymer as a polysulfide adsorptive 
cathode for high sulfur loading lithium sulfur batteries. J. Mater. Chem. A 5, 14775-14782 (2017)

251. Li, Y., Fu, K.K., Chen, C., et al.: Enabling high-areal-capacity lithium-sulfur batteries: designing anisotropic and low-tortuosity porous architectures. ACS Nano 11, 4801-4807 (2017)

252. Ling, M., Zhang, L., Zheng, T., et al.: Nucleophilic substitution between polysulfides and binders unexpectedly stabilizing lithium sulfur battery. Nano Energy 38, 82-90 (2017)

253. Liu, Y., Li, G., Chen, Z., et al.: CNT-threaded N-doped porous carbon film as binder-free electrode for high-capacity supercapacitor and Li-S battery. J. Mater. Chem. A 5, 9775-9784 (2017)

254. Luo, L., Chung, S.H., Chang, C.H., et al.: A nickel-foam @ carbon-shell with a pie-like architecture as an efficient polysulfide trap for high-energy Li-S batteries. J. Mater. Chem. A 5, 15002-15007 (2017)

255. Mi, Y., Liu, W., Li, X., et al.: High-performance Li-S battery cathode with catalyst-like carbon nanotube-MoP promoting polysulfide redox. Nano Res. 10, 3698-3705 (2017)

256. Qin, F., Wang, X., Zhang, K., et al.: High areal capacity cathode and electrolyte reservoir render practical $\mathrm{Li}-\mathrm{S}$ batteries. Nano Energy 38, 137-146 (2017)

257. Ummethala, R., Fritzsche, M., Jaumann, T., et al.: Lightweight, free-standing 3D interconnected carbon nanotube foam as a flexible sulfur host for high performance lithium-sulfur battery cathodes. Energy Storage Mater. 10, 206-215 (2017)

258. Yu, M., Wang, Z., Wang, Y., et al.: Freestanding flexible $\mathrm{Li}_{2} \mathrm{~S}$ paper electrode with high mass and capacity loading for highenergy Li-S batteries. Adv. Energy Mater. 7, 1700018 (2017)

259. Carter, R., Davis, B., Oakes, L., et al.: A high areal capacity lithium-sulfur battery cathode prepared by site-selective vapor infiltration of hierarchical carbon nanotube arrays. Nanoscale 9, 15018-15026 (2017)

260. Chang, C.H., Manthiram, A.: Covalently grafted polysulfurgraphene nanocomposites for ultrahigh sulfur-loading lithiumpolysulfur batteries. ACS Energy Lett. 3, 72-77 (2018)

261. Chen, H., Chen, C., Liu, Y., et al.: High-quality graphene microflower design for high-performance $\mathrm{Li}-\mathrm{S}$ and Al-ion batteries. Adv. Energy Mater. 7, 1700051 (2017)

262. Chung, S.H., Han, P., Chang, C.H., et al.: A shell-shaped carbon architecture with high-loading capability for lithium sulfide cathodes. Adv. Energy Mater. 7, 1700537 (2017)

263. Fang, R., Li, G., Zhao, S., et al.: Single-wall carbon nanotube network enabled ultrahigh sulfur-content electrodes for high-performance lithium-sulfur batteries. Nano Energy 42, 205-214 (2017)

264. Gao, S., Wang, K., Wang, R., et al.: Poly(vinylidene fluoride)based hybrid gel polymer electrolytes for additive-free lithium sulfur batteries. J. Mater. Chem. A 5, 17889-17895 (2017)

265. Hu, C., Kirk, C., Cai, Q., et al.: A high-volumetric-capacity cathode based on interconnected close-packed $\mathrm{N}$-doped porous carbon nanospheres for long-life lithium-sulfur batteries. Adv. Energy Mater. 7, 1701082 (2017)

266. Hu, C., Kirk, C., Silvestre-Albero, J., et al.: Free-standing compact cathodes for high volumetric and gravimetric capacity Li-S batteries. J. Mater. Chem. A 5, 19924-19933 (2017)

267. Li, F., Qin, F., Zhang, K., et al.: Hierarchically porous carbon derived from banana peel for lithium sulfur battery with high areal and gravimetric sulfur loading. J. Power Sources 362, 160-167 (2017)

268. Li, L., Pascal, T.A., Connell, J.G., et al.: Molecular understanding of polyelectrolyte binders that actively regulate ion transport in sulfur cathodes. Nat. Commun. 8, 2277 (2017)

269. Li, M., Zhang, Y., Hassan, F., et al.: Compact high volumetric and areal capacity lithium sulfur batteries through rock salt induced nano-architectured sulfur hosts. J. Mater. Chem. A 5, 21435-21441 (2017)

270. Ling, M., Yan, W., Kawase, A., et al.: Electrostatic polysulfides confinement to inhibit redox shuttle process in the lithium sulfur batteries. ACS Appl. Mater. Interfaces 9, 31741-31745 (2017)

271. Luo, L., Manthiram, A.: Rational design of high-loading sulfur cathodes with a poached-egg-shaped architecture for longcycle lithium-sulfur batteries. ACS Energy Lett. 2, 2205-2211 (2017)

272. Ma, L., Yuan, H., Zhang, W., et al.: Porous-shell vanadium nitride nanobubbles with ultrahigh areal sulfur loading for high-capacity and long-life lithium-sulfur batteries. Nano Lett. 17, 7839-7846 (2017)

273. Pei, F., Lin, L., Ou, D., et al.: Self-supporting sulfur cathodes enabled by two-dimensional carbon yolk-shell nanosheets for high-energy-density lithium-sulfur batteries. Nat. Commun. 8, 482 (2017)

274. Su, H., Fu, C., Zhao, Y., et al.: Polycation binders: an effective approach toward lithium polysulfide sequestration in $\mathrm{Li}-\mathrm{S}$ batteries. ACS Energy Lett. 2, 2591-2597 (2017)

275. Tang, H., Yang, J., Zhang, G., et al.: Self-assembled N-graphene nanohollows enabling ultrahigh energy density cathode for Li-S batteries. Nanoscale 10, 386-395 (2018)

276. Wang, J., Cheng, S., Li, W., et al.: Robust electrical "highway" network for high mass loading sulfur cathode. Nano Energy 40, 390-398 (2017)

277. Xiang, M., Wu, H., Liu, H., et al.: A flexible 3D multifunctional MgO-decorated carbon Foam@CNTs hybrid as self-supported cathode for high-performance lithium-sulfur batteries. Adv. Funct. Mater. 27, 1702573 (2017)

278. Xiang, M., Yang, L., Zheng, Y., et al.: A freestanding and flexible nitrogen-doped carbon foam/sulfur cathode composited with reduced graphene oxide for high sulfur loading lithiumsulfur batteries. J. Mater. Chem. A 5, 18020-18028 (2017)

279. Ye, Y., Wang, L., Guan, L., et al.: A modularly-assembled interlayer to entrap polysulfides and protect lithium metal anode for high areal capacity lithium-sulfur batteries. Energy Storage Mater. 9, 126-133 (2017)

280. Zhang, J., You, C., Zhang, W., et al.: Conductive bridging effect of TiN nanoparticles on the electrochemical performance of TiN@CNT-S composite cathode. Electrochim. Acta 250, 159-166 (2017)

281. Zhang, L., Ling, M., Feng, J., et al.: Effective electrostatic confinement of polysulfides in lithium/sulfur batteries by a functional binder. Nano Energy 40, 559-565 (2017)

282. Zhong, L., Yang, K., Guan, R., et al.: Toward theoretically cycling-stable lithium-sulfur battery using a foldable and compositionally heterogeneous cathode. ACS Appl. Mater. Interfaces 9, 43640-43647 (2017)

283. Cai, W., Li, G., Zhang, K., et al.: Conductive nanocrystalline niobium carbide as high-efficiency polysulfides tamer for lithium-sulfur batteries. Adv. Funct. Mater. 28, 1704865 (2018)

284. Chung, S.H., Manthiram, A.: Rational design of statically and dynamically stable lithium-sulfur batteries with high sulfur loading and low electrolyte/sulfur ratio. Adv. Mater. 30, 1705951 (2018)

285. Chung, S.H., Luo, L., Manthiram, A.: TiS ${ }_{2}$-polysulfide hybrid cathode with high sulfur loading and low electrolyte consumption for lithium-sulfur batteries. ACS Energy Lett. 3, 568-573 (2018)

286. Gao, P., Xu, S., Chen, Z., et al.: Flexible and hierarchically structured sulfur composite cathode based on the carbonized textile for high-performance Li-S batteries. ACS Appl. Mater. Interfaces 10, 3938-3947 (2018) 
287. Li, F., Qin, F., Wang, G., et al.: $\mathrm{A} \mathrm{LiAlO}_{2} /$ nitrogen-doped hollow carbon spheres (NdHCSs) modified separator for advanced lithium-sulfur batteries. RSC Adv. 8, 1632-1637 (2018)

288. Li, G., Lei, W., Luo, D., et al.: 3D porous carbon sheets with multidirectional ion pathways for fast and durable lithium-sulfur batteries. Adv. Energy Mater. 8, 1702381 (2018)

289. Qu, H., Zhang, J., Du, A., et al.: Multifunctional sandwich-structured electrolyte for high-performance lithium-sulfur batteries. Adv Sci. 5, 1700503 (2018)

290. Wang, J., Wu, T., Zhang, S., et al.: Metal-organic-frameworkderived N-C-Co film as a shuttle-suppressing interlayer for lithium sulfur battery. Chem. Eng. J. 334, 2356-2362 (2018)

291. Yun, J.H., Kim, J.H., Kim, D.K., et al.: Suppressing polysulfide dissolution via cohesive forces by interwoven carbon nanofibers for high-areal-capacity lithium-sulfur batteries. Nano Lett. 18, 475-481 (2018)

292. Zhang, H., Zhao, W., Zou, M., et al.: 3D, mutually embedded MOF@Carbon nanotube hybrid networks for high-performance lithium-sulfur batteries. Adv. Energy Mater. 1800013 (2018). https://doi.org/10.1002/aenm.201800013

293. Zhang, Y.Z., Zhang, Z., Liu, S., et al.: Free-standing porous carbon nanofiber/carbon nanotube film as sulfur immobilizer with high areal capacity for lithium-sulfur battery. ACS Appl. Mater. Interfaces 10, 8749-8757 (2018)

294. Zhao, X., Kim, M., Liu, Y., et al.: Root-like porous carbon nanofibers with high sulfur loading enabling superior areal capacity of lithium sulfur batteries. Carbon 128, 138-146 (2018)

295. Zhong, Y., Yin, L., He, P., et al.: Surface chemistry in cobalt phosphide-stabilized lithium-sulfur batteries. J. Am. Chem. Soc. 140, 1455-1459 (2018)

296. Zheng, J., Lv, D., Gu, M., et al.: How to obtain reproducible results for lithium sulfur batteries? J. Electrochem. Soc. 160, A2288-A2292 (2013)

297. Kim, J.E., Jin, C.S., Shin, K.H., et al.: Optimized cell conditions for a high-energy density, large-scale Li-S battery. Int. J. Energy Res. 40, 670-676 (2016)

298. Cheng, X.B., Huang, J.Q., Peng, H.J., et al.: Polysulfide shuttle control: towards a lithium-sulfur battery with superior capacity performance up to 1000 cycles by matching the sulfur/electrolyte loading. J. Power Sources 253, 263-268 (2014)

299. Fan, F.Y., Chiang, Y.M.: Electrodeposition kinetics in Li-S batteries: effects of low electrolyte/sulfur ratios and deposition surface composition. J. Electrochem. Soc. 164, A917-A922 (2017)

300. Ma, G., Wen, Z., Wu, M., et al.: A lithium anode protection guided highly-stable lithium-sulfur battery. Chem. Commun. 50, 14209-14212 (2014)

301. Ma, G., Wen, Z., Wang, Q., et al.: Enhanced cycle performance of a $\mathrm{Li}-\mathrm{S}$ battery based on a protected lithium anode. J. Mater. Chem. A 2, 19355-19359 (2014)

302. Wu, M., Wen, Z., Jin, J., et al.: Trimethylsilyl chloride-modified $\mathrm{Li}$ anode for enhanced performance of $\mathrm{Li}-\mathrm{S}$ cells. ACS Appl. Mater. Interfaces 8, 16386-16395 (2016)

303. Jing, H.K., Kong, L.L., Liu, S., et al.: Protected lithium anode with porous $\mathrm{Al}_{2} \mathrm{O}_{3}$ layer for lithium-sulfur battery. J. Mater. Chem. A 3, 12213-12219 (2015)

304. Wu, M., Jin, J., Wen, Z.: Influence of a surface modified Li anode on the electrochemical performance of $\mathrm{Li}-\mathrm{S}$ batteries. RSC Adv. 6, 40270-40276 (2016)

305. Liu, J., Banis, M.N., Sun, Q., et al.: Rational design of atomiclayer-deposited $\mathrm{LiFePO}_{4}$ as a high-performance cathode for lithium-ion batteries. Adv. Mater. 26, 6472-6477 (2014)

306. Marichy, C., Bechelany, M., Pinna, N.: Atomic layer deposition of nanostructured materials for energy and environmental applications. Adv. Mater. 24, 1017-1032 (2012)
307. Li, N.W., Yin, Y.X., Li, J.Y., et al.: Passivation of lithium metal anode via hybrid ionic liquid electrolyte toward stable Li plating/ stripping. Adv. Sci. 4, 1600400 (2017)

308. Xu, R., Zhang, X.Q., Cheng, X.B., et al.: Artificial soft-rigid protective layer for dendrite-free lithium metal anode. Adv. Funct. Mater. 28, 1705838 (2018)

309. Li, N.W., Shi, Y., Yin, Y.X., et al.: A flexible solid electrolyte interphase layer for long-life lithium metal anodes. Angew. Chem. Int. Ed. 57, 1505-1509 (2018)

310. Cheng, X.B., Yan, C., Chen, X., et al.: Implantable solid electrolyte interphase in lithium-metal batteries. Chem 2, 258-270 (2017)

311. Mikhaylik, Y.V.: Electrolytes for lithium sulfur cells. U.S. Patent 7,553,590 B2, 30 Jun 2009

312. Liang, X., Wen, Z., Liu, Y., et al.: Improved cycling performances of lithium sulfur batteries with $\mathrm{LiNO}_{3}$-modified electrolyte. J. Power Sources 196, 9839-9843 (2011)

313. Aurbach, D., Pollak, E., Elazari, R., et al.: On the surface chemical aspects of very high energy density, rechargeable Li-sulfur batteries. J. Electrochem. Soc. 156, A694-A702 (2009)

314. Zhang, S.S.: Role of $\mathrm{LiNO}_{3}$ in rechargeable lithium/sulfur battery. Electrochim. Acta 70, 344-348 (2012)

315. Zhang, L., Ling, M., Feng, J., et al.: The synergetic interaction between $\mathrm{LiNO}_{3}$ and lithium polysulfides for suppressing shuttle effect of lithium-sulfur batteries. Energy Storage Mater. 11, 24-29 (2018)

316. Zhao, C.Z., Cheng, X.B., Zhang, R., et al.: $\mathrm{Li}_{2} \mathrm{~S}_{5}$-based ternarysalt electrolyte for robust lithium metal anode. Energy Storage Mater. 3, 77-84 (2016)

317. Yan, C., Cheng, X.B., Zhao, C.Z., et al.: Lithium metal protection through in situ formed solid electrolyte interphase in lithium-sulfur batteries: the role of polysulfides on lithium anode. J. Power Sources 327, 212-220 (2016)

318. Li, W., Yao, H., Yan, K., et al.: The synergetic effect of lithium polysulfide and lithium nitrate to prevent lithium dendrite growth. Nat. Commun. 6, 7436 (2015)

319. Liu, S., Li, G.R., Gao, X.P.: Lanthanum nitrate as electrolyte additive to stabilize the surface morphology of lithium anode for lithium-sulfur battery. ACS Appl. Mater. Interfaces 8, 77837789 (2016)

320. Zhang, S.S.: Effect of discharge cutoff voltage on reversibility of lithium/sulfur batteries with $\mathrm{LiNO}_{3}$-contained electrolyte. J. Electrochem. Soc. 159, A920-A923 (2012)

321. Lin, Z., Liu, Z., Fu, W., et al.: Phosphorous pentasulfide as a novel additive for high-performance lithium-sulfur batteries. Adv. Funct. Mater. 23, 1064-1069 (2013)

322. Wu, F., Qian, J., Chen, R., et al.: An effective approach to protect lithium anode and improve cycle performance for $\mathrm{Li}-\mathrm{S}$ batteries. ACS Appl. Mater. Interfaces 6, 15542-15549 (2014)

323. Xiong, S., Kai, X., Hong, X., et al.: Effect of LiBOB as additive on electrochemical properties of lithium-sulfur batteries. Ionics 18, 249-254 (2011)

324. $\mathrm{Zu}, \mathrm{C}$., Manthiram, A.: Stabilized lithium-metal surface in a polysulfide-rich environment of lithium-sulfur batteries. J. Phys. Chem. Lett. 5, 2522-2527 (2014)

325. Suo, L., Hu, Y.S., Li, H., et al.: A new class of Solvent-in-Salt electrolyte for high-energy rechargeable metallic lithium batteries. Nat. Commun. 4, 1481 (2013)

326. Lu, D., Shao, Y., Lozano, T., et al.: Failure mechanism for fastcharged lithium metal batteries with liquid electrolytes. Adv. Energy Mater. 5, 1400993 (2015)

327. Yang, C.P., Yin, Y.X., Zhang, S.F., et al.: Accommodating lithium into 3D current collectors with a submicron skeleton towards long-life lithium metal anodes. Nat. Commun. 6, 8058 (2015) 
328. Yun, Q., He, Y.B., Lv, W., et al.: Chemical dealloying derived 3D porous current collector for Li metal anodes. Adv. Mater. 28, 6932-6939 (2016)

329. Lee, H., Song, J., Kim, Y.J., et al.: Structural modulation of lithium metal-electrolyte interface with three-dimensional metallic interlayer for high-performance lithium metal batteries. Sci. Rep. 6, 30830 (2016)

330. Liang, Z., Zheng, G., Liu, C., et al.: Polymer nanofiber-guided uniform lithium deposition for battery electrodes. Nano Lett. 15, 2910-2916 (2015)

331. Cheng, X.B., Peng, H.J., Huang, J.Q., et al.: Dendrite-free nanostructured anode: entrapment of lithium in a 3D fibrous matrix for ultra-stable lithium-sulfur batteries. Small 10, 4257-4263 (2014)

332. Liang, Z., Lin, D., Zhao, J., et al.: Composite lithium metal anode by melt infusion of lithium into a 3D conducting scaffold with lithiophilic coating. Proc. Natl. Acad. Sci. USA 113, 2862-2867 (2016)

333. Ding, F., Xu, W., Graff, G.L., et al.: Dendrite-free lithium deposition via self-healing electrostatic shield mechanism. J. Am. Chem. Soc. 135, 4450-4456 (2013)

334. Yan, K., Lu, Z., Lee, H.W., et al.: Selective deposition and stable encapsulation of lithium through heterogeneous seeded growth. Nat. Energy 1, 16010 (2016)

335. Yang, C., Yao, Y., He, S., et al.: Ultrafine silver nanoparticles for seeded lithium deposition toward stable lithium metal anode. Adv. Mater. 29, 1702714 (2017)

336. Zhang, Y., Qian, J., Xu, W., et al.: Dendrite-free lithium deposition with self-aligned nanorod structure. Nano Lett. 14, 68896896 (2014)

337. Zhang, X.Q., Chen, X., Xu, R., et al.: Columnar lithium metal anodes. Angew. Chem. Int. Edit. 56, 14207-14211 (2017)

338. Liu, Y., Lin, D., Liang, Z., et al.: Lithium-coated polymeric matrix as a minimum volume-change and dendrite-free lithium metal anode. Nat. Commun. 7, 10992 (2016)

339. Lin, D., Liu, Y., Liang, Z., et al.: Layered reduced graphene oxide with nanoscale interlayer gaps as a stable host for lithium metal anodes. Nat. Nanotechnol. 11, 626-632 (2016)

340. Chi, S.S., Liu, Y., Song, W.L., et al.: Prestoring lithium into Stable 3D nickel foam host as dendrite-free lithium metal anode. Adv. Funct. Mater. 27, 1700348 (2017)

341. Zhang, Y., Luo, W., Wang, C., et al.: High-capacity, low-tortuosity, and channel-guided lithium metal anode. Proc. Natl. Acad. Sci. USA 114, 3584-3589 (2017)

342. Lin, D., Zhao, J., Sun, J., et al.: Three-dimensional stable lithium metal anode with nanoscale lithium islands embedded in ionically conductive solid matrix. Proc. Natl. Acad. Sci. USA 114, 4613-4618 (2017)

343. Zhang, R., Chen, X.R., Chen, X., et al.: Lithiophilic sites in doped graphene guide uniform lithium nucleation for dendritefree lithium metal anodes. Angew. Chem. Int. Ed. 56, 7764-7768 (2017)

344. Qian, J., Xu, W., Bhattacharya, P., et al.: Dendrite-free Li deposition using trace-amounts of water as an electrolyte additive. Nano Energy 15, 135-144 (2015)

345. Sion Power. http://www.sionpower.com. Accessed 20 Apr 2018

346. Samaniego, B., Carla, E., et al.: High specific energy Lithium Sulfur cell for space application. E3S Web of Conferences, vol. 16, 08006. EDP Sciences, Les Ulis Cedex (2017)

347. Barnard Microsystems. http://www.barnardmicrosystems.com/ UAV/engines/batteries.html. Accessed on 20 Apr 2018

348. Fotouhi, A., Auger, D., O'Neill, L., et al.: Lithium-sulfur battery technology readiness and applications-a review. Energies 10, 1937 (2017)

349. Dalian Institute of Chemical Physics, Chinese Academy of Sciences: New achievements in Li-S batteries R\&D at Dalian
Institute of Chemical Physics. http://english.dicp.cas.cn/ ns_17179/ue/201509/t20150928_153096.html. Accessed on 24 Apr 2018

350. Yu, X., Manthiram, A.: Electrode-electrolyte interfaces in lithium-sulfur batteries with liquid or inorganic solid electrolytes. Acc. Chem. Res. 50, 2653-2660 (2017)

351. Sun, Y.Z., Huang, J.Q., Zhao, C.Z., et al.: A review of solid electrolytes for safe lithium-sulfur batteries. Sci. China Chem. 60, 1508-1526 (2017)

352. Machida, N., Kobayashi, K., Nishikawa, Y., et al.: Electrochemical properties of sulfur as cathode materials in a solid-state lithium battery with inorganic solid electrolytes. Solid State Ionics 175, 247-250 (2004)

353. Chen, R., Zhao, T., Wu, F.: From a historic review to horizons beyond: lithium-sulphur batteries run on the wheels. Chem. Commun. 51, 18-33 (2015)

354. Evers, S., Nazar, L.F.: New approaches for high energy density lithium-sulfur battery cathodes. Acc. Chem. Res. 46, 1135-1143 (2013)

355. Kamaya, N., Homma, K., Yamakawa, Y., et al.: A lithium superionic conductor. Nat. Mater. 10, 682-686 (2011)

356. Quartarone, E., Mustarelli, P.: Electrolytes for solid-state lithium rechargeable batteries: recent advances and perspectives. Chem. Soc. Rev. 40, 2525-2540 (2011)

357. Knauth, P.: Inorganic solid Li ion conductors: an overview. Solid State Ionics 180, 911-916 (2009)

358. Tatsumisago, M., Nagao, M., Hayashi, A.: Recent development of sulfide solid electrolytes and interfacial modification for allsolid-state rechargeable lithium batteries. J. Asian Ceram. Soc. 1, 17-25 (2013)

359. Liang, G., Wu, J., Qin, X., et al.: Ultrafine $\mathrm{TiO}_{2}$ decorated carbon nanofibers as multifunctional interlayer for high-performance lithium-sulfur battery. ACS Appl. Mater. Interfaces 8, 2310523113 (2016)

360. Chen, R., Qu, W., Guo, X., et al.: The pursuit of solid-state electrolytes for lithium batteries: from comprehensive insight to emerging horizons. Mater. Horiz. 3, 487-516 (2016)

361. Shao, H., Wang, W., Zhang, H., et al.: Nano- $\mathrm{TiO}_{2}$ decorated carbon coating on the separator to physically and chemically suppress the shuttle effect for lithium-sulfur battery. J. Power Sources 378, 537-545 (2018)

362. Manthiram, A., Yu, X., Wang, S.: Lithium battery chemistries enabled by solid-state electrolytes. Nat. Rev. Mater. 2, 16103 (2017)

363. Barghamadi, M., Best, A.S., Bhatt, A.I., et al.: Lithium-sulfur batteries - the solution is in the electrolyte, but is the electrolyte a solution? Energy Environ. Sci. 7, 3902-3920 (2014)

364. Chen, L., Shaw, L.L.: Recent advances in lithium-sulfur batteries. J. Power Sources 267, 770-783 (2014)

365. Scheers, J., Fantini, S., Johansson, P.: A review of electrolytes for lithium-sulphur batteries. J. Power Sources 255, 204-218 (2014)

366. Goodenough, J.B., Singh, P.: Review-solid electrolytes in rechargeable electrochemical cells. J. Electrochem. Soc. 162, A2387-A2392 (2015)

367. Hayashi, A., Ohtomo, T., Mizuno, F., et al.: All-solid-state Li/S batteries with highly conductive glass-ceramic electrolytes. Electrochem. Commun. 5, 701-705 (2003)

368. Hayashi, A., Ohtsubo, R., Ohtomo, T., et al.: All-solid-state rechargeable lithium batteries with $\mathrm{Li}_{2} \mathrm{~S}$ as a positive electrode material. J. Power Sources 183, 422-426 (2008)

369. Nagao, M., Hayashi, A., Tatsumisago, M.: Sulfur-carbon composite electrode for all-solid-state $\mathrm{Li} / \mathrm{S}$ battery with $\mathrm{Li}_{2} \mathrm{~S}_{-} \mathrm{P}_{2} \mathrm{~S}_{5}$ solid electrolyte. Electrochim. Acta 56, 6055-6059 (2011)

370. Nagao, M., Hayashi, A., Tatsumisago, M.: Fabrication of favorable interface between sulfide solid electrolyte and Li metal 
electrode for bulk-type solid-state Li/S battery. Electrochem. Commun. 22, 177-180 (2012)

371. Chen, M., Adams, S.: High performance all-solid-state lithium/ sulfur batteries using lithium argyrodite electrolyte. J. Solid State Electrochem. 19, 697-702 (2015)

372. Nagao, M., Imade, Y., Narisawa, H., et al.: All-solid-state Li-sulfur batteries with mesoporous electrode and thio-LISICON solid electrolyte. J. Power Sources 222, 237-242 (2013)

373. Chen, H.M., Chen, M., Adams, S.: Stability and ionic mobility in argyrodite-related lithium-ion solid electrolytes. Phys. Chem. Chem. Phys. 17, 16494-16506 (2015)

374. Chen, M., Yin, X., Reddy, M.V., et al.: All-solid-state $\mathrm{MoS}_{2} /$ $\mathrm{Li}_{6} \mathrm{PS}_{5} \mathrm{Br} / \mathrm{In}-\mathrm{Li}$ batteries as a novel type of $\mathrm{Li} / \mathrm{S}$ battery. J. Mater. Chem. A 3, 10698-10702 (2015)

375. Palacin, M.R., de Guibert, A.: Why do batteries fail? Science 351, 1253292 (2016)

376. Lin, Z., Liu, Z., Fu, W., et al.: Lithium polysulfidophosphates: a family of lithium-conducting sulfur-rich compounds for lithium-sulfur batteries. Angew. Chem. Int. Ed. 52, 7460-7463 (2013)

377. Lin, Z., Liu, Z., Dudney, N.J., et al.: Lithium superionic sulfide cathode for all-solid lithium-sulfur batteries. ACS Nano 7, 2829-2833 (2013)

378. Han, F., Yue, J., Fan, X., et al.: High-performance all-solidstate lithium-sulfur battery enabled by a mixed-conductive $\mathrm{Li}_{2} \mathrm{~S}$ nanocomposite. Nano Lett. 16, 4521-4527 (2016)

379. Yao, X., Huang, N., Han, F., et al.: High-performance all-solidstate lithium-sulfur batteries enabled by amorphous sulfurcoated reduced graphene oxide cathodes. Adv. Energy Mater. 7, 1602923 (2017)

380. Nagao, M., Hayashi, A., Tatsumisago, M.: High-capacity $\mathrm{Li}_{2} \mathrm{~S}$-nanocarbon composite electrode for all-solid-state rechargeable lithium batteries. J. Mater. Chem. 22, 1001510020 (2012)

381. Kinoshita, S., Okuda, K., Machida, N., et al.: All-solid-state lithium battery with sulfur/carbon composites as positive electrode materials. Solid State Ionics 256, 97-102 (2014)

382. Kinoshita, S., Okuda, K., Machida, N., et al.: Additive effect of ionic liquids on the electrochemical property of a sulfur composite electrode for all-solid-state lithium-sulfur battery. J. Power Sources 269, 727-734 (2014)

383. Nagata, H., Chikusa, Y.: Activation of sulfur active material in an all-solid-state lithium-sulfur battery. J. Power Sources 263, 141-144 (2014)

384. Nagata, H., Chikusa, Y.: All-solid-state lithium-sulfur batteries using a conductive composite containing activated carbon and electroconductive polymers. Chem. Lett. 43, 1335-1336 (2014)

385. Hakari, T., Hayashi, A., Tatsumisago, M.: Highly utilized lithium sulfide active material by enhancing conductivity in all-solidstate batteries. Chem. Lett. 44, 1664-1666 (2015)

386. Nagao, M., Hayashi, A., Tatsumisago, M., et al.: $\mathrm{Li}_{2} \mathrm{~S}$ nanocomposites underlying high-capacity and cycling stability in all-solid-state lithium-sulfur batteries. J. Power Sources 274, 471-476 (2015)

387. Yamada, T., Ito, S., Omoda, R., et al.: All solid-state lithium-sulfur battery using a glass-type P2S5-Li2S electrolyte: benefits on anode kinetics. J. Electrochem. Soc. 162, A646-A651 (2015)

388. Yu, C., van Eijck, L., Ganapathy, S., et al.: Synthesis, structure and electrochemical performance of the argyrodite $\mathrm{Li}_{6} \mathrm{PS}_{5} \mathrm{Cl}$ solid electrolyte for Li-ion solid state batteries. Electrochim. Acta 215, 93-99 (2016)

389. Xu, R., Wu, Z., Zhang, S., et al.: Construction of all-solidstate batteries based on a sulfur-graphene composite and $\mathrm{Li}_{9.54} \mathrm{Si}_{1.74} \mathrm{P}_{1.44} \mathrm{~S}_{11.7} \mathrm{Cl}_{0.3}$ solid electrolyte. Chem. Eur. J. 23, 13950-13956 (2017)
390. Xu, R.C., Xia, X.H., Li, S.H., et al.: All-solid-state lithium-sulfur batteries based on a newly designed $\mathrm{Li}_{7} \mathrm{P}_{2.9} \mathrm{Mn}_{0.1} \mathrm{~S}_{10.7} \mathrm{I}_{0.3}$ superionic conductor. J. Mater. Chem. A 5, 6310-6317 (2017)

391. Zhang, Y., Chen, K., Shen, Y., et al.: Synergistic effect of processing and composition $x$ on conductivity of $x \mathrm{Li}_{2} \mathrm{~S}-(100-x)$ $\mathrm{P}_{2} \mathrm{~S}_{5}$ electrolytes. Solid State Ionics 305, 1-6 (2017)

392. Unemoto, A., Chen, C., Wang, Z., et al.: Pseudo-binary electrolyte, $\mathrm{LiBH}_{4}-\mathrm{LiCl}$, for bulk-type all-solid-state lithium-sulfur battery. Nanotechnology 26, 254001 (2015)

393. Wang, S., Ding, Y., Zhou, G., et al.: Durability of the $\mathrm{Li}_{1+x} \mathrm{Ti}_{2-x} \mathrm{Al}_{x}\left(\mathrm{PO}_{4}\right)_{3}$ solid electrolyte in lithium-sulfur batteries. ACS Energy Lett. 1, 1080-1085 (2016)

394. Marmorstein, D., Yu, T.H., Striebel, K.A., et al.: Electrochemical performance of lithium/sulfur cells with three different polymer electrolytes. J. Power Sources 89, 219-226 (2000)

395. Jeon, B.H., Yeon, J.H., Kim, K.M., et al.: Preparation and electrochemical properties of lithium-sulfur polymer batteries. J. Power Sources 109, 89-97 (2002)

396. Hassoun, J., Scrosati, B.: Moving to a solid-state configuration: a valid approach to making lithium-sulfur batteries viable for practical applications. Adv. Mater. 22, 5198-5201 (2010)

397. Jin, J., Wen, Z., Liang, X., et al.: Gel polymer electrolyte with ionic liquid for high performance lithium sulfur battery. Solid State Ionics 225, 604-607 (2012)

398. Lacey, M.J., Jeschull, F., Edstrom, K., et al.: Why PEO as a binder or polymer coating increases capacity in the Li-S system. Chem. Commun. (Camb.) 49, 8531-8533 (2013)

399. Dutta, S., Bhaumik, A., Wu, K.C.W.: Hierarchically porous carbon derived from polymers and biomass: effect of interconnected pores on energy applications. Energy Environ. Sci. 7, 3574-3592 (2014)

400. Zhou, G., Li, F., Cheng, H.M.: Progress in flexible lithium batteries and future prospects. Energy Environ. Sci. 7, 1307-1338 (2014)

401. Shi, Y., Peng, L., Ding, Y., et al.: Nanostructured conductive polymers for advanced energy storage. Chem. Soc. Rev. 44, 6684-6696 (2015)

402. Zhang, S.S.: A concept for making poly(ethylene oxide) based composite gel polymer electrolyte lithium/sulfur battery. J. Electrochem. Soc. 160, A1421-A1424 (2013)

403. Jeddi, K., Sarikhani, K., Qazvini, N.T., et al.: Stabilizing lithium/ sulfur batteries by a composite polymer electrolyte containing mesoporous silica particles. J. Power Sources 245, 656-662 (2014)

404. Unemoto, A., Ogawa, H., Gambe, Y., et al.: Development of lithium-sulfur batteries using room temperature ionic liquid-based quasi-solid-state electrolytes. Electrochim. Acta 125, 386-394 (2014)

405. Zhang, Y., Zhao, Y., Bakenov, Z., et al.: Poly(vinylidene fluorideco-hexafluoropropylene)/poly(methylmethacrylate)/nanoclay composite gel polymer electrolyte for lithium/sulfur batteries. J. Solid State Electr. 18, 1111-1116 (2014)

406. Zhang, Y., Zhao, Y., Gosselink, D., et al.: Synthesis of poly(ethylene-oxide)/nanoclay solid polymer electrolyte for all solid-state lithium/sulfur battery. Ionics 21, 381-385 (2015)

407. Zhang, C., Lin, Y., Liu, J.: Sulfur double locked by a macrostructural cathode and a solid polymer electrolyte for lithiumsulfur batteries. J. Mater. Chem. A 3, 10760-10766 (2015)

408. Marceau, H., Kim, C.S., Paolella, A., et al.: In operando scanning electron microscopy and ultraviolet-visible spectroscopy studies of lithium/sulfur cells using all solid-state polymer electrolyte. J. Power Sources 319, 247-254 (2016)

409. Eshetu, G.G., Judez, X., Li, C., et al.: Lithium azide as an electrolyte additive for all-solid-state lithium-sulfur batteries. Angew. Chem. Int. Ed. 56, 15368-15372 (2017) 
410. Chen, L., Fan, L.Z.: Dendrite-free Li metal deposition in allsolid-state lithium sulfur batteries with polymer-in-salt polysiloxane electrolyte. Energy Storage Mater. 15, 37-45 (2018)

411. Judez, X., Zhang, H., Li, C., et al.: Lithium bis(fluorosulfonyl) imide/poly(ethylene oxide) polymer electrolyte for all solid-State Li-S cell. J. Phys. Chem. Lett. 8, 1956-1960 (2017)

412. Li, Y., Xu, B., Xu, H., et al.: Hybrid polymer/garnet electrolyte with a small interfacial resistance for lithium-ion batteries. Angew. Chem. Int. Ed. 56, 753-756 (2017)

413. Tao, X., Liu, Y., Liu, W., et al.: Solid-state lithium-sulfur batteries operated at $37{ }^{\circ} \mathrm{C}$ with composites of nanostructured $\mathrm{Li}_{7} \mathrm{La}_{3} \mathrm{Zr}_{2} \mathrm{O}_{12} /$ carbon foam and polymer. Nano Lett. 17, 2967$2972(2017)$

414. Wang, Q., Guo, J., Wu, T., et al.: Improved performance of Li-S battery with hybrid electrolyte by interface modification. Solid State Ionics 300, 67-72 (2017)

415. Zhang, C., Lin, Y., Zhu, Y., et al.: Improved lithium-ion and electrically conductive sulfur cathode for all-solid-state lithiumsulfur batteries. RSC Adv. 7, 19231-19236 (2017)

416. Chen, Y., Zhang, H., Xu, W., et al.: Polysulfide stabilization: a pivotal strategy to achieve high energy density Li-S batteries with long cycle life. Adv. Funct. Mater. 134, 1704987 (2018)

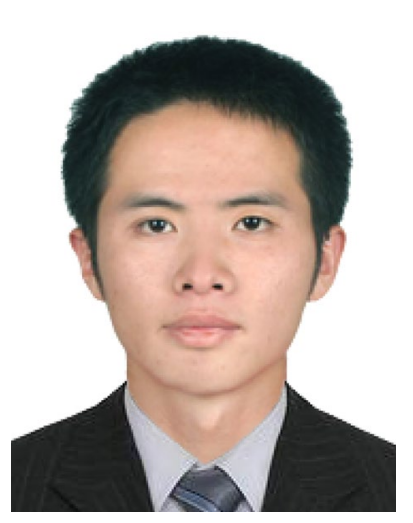

Xiaofei Yang is currently a visiting student in Prof. Xueliang (Andy) Sun's Nanomaterials and Energy Group as well as a Ph.D. candidate in Chemical Engineering of Dalian Institute of Chemical Physics, Chinese Academy of Science (DICP) under the supervision of Prof. Huamin Zhang. $\mathrm{He}$ obtained his B.E. degree in Chemical Engineering from Anhui University in 2013. His research interests focus on $\mathrm{Li}-\mathrm{S}$ batteries, all-solid-state $\mathrm{Li}-\mathrm{S}$ batteries and battery interface studies via synchrotron X-ray

characterizations.

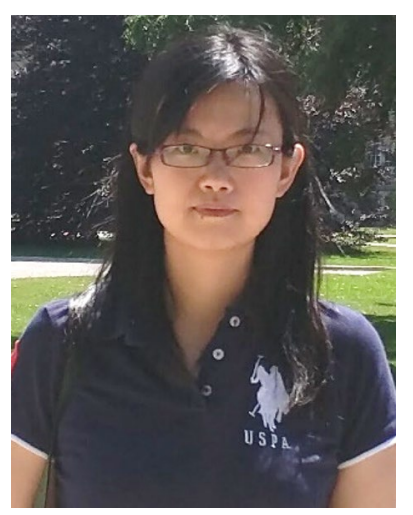

Dr. Xia Li is currently a postdoctoral fellow in Prof. Xueliang (Andy) Sun's Nanomaterials and Energy Group. She received her Bachelor degree in Chemical Engineering from Dalian University of Technology, China, in 2009 and Master degree in Materials Physics and Chemistry from Nankai University, China, in 2012. In 2016, she received her Ph.D. degree at the University of Western Ontario, Canada. Her current research interests focus on $\mathrm{Li}-\mathrm{S}$ batteries, all-solid-state Li-ion and $\mathrm{Li}-\mathrm{S}$ batteries, and battery interface studies via synchrotron X-ray characterizations.

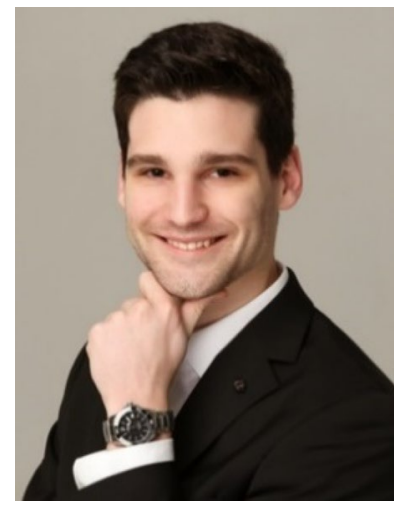

Keegan Adair received his B.Sc. in chemistry from the University of British Columbia in 2016. He is currently a Ph.D. candidate in Prof. Xueliang (Andy) Sun's Nanomaterials and Energy Group at the University of Western Ontario, Canada. Prior to starting his Ph.D. program, Keegan had previously worked in the battery industry at E-One Moli Energy and has conducted battery R\&D for General Motors. His research interests include the fabrication of highperformance Li metal anodes for next-generation battery systems and nanoscale interfacial coatings for energy storage applications.

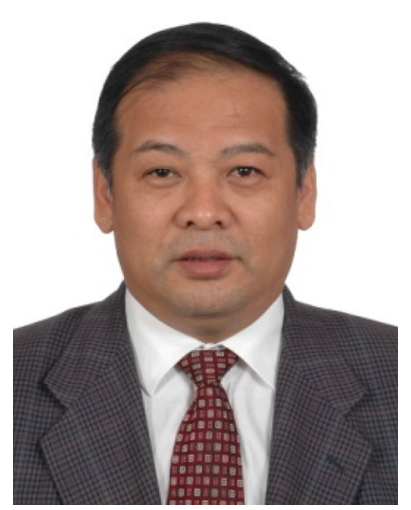

Prof. Huamin Zhang currently is a full professor at Dalian Institute of Chemical Physics, Chinese Academy of Science; he serves as the head of energy storage division, chief scientist of 973 National Project on Flow Battery and CTO of Dalian Rongke Power Co., Ltd. His research interests mainly focus on the topic of energy and energy storage, e.g., fuel cells, flow batteries and batteries with high specific energy density. Professor Zhang has co-authored more than 260 research papers published in refereed journals and more than 150 patents.

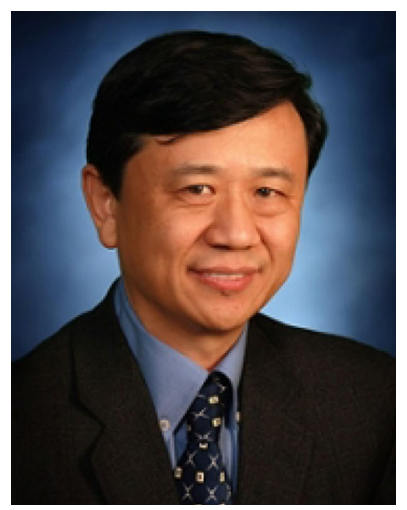

Prof. Xueliang Sun is a Canada Research Chair in Development of Nanomaterials for Clean Energy, Fellow of the Royal Society of Canada and Canadian Academy of Engineering and Full Professor at the University of Western Ontario, Canada. Dr. Sun received his Ph.D. in materials chemistry in 1999 from the University of Manchester, UK, which he followed up by working as a postdoctoral fellow at the University of British Columbia, Canada. His current research interests are focused on advanced materials for electrochemical energy storage and conversion, including electrocatalysis in fuel cells, electrodes in lithium-based batteries and metal-air batteries, and all-solid-state batteries. 